\title{
UTILIZAÇÃO DE MADEIRA DE EUCALYPTUS EM ESTRUTURAS DE PONTES
}

\author{
ANNA CRISTINA PACHECO BALLASSINI ABDALIA
}

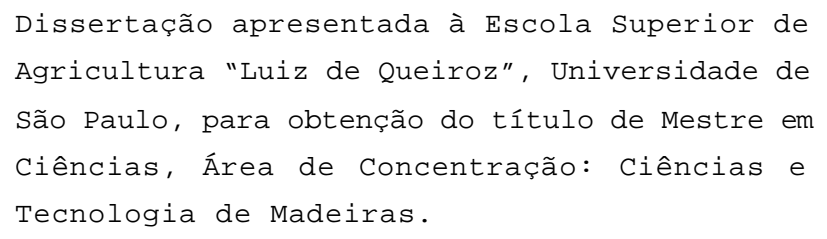

PIRACICABA

Estado de São Paulo - Brasil

Fevereiro - 2002 


\title{
UTILIZAÇÃO DE MADEIRA DE EUCALYPTUS EM ESTRUTURAS DE PONTES
}

\author{
ANNA CRISTINA PACHECO BALIASSINI ABDALLA \\ Engenheiro Civil
}

Orientador: Prof. Dr. JOSÉ NIVALDO GARCIA

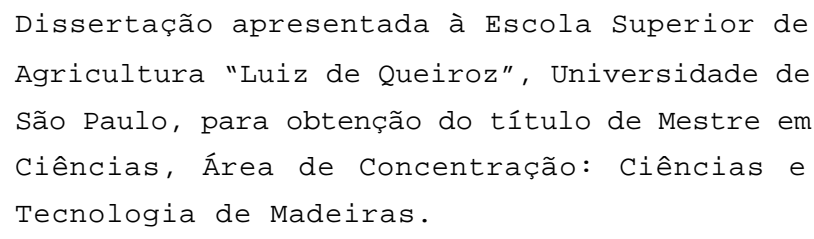

PIRACICABA

Estado de São Paulo - Brasil

Fevereiro - 2002 
Dados Internacionais de Catalogação na Publicação (CIP)

DIVISÃO DE BIBLIOTECA E DOCUMENTAÇÃO - ESALQ/USP

\author{
Abdalla, Anna Cristina Pacheco Ballassini \\ Utilização de madeira de Eucalyptus em estruturas de pontes / Anna \\ Cristina Ballassini Abdalla. - - Piracicaba, 2002. \\ 108 p. : il. \\ Dissertação (mestrado) - - Escola Superior de Agricultura Luiz de Queiroz, \\ 2002. \\ Bibliografia. \\ 1. Estrutura da madeira 2. Eucalipto 3. Pontes de madeira 4. Tecnologia \\ da madeira I. Título \\ CDD 674.142
}

\title{
"Permitida a cópia total ou parcial deste documento, desde que citada a fonte - $O$ autor"
}


Ao Deus do meu coração, Deus da minha compreensão, por sua inefável presença, pelo dom da vida e por mais esta oportunidade.

\section{Ofereço}

Aos meus pais, Wilson e Ercilia, pilares da minha existência, fonte inesgotável de amor e paz.

Aos meus irmãos Wilson - Ana Maria e seus filhos pelo carinho e encorajamento na conclusão deste trabalho. Aos meus familiares pelo incentivo.

\section{Dedico}

Ao meu marido Ronaldo e ao meu filho Henrique pela compreensão da minha ausência e falta de dedicação. Mais que uma família, somos um para o outro o amigo das horas difíceis. 


\section{AGRADECIMENTOS}

Ao Prof. Dr. José Nivaldo Garcia, orientador deste trabalho, por seus ensinamentos, confiança e amizade depositadas.

Ao Prof. Dr. Nilson Franco e Takashi pelas sugestões sempre oportunas.

Aos Professores do Curso de Ciências e Tecnologia de Madeiras pelos ensinamentos durante todo o período.

Ao ex- secretário da Secretaria Municipal de Agricultura e Abastecimento da Prefeitura de Piracicaba, Prof. Dr. José Otávio Mentten, pelo transporte de toda madeira e verba para fabricação da ferramenta utilizada neste trabalho.

Ao amigo Carlão que doou todos os anéis metálicos.

Ao diretor da Manetoni Central de Serviços Belgo Mineira, Eng. Rafael Angelo D'Abronzo por mostrar-se sempre sensível as minhas saídas do trabalho.

Aos técnicos de laboratório Luís Eduardo Facco do Laboratório de Engenharia da Madeira da ESALQ - USP e Paulo de Assis do IPT pelo valiosa colaboração durante os ensaios.

Aos colegas de curso em especial à Carla e Érica pelo convívio e amizade. 


\section{SUMÁRIO}

RESUMO .............................. vi

SUMMARY .................................... vi

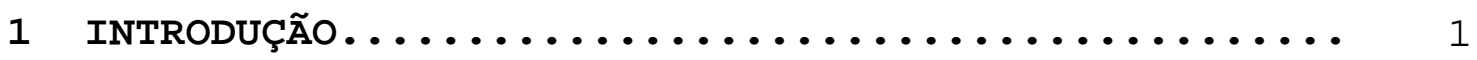

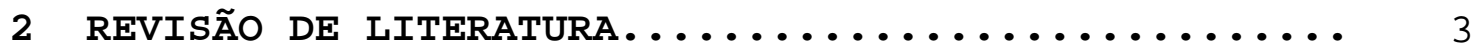

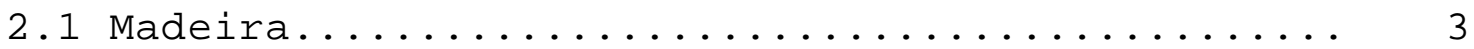

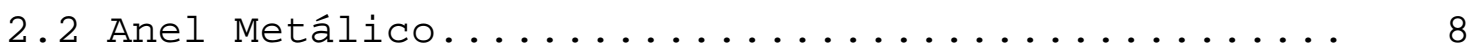

2.3 Resistência da ligação da madeira por anéis

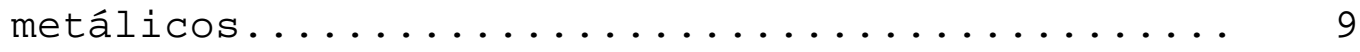

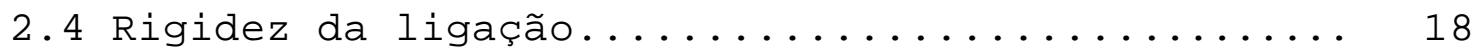

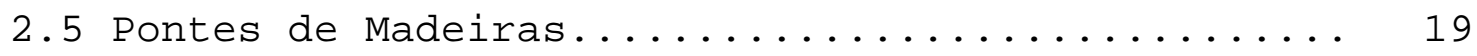

2.6 Longarinas ou Vigas Principais.............. 24

2.7 Tabuleiro ou Superfície de Rolamento.......... 25

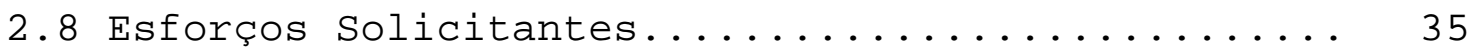

2.9 Manutenção das Pontes de Madeira............. 36

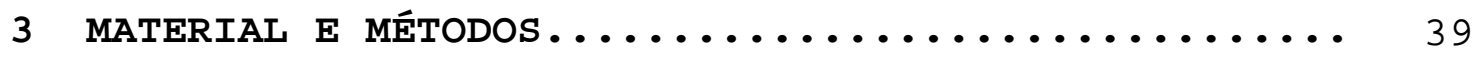

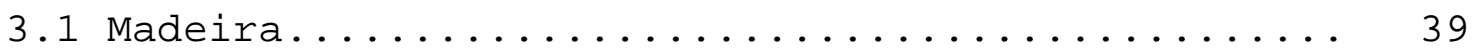

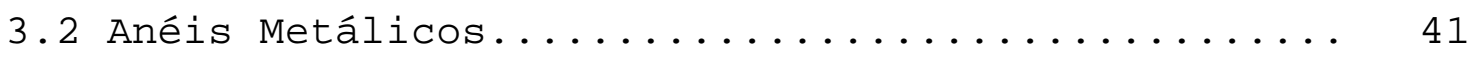

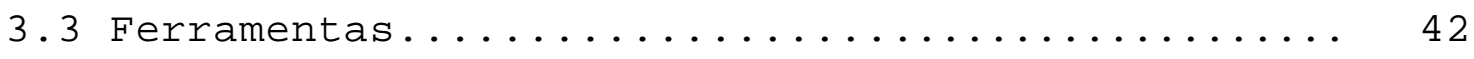

3.4 Determinação das propriedades físico-mecânicas da

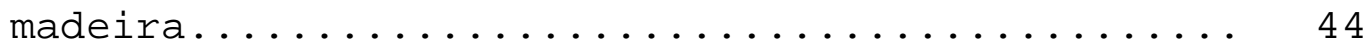

3.5 Determinação da rigidez e resitência do conjunto de duas peças de seção circular unidas por um

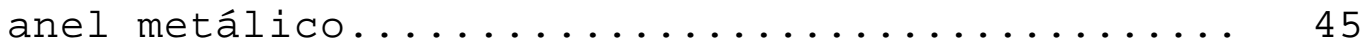

3.6 Montagem e ensaio da Viga bi-circular.......... 54 
4 RESULTADOS E DISCUSSÃo................. 60

4.1 Propriedades físico-mecânicas da madeira....... 60

4.2 Rigidez e resistência da ligação por anel...... 72

4.3 Espaçamento entre anéis e elástica da viga bi- 75

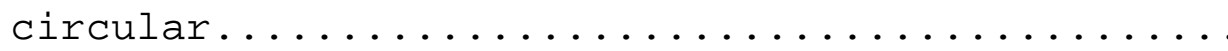

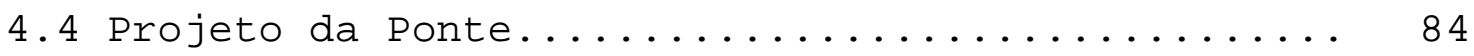

4.5 Cálculo da Ponte por analogia de grelha....... 86

4.5.1 Grelha de 1 transversina idealizada......... 86

4.5.2 Grelha de 3 transversinas idealizadas........ 97

4.5.3 Grelha completa com 33 transversinas......... 109

4.5.4 Dimensionamento da viga bi-circular.......... 114

4.5 .5 Comprovação Experimental............... 117

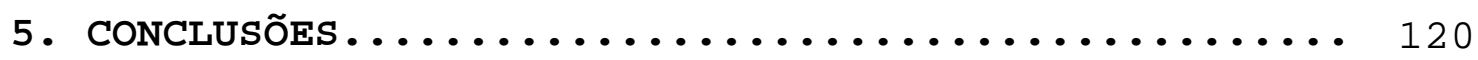

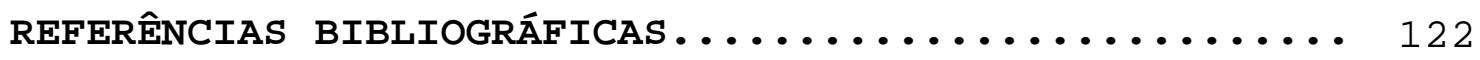




\section{UTILIZAÇÃO DE MADEIRA DE EUCALYPTUS EM ESTRUTURAS DE PONTES}

Autora : ANNA CRISTINA P. B. ABDALLA

Orientador : Prof. Dr. JOSÉ NIVALDO GARCIA

\section{RESUMO}

o presente trabalho teve por objetivo o estudo teórico e experimental de uma ponte de madeira constituída exclusivamente de madeira roliça de eucalipto citriodora. Para tanto foram analisados e comparados diversos procedimentos teóricos desenvolvidos para dimensionamento dos elementos estruturais. Um programa desenvolvido com base no método dos esforços, numa planilha eletrônica permitiu o cálculo mais preciso da ponte, admitida como grelha simplificada. Foram ensaiadas ligações de peças roliças por anéis metálicos e estudados o efeito de sua deformabilidade no deslocamento global de vigas compostas bi-circulares.

Palavras-chave: eucalipto, ponte de madeira, estrutura de madeira, sistemas de ligações, deformação. 


\title{
UTILIZAÇÃO DE MADEIRA DE EUCALYPTUS EM ESTRUTURAS DE PONTES
}

\author{
Author : ANNA CRISTINA P. B. ABDALLA \\ Adyviser : Prof. Dr. JOSÉ NIVALDO GARCIA
}

\section{SUMMARY}

The present work had as a main objective a theoretical and experimental study of a bridge constituted exclusively of round wood pieces of Eucalyptus citriodora. Several theoretical procedures which were developed for calculating the main bridge structural elements have been analyzed and compared. A program developed according to the efforts method in an electronic spread sheet has allowed a precise calculation of the bridge, admitted as simplified hiperestatic frames. Steel rings were utilized as a fastening system for connecting two round pieces together and the effects of their measured deformations under load was considered on the calculation of the global displacement of twin circular composed beams.

Keywords: Eucalyptus, wooden bridge, wooden structures, fastening systems, strain. 


\section{INTRODUÇÃO}

A utilização da madeira como material para engenharia estrutural no Brasil tem sido notadamente lento em comparação com o progresso feito por países como Canadá, Estados Unidos, Austrália, Suíça e Japão.

Dentre as razões para o desestímulo do uso da madeira pode-se citar a cultura do país, cuja ascendência ibérica promoveu o uso da pedra, alvenaria e concreto nas construções civis, relegando à madeira usos menos nobres. A falta de apoio e de programas específicos nas Universidades nas áreas de madeira e estruturas de madeira tem levado os profissionais a utilizarem os materiais tradicionais, esquecendo as vantagens e benefícios ecológicos trazidos pela madeira.

Duas são as principais razões para a rejeição da madeira como material estrutural:

a) as dificuldades para formar um conjunto que possa transferir todos os esforços para todas as peças através de ligações simples e econômicas;

b) as limitações de dimensões e forma do material naturalmente disponível.

A abertura de estradas vicinais para escoamento da produção agrícola, pecuária e mineral implica na necessidade de construção de pontes e neste caso, a madeira, por sua disponibilidade no meio rural, por sua 
resistência e por ser economicamente interessante, pode ser a solução adequada.

Antes de se discutir a forma estrutural a ser proposta e a metodologia construtiva, é impositivo que toda a madeira a ser utilizada na estrutura seja ser tratada adequadamente com produtos preservantes. Há muitos produtos preservantes disponíveis no mercado, para atender as necessidades específicas de cada caso em particular, trazendo especiais vantagens em seu uso.

Alem disto, a vida útil de uma estrutura não é limitada somente pela qualidade da madeira mas, principalmente, pelo seu bom uso. Deve-se respeitar a capacidade de carga do material, cuidar da boa execução dos detalhes construtivos projetados e adotar-se a prática de manutenções periódicas.

Para estudar-se o comportamento, sob flexão, de um tabuleiro formado por postes de Eucalipto citriodora dispostos transversalmente à direção do tráfego e apoiados sobre cinco longarinas bi-apoiadas e de seção composta do tipo bi-circular o presente trabalho teve por objetivo avaliar as ligações por anéis metálicos utilizados para compor a seção das vigas principais, uma vez que a eficiência da ligação é o fator primordial na transferência de esforços e o que assegura a continuidade e interfere diretamente sobre a rigidez da viga.

A validação das hipóteses de cálculo será feita a partir da comparação dos valores calculados com aqueles obtidos de ensaios de corpos de prova e, principalmente, estruturais. 


\section{REVISÃO DE LITERATURA}

\subsection{Madeira}

O emprego de qualquer material seja como matéria prima de um processo ou utilizado em seu estado natural, requer o conhecimento de suas propriedades.

Uma das grandes limitações práticas da madeira deve-se à sua heterogeneidade, anisotropia e variabilidade , sendo que, nem mesmo dois pedaços de madeira de uma mesma espécie são absolutamente iguais, pois dependem da localização no tronco e dos defeitos naturais que possam apresentar (Richter \& Burger, 1978).

"A madeira é um material heterogêneo com grande probabilidade de ter falhas naturais internas, oriundas de seu crescimento. Pode ser considerada como um material homogêneo ortótropo, de comportamento elasto-plástico na compressão e elasto-frágil na tração, com três direções principais de resistência coincidentes com as direções principais de elasticidade" (Almeida, 1990).

As propriedades mecânicas da madeira variam com a densidade, estrutura anatômica, presença de extrativos e umidade. Entretanto, de uma maneira geral, estudos sobre madeira comprovam que: 
$\checkmark$ a madeira é um material com excelente relação resistência/peso;

$\checkmark$ a resistência mecânica diminui com o aumento do ângulo existente entre a direção da fibra e a direção do esforço solicitante;

$\checkmark$ a presença de extrativos altera as propriedades mecânicas;

$\checkmark$ a resistência mecânica da madeira diminui com o aumento da umidade porem a taxas acentuadamente decrescentes;

$\checkmark$ a resistência mecânica da madeira aumenta com o aumento da densidade;

$\checkmark$ os deslocamentos de pontos importantes das estruturas aumentam com o aumento da duração do carregamento.

O gênero Eucalyptus, que pertence à família das Myrtacea, conta com um grande número de espécies e híbridos. Foram trazidos, principalmente, da Austrália e vizinhanças no início do século passado para proteção de lavouras como barreira contra o vento e principalmente para fins energéticos para as ferrovias.

Busnardo et al.(1978) ressaltam que o clima da região sul e Sudeste do Brasil favoreceram, pela perfeita adaptação das variadas espécies às diversas condições de solos, o estabelecimento de florestas plantadas de eucaliptos.

Com a utilização do petróleo e seus derivados, a lenha passou a ter um papel secundário nas ferrovias e as inúmeras áreas reflorestadas com esse gênero passaram a interessar às indústrias consumidoras de carvão, produtoras de celulose, papel, chapas de fibras, de painéis em geral e serraria. 
Atualmente com as dificuldades de se obter as tradicionais madeiras de florestas naturais devida à exploração predatória do passado e o seu já elevado custo, - eucalipto pode tornar-se a melhor alternativa para a produção de madeira serrada, painéis e outros produtos à base de madeira.

O IPT - Instituto de Pesquisas Tecnológicas do Estado de São Paulo S.A. foi um dos precursores dos ensaios de caracterização de madeiras de eucalipto quando da publicação dos boletins números 6 e 8 em 1932 e 1933 respectivamente, (Hellmeister, 1992).

Os ensaios de caracterização, ainda que destrutivos, é de fundamental importância pois permitem a utilização das propriedades do material nos cálculos estruturais possibilitando projetar-se a seção mínima possível sem prejuízo da segurança da estrutura.

A classificação estrutural de madeiras através da resistência mecânica, permite diferenciá-las quanto à sua capacidade de suportar cargas. Para essa classificação é possível e talvez vantajosa à substituição dos ensaios de pequenos corpos de prova isentos de defeitos por ensaios não destrutivos da própria peça a ser utilizada na estrutura. A principal vantagem da classificação da madeira é a perfeita adequação do coeficiente de segurança (Melo, 1984).

Sales (1991) estudou a viabilidade do emprego de madeiras de eucalipto na construção de estruturas a partir da análise de suas propriedades. Concluiu que não existe dependência linear entre os valores médios das propriedades e as idades ou regiões de origem. 
Para as espécies de Eucalipto do Estado de São Paulo estudadas (E. maculata, E. paniculata, E. citriodora, E. punctata e E. terericornis) ficou evidenciada a possibilidade de seu emprego na construção de estrutura para qualquer finalidade.

A Tabela 1 mostra os valores médios de propriedades da madeira úmida (acima do ponto de saturação das fibras - PSF) de Eucalyptus citriodora. Os valores que aparecem logo abaixo da média da propriedade indicam os limites do intervalo de confiança da média a 95\% de probabilidade.

Tabela 1. Valor médio das propriedades físico-mecanicas do Eucalyptus citriodora - umidade acima do PSF.

\begin{tabular}{|c|c|c|c|c|c|}
\hline $\begin{array}{l}\text { Idade } \\
\text { (anos) }\end{array}$ & $\begin{array}{c}\tilde{\mathrm{n}}_{\mathrm{ap}} \\
\left(\mathrm{g} / \mathrm{cm}^{3}\right)\end{array}$ & $\begin{array}{c}f_{\mathrm{C} 0} \\
\left(\mathrm{daN} / \mathrm{cm}^{2}\right)\end{array}$ & $\begin{array}{c}f_{t 0} \\
\left(\mathrm{daN} / \mathrm{cm}^{2}\right)\end{array}$ & $\begin{array}{c}\mathrm{f}_{\mathrm{v}} \\
\left(\mathrm{daN} / \mathrm{cm}^{2}\right)\end{array}$ & $\begin{array}{c}\mathrm{n}^{\circ} \\
\mathrm{c} \cdot \mathrm{p} .\end{array}$ \\
\hline \multirow{2}{*}{16} & 0,91 & 419 & 1453 & 137 & \multirow{2}{*}{07} \\
\hline & 0,80 a 1,00 & 324 a 514 & 884 a 2022 & 102 a 172 & \\
\hline \multirow{2}{*}{19} & 1,19 & 593 & 833 & 137 & \multirow{2}{*}{08} \\
\hline & 1,11 a 1,27 & 561 a 625 & 583 a 1083 & 131 a 143 & \\
\hline \multirow{2}{*}{28} & 1,14 & 569 & 1228 & 134 & \multirow{2}{*}{36} \\
\hline & 1,11 a 1,17 & 543 a 595 & 1100 a 1356 & 155 a 173 & \\
\hline \multirow{2}{*}{41} & 1,22 & 511 & 790 & 120 & \multirow{2}{*}{07} \\
\hline & 1,16 a 1,28 & 420 a 602 & 488 a 1092 & 95 a 145 & \\
\hline \multirow{2}{*}{50} & 1,13 & 656 & 1224 & 176 & \multirow{2}{*}{06} \\
\hline & 1,10 a 1,16 & 640 a 672 & 884 a 1564 & 158 a 194 & \\
\hline
\end{tabular}

Fonte: Sales (1991) - Adaptado

Oliveira (1997), estudando a caracterização da madeira de Eucalipto para a construção civil, concluiu que 
um material tão complexo quanto a madeira deste gênero somente poderá ser utilizado ou substituir as madeiras tradicionais caso se tenha um conhecimento científico de suas características, propriedades físico-mecânicas que são peculiares a cada espécie inclusive condições de crescimento e principalmente a idade de corte. Na Tabela 2 encontram-se os valores médios de seis propriedades mecânicas da madeira de sete espécies de Eucalyptus.

Tabela 2. Valores estimados de algumas propriedades mecânicas ao nível de DAP, da madeira verde

\begin{tabular}{lcccccccc}
\hline \multirow{2}{*}{ Espécies } & $\mathrm{N}^{1}$ & \multicolumn{2}{c}{$\tilde{\mathrm{n}}$} & \multicolumn{2}{c}{ Propriedades } & Mecânicas * & (MPa) \\
& & $\left(\mathrm{g} / \mathrm{cm}^{3}\right)$ & MOE & MOR & MRCP & MRC & Dureza & MRTP \\
\hline E. citriodora & 57 & 0,72 & 12.511 & 96 & 49 & 12 & 63 & 99 \\
E. tereticornis & 61 & 0,63 & 11.104 & 79 & 42 & 11 & 48 & 83 \\
E. paniculata & 50 & 0,72 & 12.485 & 95 & 49 & 12 & 63 & 98 \\
E. pilularis & 52 & 0,55 & 9.968 & 67 & 36 & 9 & 35 & 71 \\
E. Cloeziana & 60 & 0,69 & 12.017 & 90 & 46 & 12 & 58 & 93 \\
E. urophylla & 67 & 0,52 & 9.398 & 60 & 34 & 9 & 29 & 65 \\
E. grandis & 84 & 0,46 & 8.584 & 52 & 30 & 8 & 21 & 57 \\
\hline
\end{tabular}

Fonte: Oliveira (1997) - Adaptado

* MOE: módulo de elasticidade à flexão; MOR: módulo de ruptura na flexão; MRCP: máxima resistência à compressão paralela às fibras; MRC: máxima resistência ao cisalhamento paralelo às fibras; MRTP: máxima resistência à tração paralela às fibras.

1 - número de observações.

2 - dureza Janka, transversal às fibras. 
Esse mesmo autor concluiu que o $E$. citriodora além de possuir propriedades mecânicas variando de média a elevada, caracteriza-se pelo excelente valor de seu fator anisotrópico apesar de apresentar elevados valores de contração volumétrica. Quanto à durabilidade natural o E. citriodora, em condições normais de pequeno risco de incidência dos organismos xilófagos, não apresenta restrições. Mostra-se resistente ao apodrecimento e possui permeabilidade média.

\subsection{Anel Metálico}

O anel metálico pode ser fechado ou aberto, liso ou com ranhura. Quando embutido entre peças de madeira permite-lhes vencer maiores esforços cortantes oriundos da flexão. O anel é encaixado em cada uma das faces de peças adjacentes, em sulcos previamente abertos, com ferramentas especiais. Este sulco deve ter espessura igual ou no máximo $0,5 \mathrm{~mm}$ maior que a espessura do anel para um perfeito ajuste. O Laboratório de Madeira e Estruturas de Madeira da EESC-USP (LaMEM) projetou para fazer os sulcos, a ferramenta especial mostrada na Figura 1. É formada por facas com o corpo principal projetado para acoplar a broca que ao furar as peças de madeira por onde deverá passar o parafuso, serve de guia para a ferramenta. 


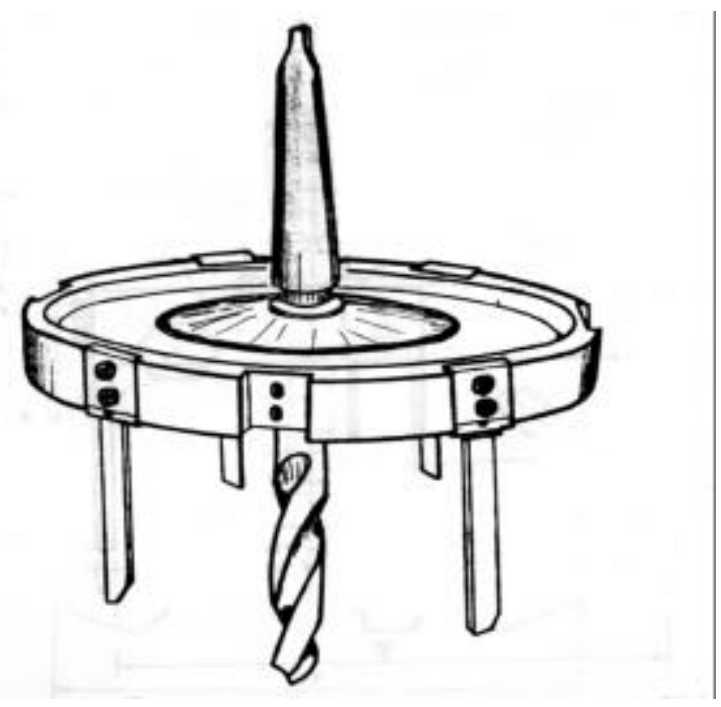

Figura 1 - Ferramenta para preparação do sulco de alojamento do anel.

Fonte: Hellmeister (1978)

\subsection{Resistência da ligação da madeira por anéis metálicos}

Para Hellmeister (1978) os anéis metálicos são apresentados em toda literatura Internacional, mas não são conhecidos e nem são empregados no Brasil. No LaMEM o estudo dos anéis metálicos para ligações de peças estruturais de madeira vem sendo desenvolvido desde 1971. Estes estudos iniciaram-se a partir da adoção de anel metálico obtido através de cortes em tubos galvanizados simplificando os anéis partidos "split ring" de fabricação esmerada adotados pelo American Institute of Timber Construction, protegidos por inúmeras patentes. 
Após extensa revisão bibliográfica internacional, Matthiesen (1981) fez um estudo relativo à capacidade de carga de anéis metálicos partidos de diâmetro de 3", 4" e 5" em ensaios de compressão e de tração de corpos de prova confeccionados de peroba rosa (Figuras 2 a 4). Apresentou a eq. (1) para cálculo teórico da capacidade de carga da ligação e publicou os resultados mostrados nas Tabelas 3 e 4 .
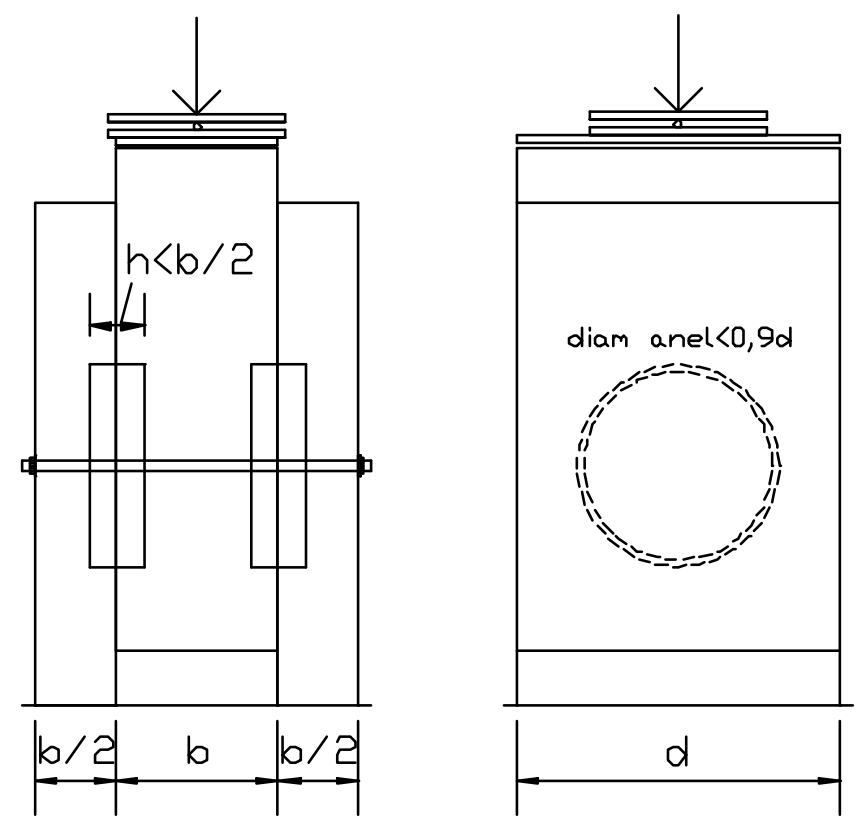

Figura 2 - Corpo de prova para o ensaio à compressão da ligação por anel metálico.

Fonte: Matthiesen (1981)

$R=\frac{\partial d^{2}}{4} f_{v d}$ onde:

$\mathrm{R}=$ Resistência do anel;

$\mathrm{d}=$ diâmetro interno do anel;

$\mathrm{f}_{\mathrm{vd}}=$ resistência da madeira valor de cálculo, ao cisalhamento 
Tabela 3. Valores médios da carga de ruptura da ligação madeira - anel metálico partido sujeita à compressão paralela às fibras em peroba rosa.

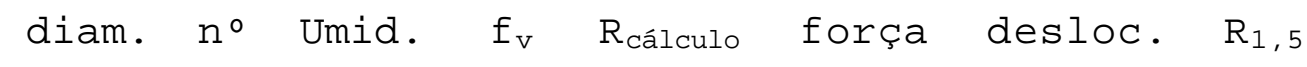
anel C.P. ( $\%$ (MPa) (daN) ruptura relativo (daN)

\begin{tabular}{llllllll} 
& \multicolumn{1}{c}{$(\mathrm{daN})$} & $(\mathrm{mm})$ \\
\hline $3 " 10$ & 13,9 & 17,66 & 780 & 6.066 & 3,0 & 3.500
\end{tabular}

$\begin{array}{llllllll}4^{\prime \prime} & 10 & 41,2 & 12,46 & 978 & 7.905 & 3,0 & 5.500\end{array}$

5" $\quad 10 \quad 24,3 \quad 14,42 \quad 1.768 \quad 11.100 \quad 3,0 \quad 8.000$

Fonte: Matthiesen (1981)

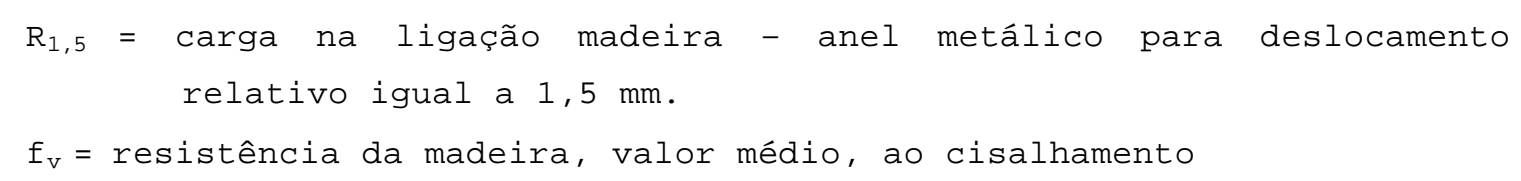

Observa-se nesta Tabela que os valores da resistência da ligação calculada segundo a eq. encontra-se abaixo da resistência correspondente ao deslocamento relativo permitido de $1,5 \mathrm{~mm}$ entre as peças interligadas segundo a NBR 7190/82.

Na Tabela 4 encontram-se os dados colhidos para a o mesmo ensaio utilizando-se madeira de E. citriodora. 
Tabela 4. Valores médios da carga de ruptura da ligação madeira-anel metálico partido sujeita à compressão paralela às fibras em E. citriodora.

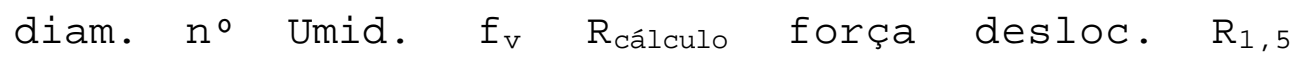
anel C.P. ( $\left.\frac{\circ}{\circ}\right)$ (MPa) (daN) ruptura relativo (daN)

\begin{tabular}{rlrrrrrr} 
& & \multicolumn{9}{c}{ (daN) } & (mm) \\
\hline $3 "$ & 5 & 27 & 17,56 & 775 & 6.908 & 3,0 & 5.600 \\
$4 "$ & 5 & 27 & 17,56 & 1.378 & 9.066 & 3,8 & 7.000 \\
$5 "$ & 5 & 27 & 17,56 & 2.154 & 11.403 & 3,6 & 8.500
\end{tabular}

Fonte: (Matthiesen, 1981)

$\mathrm{R}_{1,5}=$ carga na ligação madeira - anel metálico para deslocamento relativo igual a $1,5 \mathrm{~mm}$.

$f_{\mathrm{v}}=$ resistência da madeira, valor médio, ao cisalhamento

Durante a experimentação, Matthiesen pôde observar que:

$\checkmark$ a distância do anel à borda não tem influência na capacidade de carga do anel quando submetido à compressão paralela às fibras. Recomenda entretanto que não sejam utilizados diâmetros de anéis maiores que 90\% da largura da menor peça da ligação (Figura 3). 


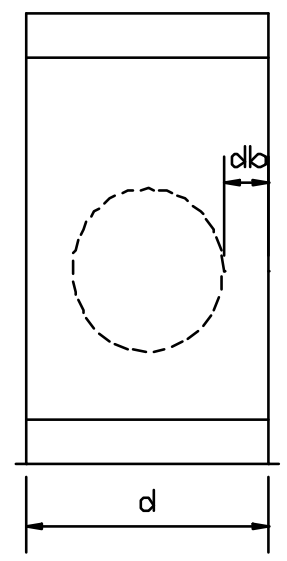

Figura 3 - Distância do anel à borda da peça ligada. Fonte: Matthiesen (1981)

$\checkmark$ a penetração do anel na madeira não deve ultrapassar a metade da espessura da menor peça da ligação, tendo em vista garantir a sua resistência, mesmo após a colocação do anel (Figura 4).

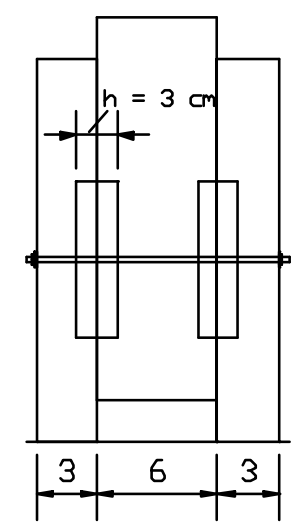

Figura 4 - Profundidade de penetração do anel na madeira. Fonte: Matthiesen (1981)

$\checkmark$ a influência da umidade da madeira na capacidade de carga do anel é maior para espécies de menor densidade. 
Para a peroba rosa ensaiada, encontrou uma diferença de 5\% nos corpos de prova saturada para os secos.

$\checkmark$ a diferença de capacidade de carga entre o anel fechado e o partido e entre o partido e o anel bipartido não é superior a $5 \%$.

$\checkmark$ os resultados obtidos nos ensaios à tração paralela às fibras foram semelhantes aos obtidos à compressão paralela às fibras.

$\checkmark$ a capacidade de carga para qualquer diâmetro e espécie de madeira não estudada, pode ser calculada através da eq. (1) .

Hilson (1968) observou que após a ruptura das peças de madeira por cisalhamento, ocorre esmagamento da madeira na lateral do anel, na direção perpendicular ao carregamento.

Quenneville et al. (1993) desenvolvendo experimentação relacionada com a influência da distância do anel à borda da peça de madeira ligada, puderam observar nos 144 corpos de prova ensaiados à compressão paralela às fibras que não houve influência significante da distancia do anel à borda na resistência da ligação. Os corpos de prova foram feitos com madeira das espécies Douglas Fir Larch e Spruce-Pine Fir com anel de $64 \mathrm{~mm}$ e $102 \mathrm{~mm}$ para um teor de umidade da madeira de 18\%. Entretanto, sugeriu manter as distancias mínimas de $50 \mathrm{~mm}$ para ligação com anel de $63 \mathrm{~mm}$ e $80 \mathrm{~mm}$ para ligação com anel de $102 \mathrm{~mm}$. 
NOGUEIRA (1996) desenvolveu num trabalho que gerou subsídios para a revisão de documentos normativos brasileiros no que se refere às ligações madeira-anel metálico. Elaborou uma proposta de método de ensaio e parâmetros para o dimensionamento de ligações entre peças de madeira por anéis metálicos fechados. A partir de uma revisão bibliográfica montou a Tabela 5 que contém as dimensões de corpos de prova especificados por diversas normas e dos propostos para a sua experimentação.

Tabela 5. Dimensões de corpos de prova para ensaio de ligação de peças de madeira por anel metálico.

\begin{tabular}{|c|c|c|c|c|c|c|}
\hline & dimensões & $\begin{array}{c}\text { Austral }{ }^{1} \text {. } \\
(\mathrm{mm})\end{array}$ & $\begin{array}{c}\text { Eur. } n^{\circ} 5^{2} \\
(m m)\end{array}$ & $\begin{array}{l}\mathrm{NDS}^{3} \\
(\mathrm{~mm})\end{array}$ & $\begin{array}{l}\text { ABNT } \\
(\mathrm{mm})\end{array}$ & $\begin{array}{c}\text { Nogueira } \\
(\mathrm{mm})\end{array}$ \\
\hline \multirow{3}{*}{$\begin{array}{l}\underset{g}{g} \\
\underset{+}{ } \\
\|_{Q} \\
Q\end{array}$} & $a$ & 140 & 89 & 88,9 & 104 & 120 \\
\hline & $\mathrm{b}$ & - & 95,5 & - & - & 120 \\
\hline & C & 72 & 72 & 72 & 72 & 72 \\
\hline 0 & $d$ & 34 & 8,5 & 8,45 & 16 & 24 \\
\hline \multirow{2}{*}{$\begin{array}{l}0 \\
0 \\
\underset{0}{0} \\
\sigma \\
0\end{array}$} & e & 100 & 51 & 139,7 & 77 & 60 \\
\hline & $\mathrm{f}$ & 100 & 44,5 & 139,7 & 77 & 60 \\
\hline \multirow{2}{*}{$\begin{array}{l}\sigma \\
\tilde{L} \\
\sigma \\
\tilde{\alpha}\end{array}$} & 9 & - & 50 & - & - & 120 \\
\hline & $\mathrm{h}$ & - & 145,5 & - & - & 240 \\
\hline \multirow{2}{*}{$\begin{array}{l}\infty \\
> \\
0 \\
+1 \\
0\end{array}$} & $i$ & 4 & 4 & 4 & 4 & 4 \\
\hline & $j$ & 64 & 64 & 64 & 64 & 64 \\
\hline 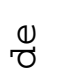 & 1 & $\mathrm{~b}$ & $\mathrm{~b}$ & $\mathrm{~b}$ & $\mathrm{~b}$ & 50 \\
\hline \multirow{3}{*}{$\begin{array}{l}\circ \\
\stackrel{0}{1} \\
\hat{H}_{1} \\
0 \\
\text { U }\end{array}$} & $\mathrm{m}$ & $\mathrm{b} / 2$ & $\mathrm{~b} / 2$ & $\mathrm{~b} / 2$ & $\mathrm{~b} / 2$ & 25 \\
\hline & $\mathrm{n}$ & - & - & - & - & 25 \\
\hline & o & - & - & 12 & 12 & 12 \\
\hline
\end{tabular}


Tabela 5. Dimensões de corpos de prova para ensaio de ligação de peças de madeira por anel metálico.

\begin{tabular}{|c|c|c|c|c|c|c|}
\hline & dimensões & $\begin{array}{c}\text { Austral }{ }^{1} \text {. } \\
\text { (mm) }\end{array}$ & $\begin{array}{c}\text { Eur. } \mathrm{n}^{\circ} 5^{2} \\
(\mathrm{~mm})\end{array}$ & $\begin{array}{l}\mathrm{NDS}^{3} \\
(\mathrm{~mm})\end{array}$ & $\begin{array}{c}\mathrm{ABNT}^{4} \\
(\mathrm{~mm})\end{array}$ & $\begin{array}{c}\text { Nogueira } \\
(\mathrm{mm})\end{array}$ \\
\hline \multirow{4}{*}{ 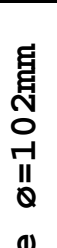 } & $a$ & 140 & 89 & 88,9 & 104 & 120 \\
\hline & $\mathrm{b}$ & - & 95,5 & - & - & 120 \\
\hline & C & 72 & 72 & 72 & 72 & 72 \\
\hline & d & 34 & 8,5 & 8,45 & 16 & 24 \\
\hline \multirow{2}{*}{ ס } & e & 100 & 51 & 139,7 & 77 & 60 \\
\hline & $\mathrm{f}$ & 100 & 44,5 & 139,7 & 77 & 60 \\
\hline \multirow{2}{*}{ 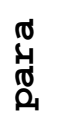 } & 9 & - & 50 & - & - & 120 \\
\hline & $\mathrm{h}$ & - & 145,5 & - & - & 240 \\
\hline \multirow{4}{*}{$\begin{array}{l}0 \\
0 \\
0 \\
\mathcal{H} \\
0 \\
0 \\
0 \\
0\end{array}$} & $i$ & 4 & 4 & 4 & 4 & 4 \\
\hline & j & 64 & 64 & 64 & 64 & 64 \\
\hline & 1 & $\mathrm{~b}$ & $\mathrm{~b}$ & $\mathrm{~b}$ & $\mathrm{~b}$ & 50 \\
\hline & $\mathrm{m}$ & $\mathrm{b} / 2$ & $\mathrm{~b} / 2$ & $\mathrm{~b} / 2$ & $\mathrm{~b} / 2$ & 25 \\
\hline \multirow{2}{*}{$\begin{array}{l}\text { O } \\
\stackrel{\circ}{4}_{4} \\
0 \\
\text { U }\end{array}$} & $\mathrm{n}$ & - & - & - & - & 25 \\
\hline & 0 & - & - & 12 & 12 & 12 \\
\hline
\end{tabular}

Fonte: Nogueira (1996)

\footnotetext{
1 Standards Association of Australian - 1994

2 Commission of the European Communities for Standardization - 1987

3 National Design Specification - 1991

4 Associação Brasileira de Normas Técnicas - NBR 7190/82
}

Seus dados de ensaios estão, de forma simplificada, montados na Tabela 6 sobre os quais concluiu que a eq. (1) baseada na resistência da madeira ao cisalhamento é adequada para o cálculo da resistência da ligação entre peças de madeira através de anéis metálicos (Figura 5). 
Tabela 6. Valores médios da carga de ruptura de ligações por anel metálico ensaiados à compressão paralela às fibras.

Classe de Força Compressão Paralela Compressão Normal Resistência de às fibras às fibras

e Espécie Ruptura Anel $64 \mathrm{~mm}$ Anel102 mm Anel $64 \mathrm{~mm}$ Anello2 mm

\begin{tabular}{ccrrrrrrrr}
\hline C20 & Exper. & 2920 & 3090 & 6130 & 6050 & 2870 & 3610 & 5440 & 5600 \\
P. Elliotti & Teórica & 3732 & 2766 & 6742 & 7027 & 3732 & 2766 & 6742 & 7027 \\
C30 & Exper. & 8200 & 8950 & 11300 & 14650 & 4300 & 4740 & 8950 & 10680 \\
Cupiúba & Teórica & 6563 & 7077 & 11604 & 12497 & 6563 & 7077 & 11604 & 12497 \\
C30 & Exper. & 8000 & 7500 & 15300 & 122001 & 6870 & 5800 & 11400 & 9600 \\
Garapa & Teórica & 5791 & 6498 & 13074 & 11930 & 5791 & 6498 & 13074 & 11930 \\
C40 & Exper. & 9600 & 10150 & 20500 & 20300 & 8020 & 9230 & 18300 & 19500 \\
E. Citrio & Teórica & 8429 & 11230 & 18958 & 20429 & 8429 & 11230 & 18958 & 20429 \\
C60 & Exper. & 12900 & 12650 & 18950 & 17000 & 11000 & 11300 & 18200 & 16700 \\
Jatobá & Teórica & 12546 & 11581 & 16506 & 15362 & 12546 & 11581 & 16506 & 15362 \\
\hline
\end{tabular}

Fonte: Nogueira (1996)
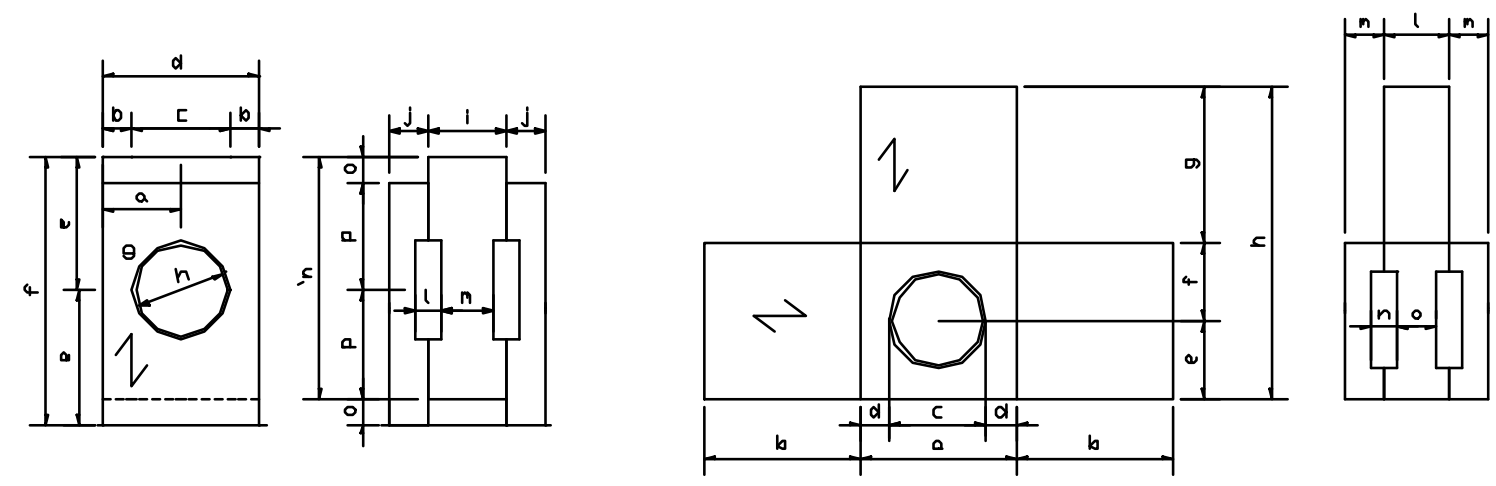

Figura 5 - Corpos de prova para ensaios de ligação por anel metálico.

Fonte: Nogueira (1996) 


\title{
2.4 Rigidez da ligação
}

\begin{abstract}
As deformações das ligações nos deslocamentos internos de estruturas raramente têm sido suficientemente estudados nas pesquisas realizadas no Brasil. A preocupação tem sido à da obtenção de carga de ruptura das ligações e dos espaçamentos mínimos entre conectores. Embora tenham sido medidos os deslocamentos relativos entre as peças, conforme prescrito nas normas de ensaio não têm sido computadas as suas influencias na flecha da estrutura.

Goodman \& Rassam (1970) desenvolveram um estudo teórico e experimental para avaliar o comportamento de colunas de madeira de seções compostas. A teoria desenvolvida permitiu conhecer os limites, inferior e superior, que a carga de ruptura pode atingir. Para tanto assumiram as possibilidades extremas onde no limite inferior estariam as colunas de seção composta de peças independentes (sem conector) e no limite superior as colunas de seção sólida. Assim a carga de ruptura da ligação qualquer que seja o tipo de conector, desde o mais rígido (peças coladas) até o menos rígido (peças pregadas) deve estar dentro desse intervalo. Obtiveram num ensaios de 5 colunas de seção composta onde foram variados o número e - espaçamento entre pregos (Figura 6) uma concordância entre os resultados calculados pela teoria.
\end{abstract}



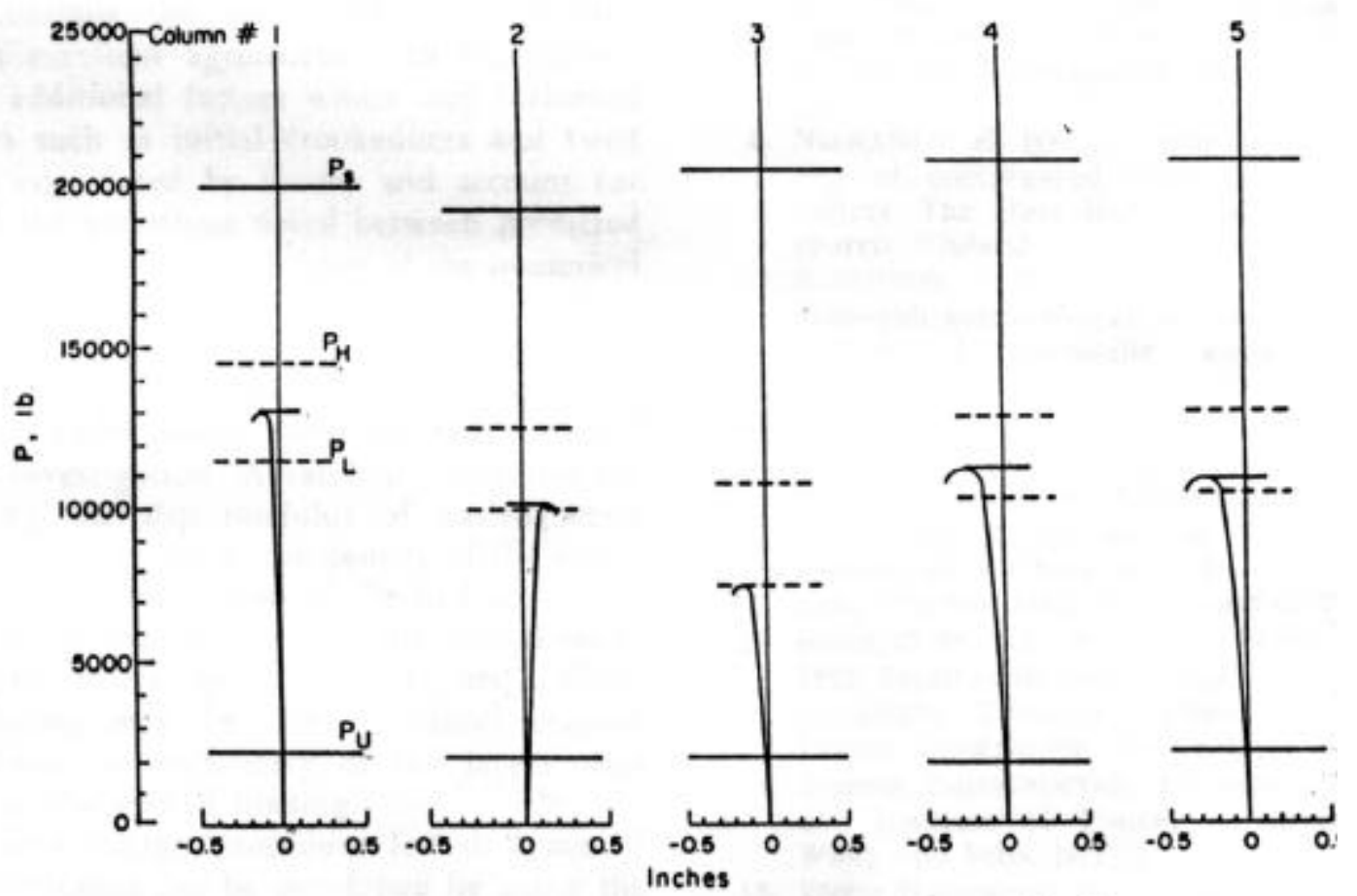

Figura 6 - Curvas de carga - deslocamento relativo entre peças de seção composta de colunas submetidas à compressão. Fonte : Goodman \& Rassam (1970)

Onde:

$\mathrm{P}_{\mathrm{U}}=$ Força de ruptura da coluna sem conector;

$\mathrm{P}_{\mathrm{S}}=$ Força de ruptura da coluna sólida;

$\mathrm{P}_{\mathrm{H}} \mathrm{e} \mathrm{P}_{\mathrm{L}}=$ Forças, máxima e mínima calculadas para cada ligação.

\subsection{Pontes de Madeiras}

De acordo com Paiva (1995), há pontes de madeira das mais variadas dimensões e soluções estruturais. Existem pontes de vigas simplesmente apoiadas, pontes de vigas 
contínuas, pontes em treliça, pontes em arco, em pórtico, pontes suspensas pênseis, estaiadas e protendida, e dentre outros materiais, pontes com madeira roliça, serrada e laminada. A Figura 7 mostra alguns exemplos citados na literatura.

\begin{tabular}{|c|c|c|}
\hline TIPO DE PONTE & ESQUEMA ESTATICO & $g\left(k N / m^{2}\right)$ \\
\hline VGGA MACICA, SIPLESMENTE APOIADA & $\nabla$ & $6,8-7,8$ \\
\hline VIGA MACICA, CONTINUA & $\Delta$ & $6,5-7,5$ \\
\hline ESTRUTURA PRINCIPAL EM PORTICO & & $7,2-8,2$ \\
\hline PENSIL, COM VIGA DE RIGIDEZ & $\sigma$ & $6.5-7.5$ \\
\hline VGA TRELICAOA, SIMP. APOIAOA & & $6,5-7,5$ \\
\hline VIGA TRELICADA CONTINUA & $\Delta N$ & $6.3-7.3$ \\
\hline VIGA ARMADA & & $7.3-8.3$ \\
\hline
\end{tabular}

Figura 7 - Tipos estruturais de pontes de madeira. Fonte: Logsdon (1982)

As pontes de madeiras dividem-se segundo Oliva et al.(1985) em quatro categorias: pontes de longarina, de tabuleiro longitudinal, sistema de cordas paralelas e as especiais (pênseis e estaiadas) (Figura 8). 

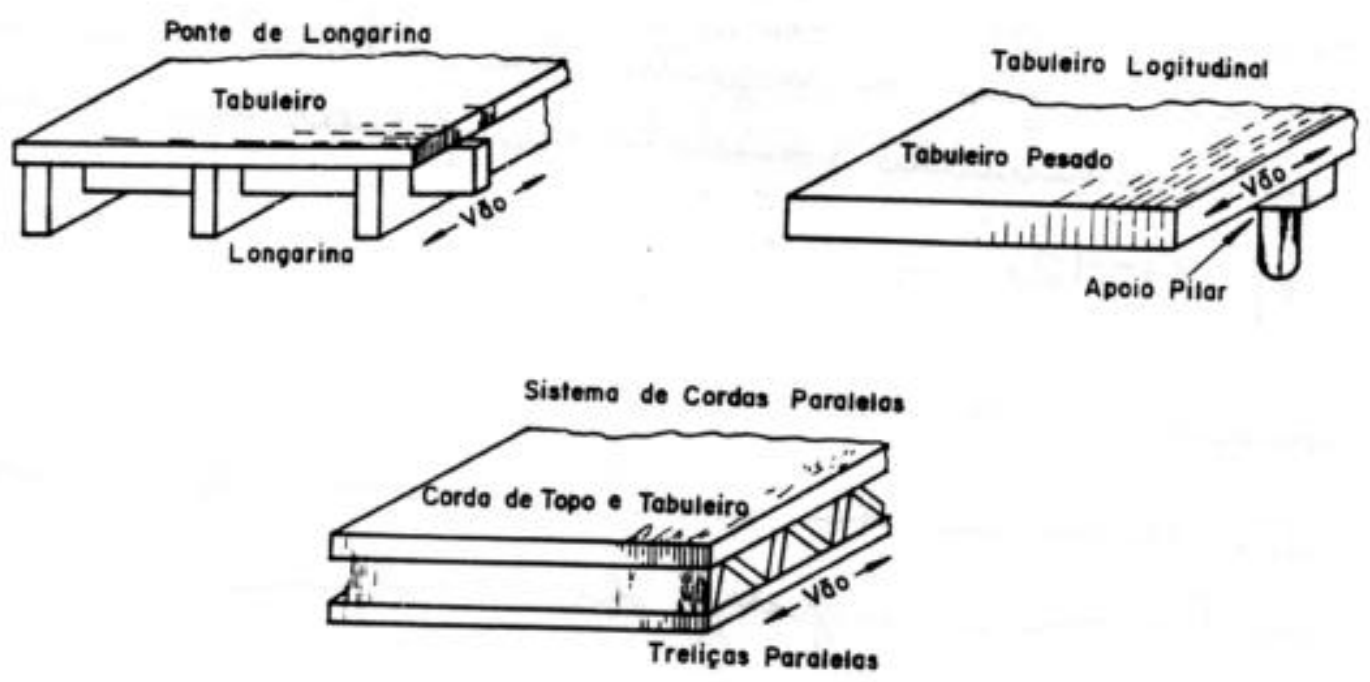

Figura 8 - Tipo de pontes de madeira.

Fonte: Oliva et al. (1985)

Os sistemas construtivos são adotados em função do carregamento previsto, número de faixas de tráfego, da dimensão do vão a transpor, etc.

Nascimento (1993), constatou que a mais utilizada nos Estados Unidos, para pontes de pequenos vãos e passarelas é a ponte de madeira com longarinas, que vencem - obstáculo e suportam o tabuleiro transversal. As longarinas produzidas com madeira laminada colada, podem ser curvas, retas, ou treliçadas. São muito utilizadas pela suas maiores viabilidade de custos em comparação com as peças maciças serradas ou em toras.

Segundo Okimoto (1997), surgiu no Canadá em 1976 - conceito de tabuleiro laminado protendido em substituição ao tabuleiro laminado pregado. Devido à deficiência do sistema pregado, basicamente a corrosão dos pregos e susceptibilidade a solicitações dinâmicas, o Ministério dos Transportes e Comunicação de Ontário iniciou um programa de 
recuperação destas pontes já que a madeira estava em boas condições, necessitando somente da substituição do mecanismo de transferência das ações. Assim o sistema de protensão transversal introduziu no tabuleiro o comportamento de placa ortotrópica recuperando as propriedades desejadas (Figura 9).

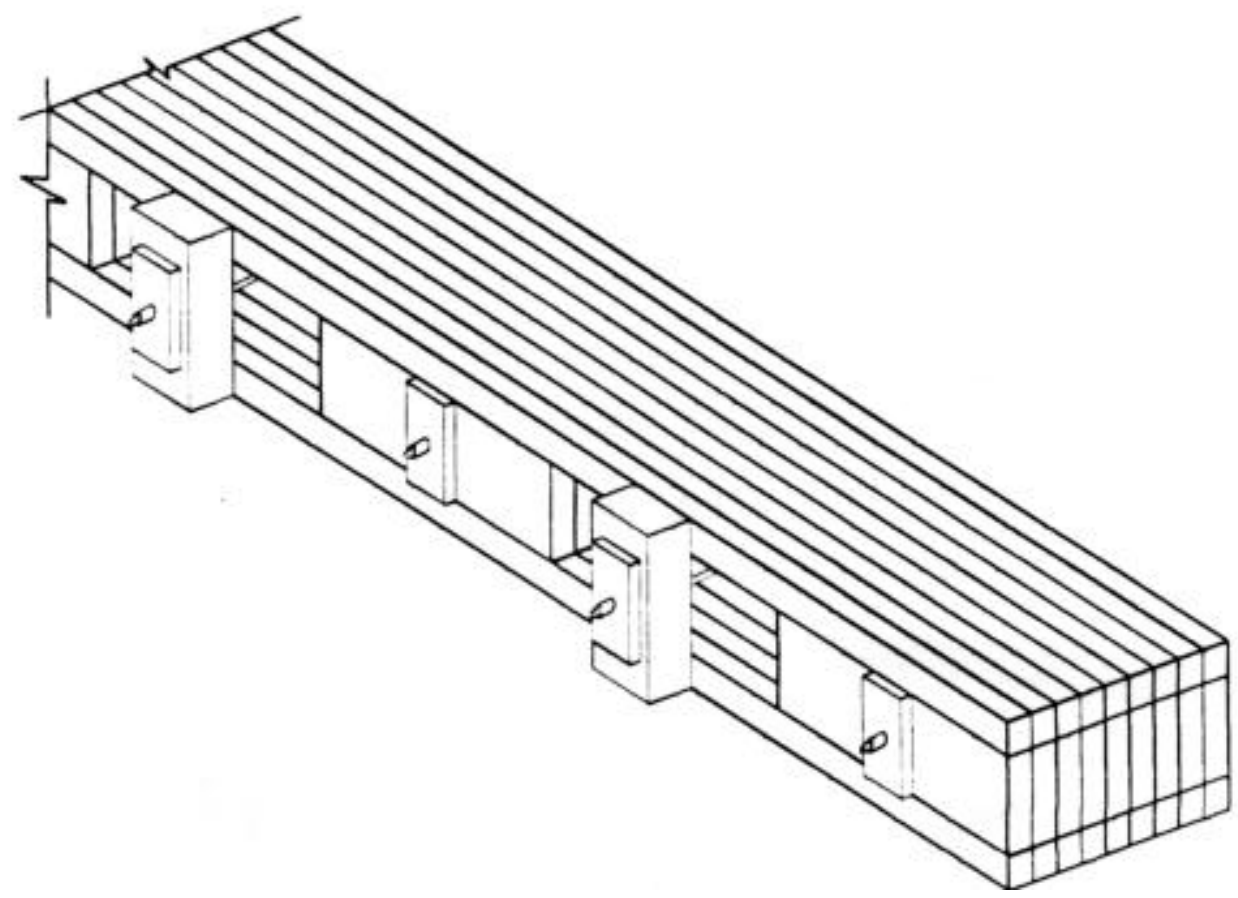

Figura 9 - Sistemas de Tablado Protendido.

Fonte: Okimoto (1997)

Muitas pontes de madeira no Brasil, têm sido construídas por proprietários de sítios e fazendas, às vezes com o auxílio de prefeituras para atender as emergências locais e quase sempre sem nenhum cálculo estrutural. Os responsáveis por suas edificações são pessoas que não possuem conhecimentos atualizados sobre a 
madeira e que, na maioria dos casos, desconhecem as características do local onde se dará a construção.

Almeida (1989) classificou as pontes de madeira do Brasil em três classes de qualidades de acordo com o tipo de arranjo estrutural adotado. A de primeira geração é caracterizada por arranjo estrutural primitivo que a leva a ruína como: ligações deficientes, pilares de madeira em contato com a água. A de segunda geração apesar de arranjo estrutural mais eficiente conserva algumas deficiências que comprometem a segurança e durabilidade da estrutura. A de terceira geração apresenta arranjo estrutural compatível com os requisitos gerais de segurança e durabilidade da estrutura.

O desenvolvimento de pontes de madeira de terceira geração iniciou-se no LaMEM, com o estudo de estruturas constituídas de postes de eucalipto citriodora. Surgiram as seções compostas bi-circulares para as longarinas formadas por dois postes interligados por anéis metálicos. Os tabuleiros também constituídos de postes foram regularizados e ao mesmo tempo enrijecido com um revestimento de concreto e asfalto. Como exemplos desses sistemas pode ser citada a ponte sobre o Ribeirão dos Porcos, a ponte de Vespaziano, ambas em pórticos e a ponte pênsil sobre o Rio Tietê, em São Miguel Paulista ( Hellmeister, 1978).

Dias (1987) detectou a necessidade de projetos de pontes de qualidade e que possibilitem a construção de estruturas satisfatórias. Observou que ainda persiste uma técnica construtiva conservadora, fruto da dificuldade de 
se transmitir do projeto para a obra, os avanços, alcançados em pesquisas específicas.

Nascimento (1993) mostra que as pesquisas, no Brasil, têm indicado diversos caminhos para a escolha de sistemas de pontes adequadas à realidade brasileira, como a análise de projetos, por critérios mais compatíveis com cada arranjo estrutural adotado. No entanto as Normas Brasileiras em vigor relacionadas às estruturas de pontes de madeiras, são ainda conservadoras, pois estabelecem critérios que nem sempre se aproximam do comportamento real da estrutura. Não é raro observar-se na prática um super dimensionamento dos elementos constituintes das pontes.

\subsection{Longarinas ou Vigas Principais}

As longarinas, vigas principais de uma ponte, devem ter comportamento satisfatório pois é através delas que se transpõe obstáculos geográficos. Para as peças de madeira maciça (roliça ou serrada) o vão livre é, quase sempre, limitado por exigir peças de grandes dimensões devido, principalmente, ao alto coeficiente de redução de resistência da madeira imposto pela NBR 7190/97.

Nos países onde as estruturas de madeira são bastante difundidas, é comum a utilização de peças estruturais de seção composta laminada colada, que na sua fabricação estão sob um maior controle de qualidade tanto do material quanto da composição propriamente dita. As peças mais resistentes são colocadas nos pontos de maior solicitação. 
Longsdon (1982) desenvolveu três projetos de pontes de madeira apresentando os cálculos detalhadamente. Nos cálculos as longarinas bi-circulares eram constituídas de postes de E. citriodora solidarizados por anéis metálicos de acordo com as proposições de Hellmeister (1978), (Figura 10). A pista de rolamento formada por postes de pequeno diâmetro que foram solidarizados nas longarinas através de cintamentos duplos com fitas metálicas de acordo com as proposições de Dias (1987).
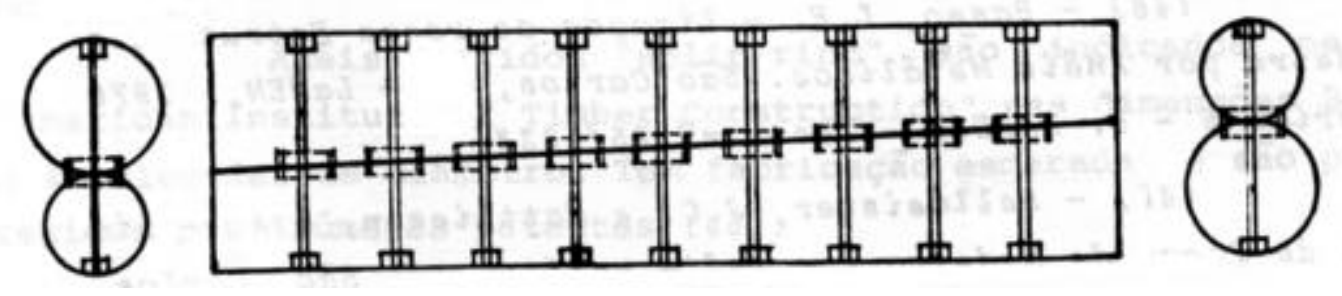

Figura 10 - Solidarização dos postes componentes da viga bi-circular por anéis metálicos.

Fonte: Hellmeister (1978)

\subsection{Tabuleiro ou Superfície de Rolamento}

O tabuleiro, superfície de rolamento, pode ser constituído por peças de madeira roliças, serradas laminadas (pregadas, coladas ou protendidas). Quando formado por peças roliças são dispostos transversalmente e de forma alternada, para compensar a conicidade existente (Figura 11). 


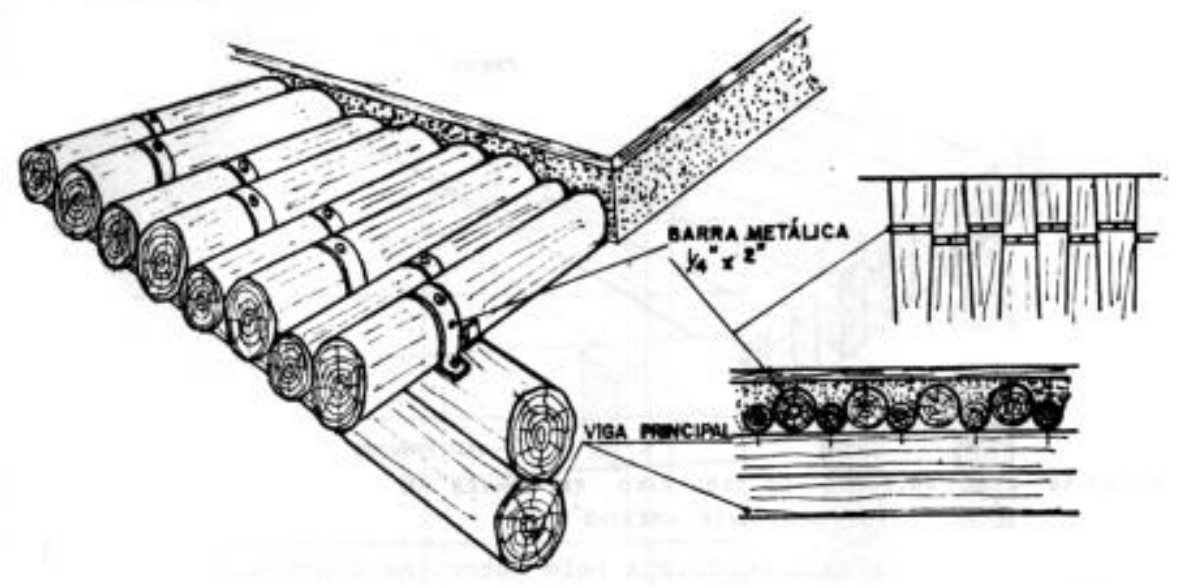

Figura 11 - Solidarização dos postes do tabuleiro na viga bi-circular por cintamento.

Fonte: Dias (1987)

Hellmeister (1978), observou os esforços solicitantes oriundos das cargas impostas pelas rodas, podem ser bastante prejudiciais para os tabuleiros formados por pequenos postes dispostos transversalmente, quando estes não estiverem adequadamente solidarizados ou muito afastados. Obteve resultados satisfatórios promovendo cintamentos duplos solidarizando-os entre si e nas longarinas (Figura 12). 

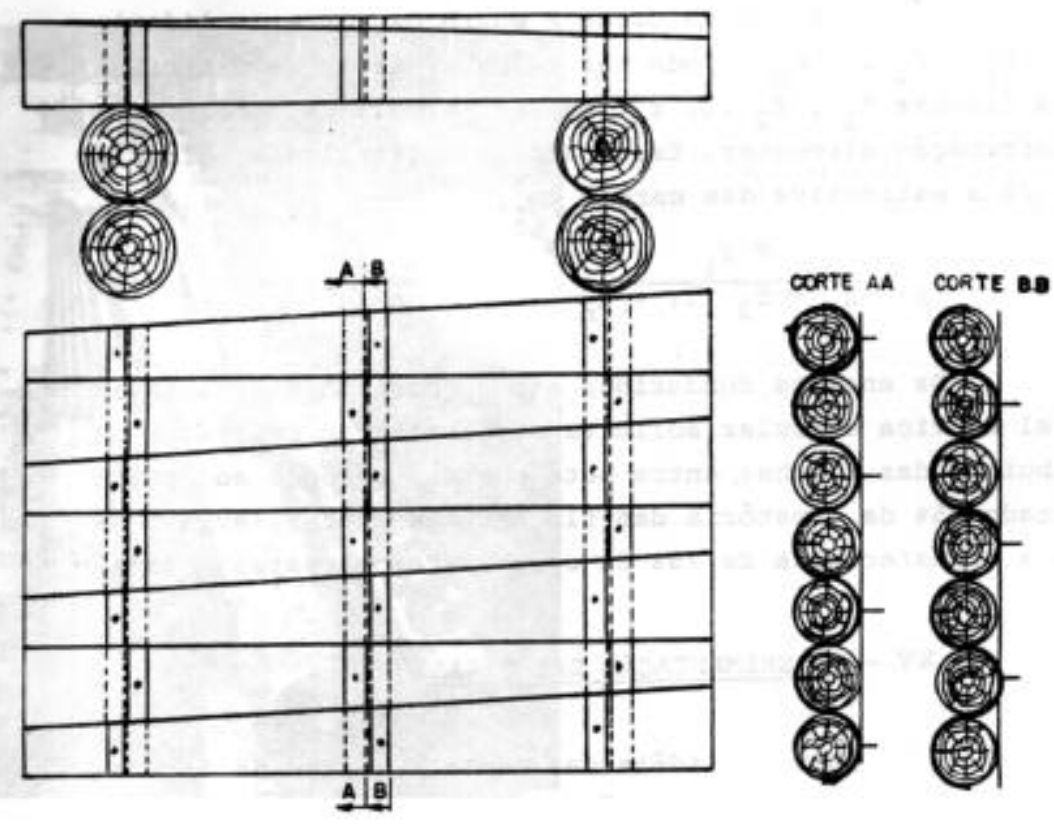

Figura 12 - Cintamento para fixação das transversinas do tabuleiro nas longarinas.

Fonte: Hellmeister (1978).

$\mathrm{Na}$ condução de um ensaio com sete postes solidarizados entre si através de cintamento duplo, Hellmeister (1978) pode constatar que o cintamento permitiu melhorar a distribuição de cargas. O poste mais solicitado recebeu apenas 25\% da carga aplicada, evidenciando assim a transferência de $75 \%$ da carga para postes laterais conferindo ao tabuleiro de postes o comportamento de laje (Figura 13). 


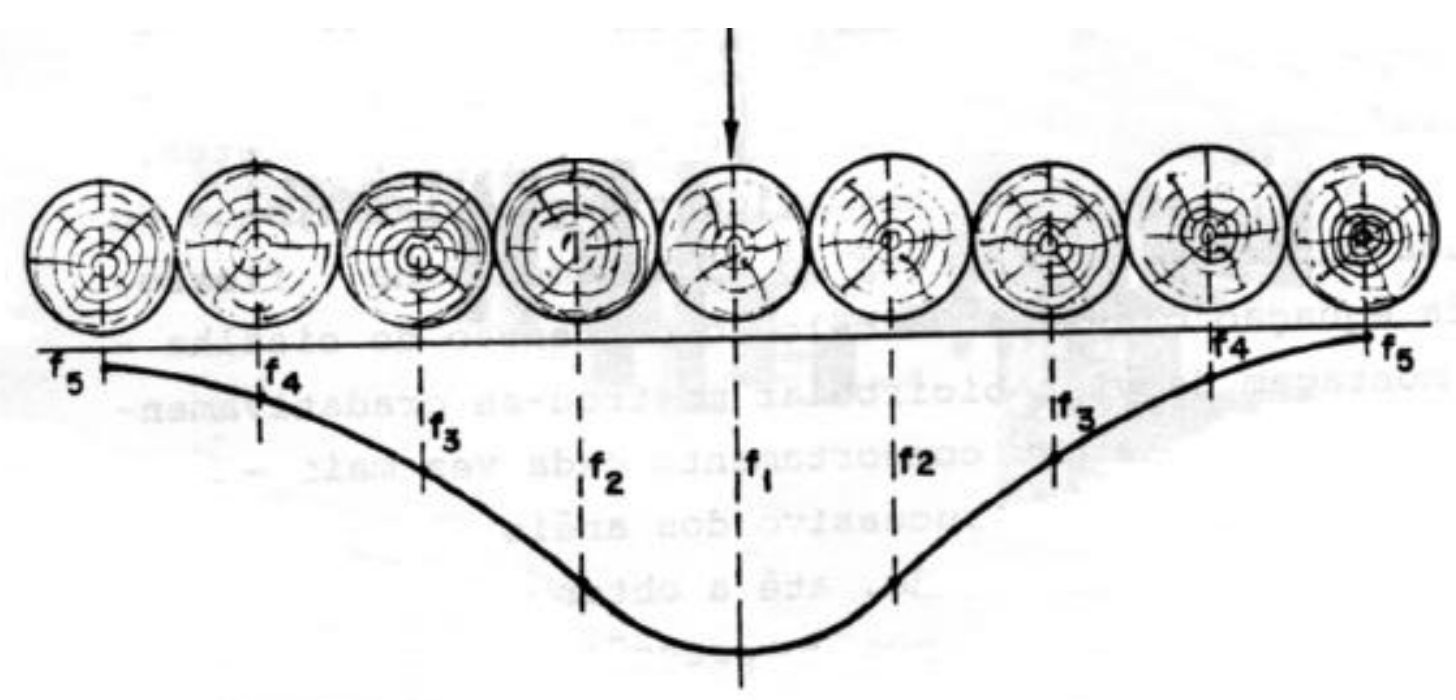

Figura 13 - Deslocamentos verticais dos postes constituintes do tabuleiro solidarizados por cintamento metálico duplo.

Fonte: Hellmeister (1978).

Dias (1987), estudando a distribuição de cargas no tabuleiro composto por postes solidarizados por cinta metálica, considerou o efeito de continuidade das transversinas, não previsto pela Norma Brasileira, adotando a teoria de grelha para os cálculos dos esforços. Observou grande concordância entre os valores obtidos na experimentação com aqueles calculados com grelhas simplificadas as quais foram denominadas grelhas idealizadas (Tabela 7). 
Tabela 7. Esforços críticos e flechas de longarinas de uma ponte de madeira.

\begin{tabular}{|c|c|c|c|c|c|c|c|c|c|c|}
\hline \multirow{2}{*}{\multicolumn{2}{|c|}{ Longarinas }} & \multicolumn{3}{|c|}{$\begin{array}{c}\text { Momento Fletor } \\
(\mathrm{KN} \cdot \mathrm{m})\end{array}$} & \multicolumn{3}{|c|}{$\begin{array}{l}\text { Cortante no } \\
\text { apoio (KN) }\end{array}$} & \multicolumn{3}{|c|}{$\begin{array}{c}\text { Flecha no meio } \\
\text { do vão }(\mathrm{cm})\end{array}$} \\
\hline & & $\mathrm{Mg}$ & $\mathrm{Mq}$ & M & Vg & $\mathrm{Vq}$ & V & $\mathrm{vg}$ & $\mathrm{vq}$ & $\mathrm{V}$ \\
\hline \multirow{3}{*}{ 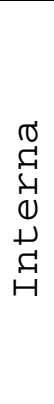 } & $\begin{array}{c}\text { Analog.de } \\
\text { grelha }\end{array}$ & 76,8 & 78,6 & 155,4 & 39,3 & 55,9 & 95,2 & 1,65 & 0,96 & 2,61 \\
\hline & $\begin{array}{l}\text { Teoria } \\
\text { Simplif. }\end{array}$ & 81,6 & 107,3 & 188,9 & 40,8 & 61,1 & 101,9 & 1,74 & 1,35 & 3,09 \\
\hline & $\begin{array}{c}\text { Diferença } \\
\left(\frac{\circ}{0}\right)\end{array}$ & $+6,3$ & $+36,5$ & $+21,6$ & $+3,8$ & $+9,3$ & $+7,0$ & $+5,5$ & $+40,5$ & $+18,4$ \\
\hline \multirow{3}{*}{ 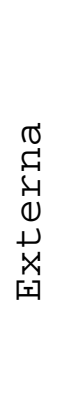 } & $\begin{array}{c}\text { Analog.de } \\
\text { grelha }\end{array}$ & 72,8 & 76,5 & 149,3 & 35,5 & 37,7 & 73,2 & 1,55 & 1,0 & 2,55 \\
\hline & $\begin{array}{l}\text { Teoria } \\
\text { Simplif. }\end{array}$ & 68,0 & 76,0 & 144,0 & 34,0 & 40,5 & 74,5 & 1,45 & 0,93 & 2,38 \\
\hline & $\begin{array}{c}\text { Diferença } \\
\text { (\%) }\end{array}$ & $-6,6$ & $-0,7$ & $-3,5$ & $-4,2$ & $+7,4$ & $+1,8$ & $-6,5$ & $-7,0$ & $-6,7$ \\
\hline
\end{tabular}

Fonte: Dias (1987)

Constatou que não houve diferenças significativas entre os valores obtidos pela analogia de grelha com os calculados. Para a estrutura estudada, Dias concluiu que o meio contínuo é representado satisfatoriamente por 7 transversinas idealizadas. Na experimentação o recobrimento de concreto utilizado para regularizar o tabuleiro constitui-se em um fator de acréscimo de rigidez inicial, levando a valores de deformações menores que os calculados. Entretanto, ainda é arriscado considerar-se a aderência 
permanentemente entre o recobrimento de concreto e o tabuleiro de madeira, constituído de peças roliças.

A importância da solidarização das peças do tabuleiro conduziu Mathiessen (1987) a avaliar através de experimentação o comportamento de dois tabuleiros de ponte, Figura 14, sendo um constituído de vigas simples (ponte em placa simples) e outro de viga simples e bi-circular (ponte em placa nervurada) solidarizados transversalmente com anéis metálicos e tirantes.

A importância da solidarização das peças do tabuleiro conduziu Mathiessen (1987) a avaliar, através de experimentação, os comportamentos de dois tabuleiros de ponte (Figura 14) sendo um constituído de vigas simples (ponte em placa plana) e outro de vigas bi-circulares intercalados por vigas simples (ponte em placa nervurada) solidarizadas transversalmente com anéis metálicos e tirantes. Observou uma boa distribuição de cargas na ponte do tipo placa plana onde a média das flechas das vigas de borda foi de aproximadamente, 80\% da flecha da viga central apresentando, portanto, um comportamento característico de placa ortotrópica. Para a ponte tipo placa nervurada a média das flechas das vigas de borda foi de apenas 50\% da flecha da viga central. Isto evidencia que a rigidez da viga bi-circular de borda não foi totalmente utilizada, provavelmente devido ao enfraquecimento da seção dos postes pela instalação dos anéis de ligação lateral.

O comportamento da ponte como placa plana permite que seja utilizado vãos maiores que os da ponte do tabuleiro formado por postes não solidarizados. 


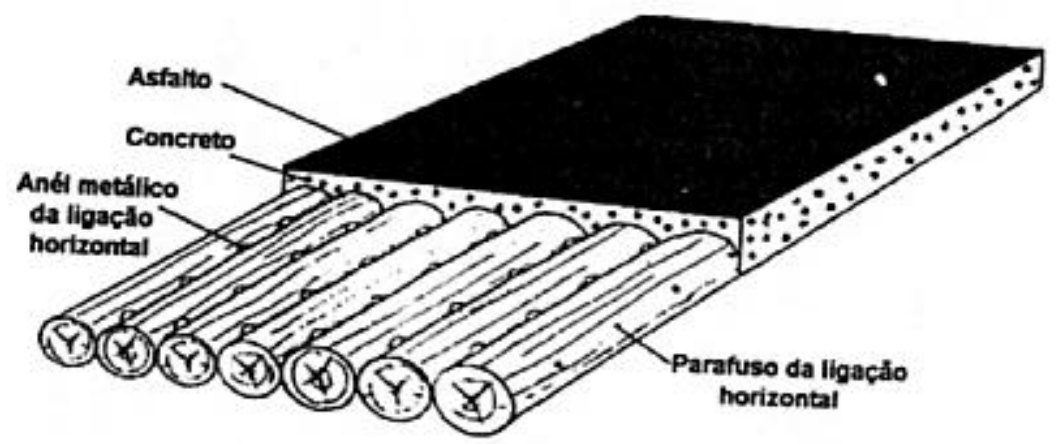

a) Ponte em placa simples

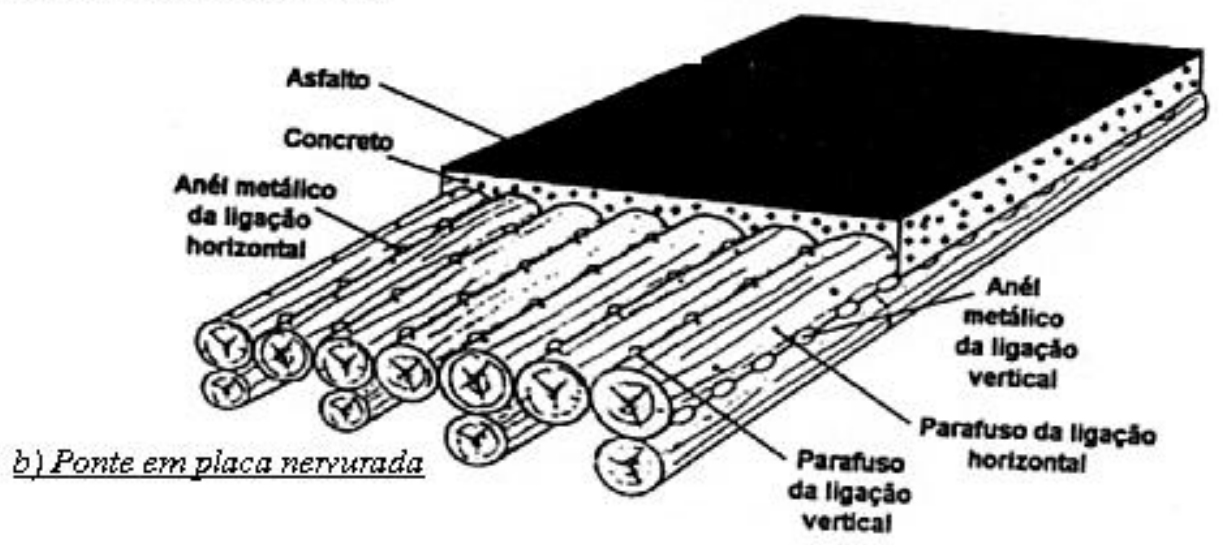

Figura 14 - Tabuleiros que apresentam comportamento de placa ortótropa.

Fonte: Mathiessen (1987)

Erickson \& Romstad (1965) realizaram pesquisas relacionadas à distribuição transversal de cargas em pontes de madeira tratada de Douglas Fir com tabuleiro laminado pregado, composto por vigas longitudinais de seção retangular. As experimentações foram desenvolvidas em laboratório e em pontes existentes. Calcularam a ponte como grelha de apenas 1 transversina idealizada com rigidez à flexão igual a $1 / 5$ da rigidez da viga longitudinal. 
Obtiveram boa aproximação dos resultados experimentais dos teóricos e em função disso recomendaram a revisão dos critérios de cálculo da AASHTO ${ }^{1}$ para a determinação dos esforços cortantes.

O comportamento de pontes protendidas de madeira de coníferas tem sido objeto de estudos na América do Norte. A utilização de madeiras de dicotiledôneas neste sistema pode levar a resultados bem diferentes dos obtidos com madeira mais leves. Isso se deve, principalmente, à rigidez transversal proporcionada pela protensão e à rigidez à torção. Nascimento (1993) comprovou na experimentação a hipótese de placa ortotrópica, e a possibilidade da utilização de madeiras de dicotiledônea em estrutura desta natureza, muito difundida nos Estados Unidos e no Canadá. Conclui que "o arranjo estrutural das pontes de tabuleiro longitudinal laminado protendido apresentam características bastante peculiares, incompatíveis com a forma de análise estática de pontes proposta pela norma NBR-7190".

O fato da madeira ser um material anisótropo não impede o comportamento ortotropico dos tabuleiros das pontes de madeira, que é conseguido pelo arranjo estrutural onde a rigidez em uma direção é muito superior à rigidez na direção perpendicular a esta. Sistemas estruturais que possam garantir o comportamento isotrópico dos tabuleiros de pontes contribuem para um melhor aproveitamento do material e conseqüente melhoria de seu desempenho (Paiva, $1995)$.

${ }^{1}$ American Association of State Highway and Transportation Officials 


Almeida (1989) analisou tabuleiros de pontes
constituidos por duas camadas ortogonais de lâminas
superpostas. As camadas eram compostas por tábuas
justapostas formando um ângulo de $45^{\circ} \mathrm{com} \circ$ eixo longitudinal da ponte. Em cada cruzamento as peças das duas camadas foram solidarizadas entre si por meio de pregos (Figura 15). Foram ensaiados dois modelos construídos com madeiras de jatobá amarelo, sendo uma placa quadrada simplesmente apoiada nos quatros lados e outra retangular simplesmente apoiada ao longo dos dois lados mais longos e livres nos outros dois. Admitindo a hipótese de placa de madeira isotrópica com coeficiente de Poisson nulo concluíram, a partir dos resultados obtidos na experimentação, que o tabuleiro pode ser calculado através da teoria de placas elásticas, de modo semelhante ao cálculo de uma placa maciça isótropa de madeira de espessura igual a uma das camadas e com coeficiente de Poisson nulo. Verificou também que o número de pregos não afeta significativamente o comportamento da placa.

Almeida (1990), baseado no estudo de Almeida (1989), calculou uma ponte de madeira de 3,60 m de largura e $28,20 \mathrm{~m}$ de vão livre, que foi construída sobre o rio Sorocaba em Iperó - S.P. 


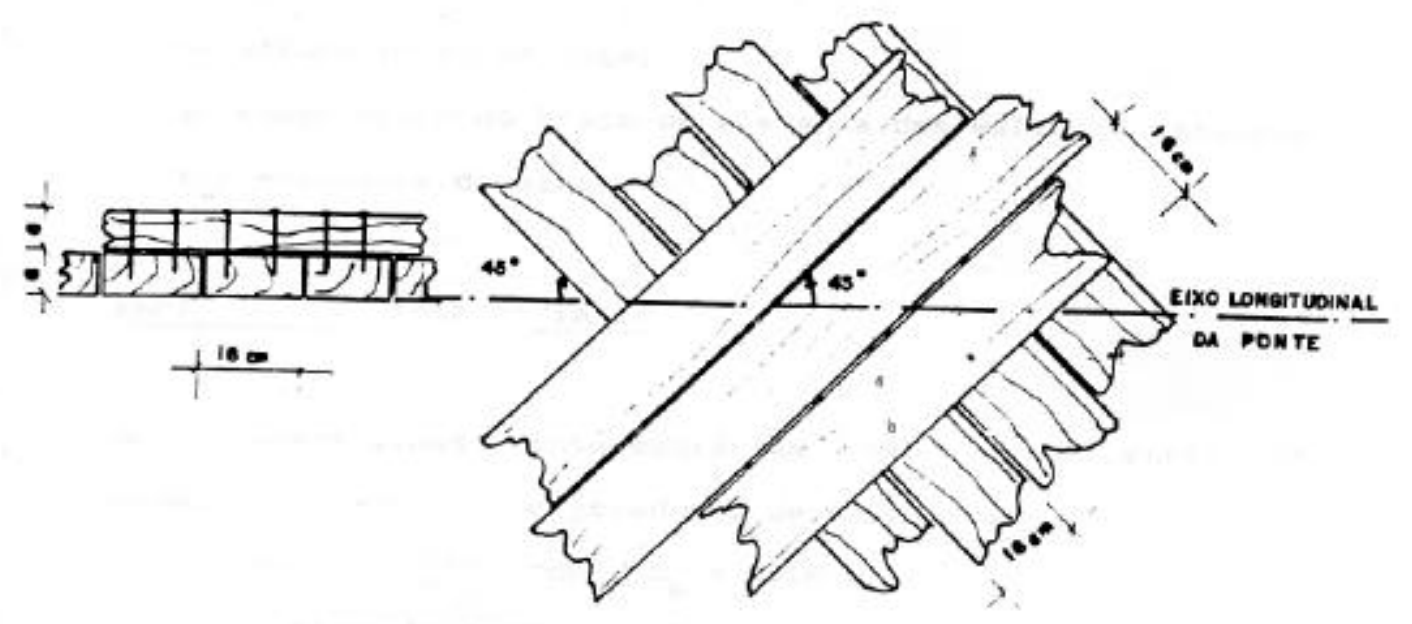

Figura 15 - Painéis de madeira que funciona como placa isótropa.

Fonte: Almeida (1990)

Paiva (1995) observou o comportamento sob flexão de tabuleiros de madeira com a configuração estrutural adotada por Almeida (1989). Avaliou a variação da rigidez do arranjo com o aumento da quantidade de pontos de ligação entre as peças componentes das duas camadas e o desempenho de tabuleiros ligados por pregos e por cavilhas de madeira (Figura 16). Através da experimentação de dois modelos reduzidos constituídos de madeira de peroba rosa concluiu que a rigidez do tabuleiro aumenta com o acréscimo de pontos de solidarização entre as peças das camadas que o compõe, tendendo assintóticamente a um máximo. Uma análise numérica mostrou que o modelo pregado (apoiado nas duas direções e configuração II) é equivalente a uma placa isótropa com módulo de elasticidade igual à média dos módulos de elasticidade das peças componentes. e de espessura da ordem de $40 \%$ do valor da espessura do modelo 
real. A configuração II (quantidade média de pontos de ligação) foi considerada ótima, não havendo vantagem relativa em se aumentar a quantidade de pontos de ligação.

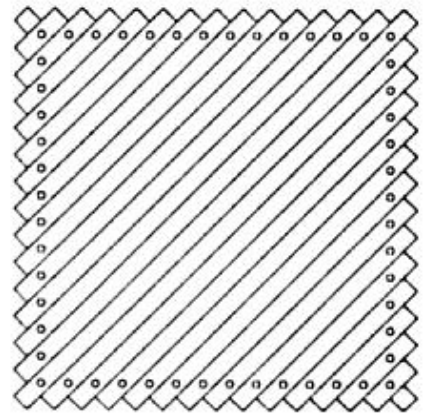

CONFIG. I

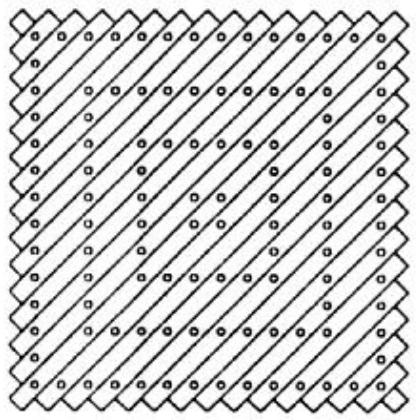

CONFIG. II

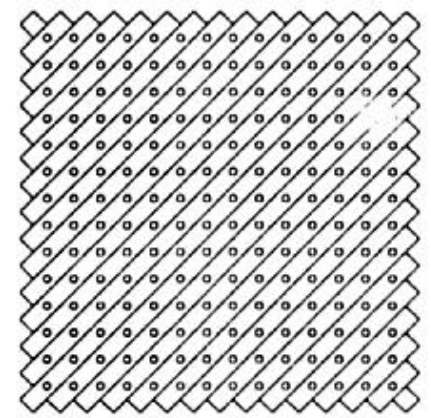

CONFIG. III

Figura 16 - Vista dos pontos de ligação entre as camadas perpendiculares da placa de madeira.

Fonte: Paiva (1995)

\subsection{Esforços Solicitantes}

As ações em pontes de madeira podem ser classificadas como: principais, adicionais e especiais. As solicitações principais, são de acordo com a NBR 7188/84 ${ }^{1}$, formadas pela carga permanente que é constituída do peso próprio da estrutura e a carga móvel que é constituída pelo trem de carga que leva em conta o trem tipo e a carga de multidão. As solicitações adicionais são aquelas que devem ser consideradas em certos tipos de estruturas como vento, força longitudinal, força centrífuga, impacto lateral e vertical (para as pontes de madeira o impacto vertical é 
uma solicitação adicional mas para as pontes metálicas ou de concreto é uma solicitação principal). As solicitações especiais aparecem com características peculiares para cada caso em particular como por exemplo choques de veículos contra pilares de pontes rodoviárias e choques de barcos contra as paredes laterais de canais.

O trem-tipo para pontes rurais tem particularidades importantes porque apesar de trafegar em estradas vicinais é normalmente muito pesado. É comum e muito utilizado no meio rural caminhões especiais para transporte de cana e outros produtos agrícolas, adubos, areia, etc. Entretanto pelo fato da maioria das pontes terem apenas uma pista de tráfego e comprimento não muito superior ao do próprio trem tipo, podem ser introduzidas algumas simplificações no trem de carga para que, sem prejuízo da segurança, tornem as pontes menos onerosas.

\subsection{Manutenção das Pontes de Madeira}

A madeira é um material biológico susceptível à deterioração, pela ação de fungos apodrecedores, insetos xilófagos, perfuradores marinhos, descoloração, agentes químicos, intemperismo e fogo.

De acordo com o Manual de Preservação de Madeiras (1986) para impedir, ou pelo menos atenuar, a ação de agentes biodeterioradores há, basicamente, três linhas de ação: 
$\checkmark$ Usar madeira dotada de elevada resistência biológica embora essa medida não impeça a ocorrência dos demais fenômenos de natureza física e/ou química;

$\checkmark$ Incorporar produtos químicos à madeira como os preservantes, produtos ignífugos e de acabamentos superficiais;

$\checkmark \quad$ Introduzir alterações químicas permanentes na estrutura dos componentes poliméricos da madeira.

Todas as medidas necessárias para aumentar-se a durabilidade das pontes de madeira devem ser estudadas e aplicadas desde o início da construção.

A manutenção de uma ponte poderá compreender a sua quase completa substituição ou apenas reparos preventivos, mas nenhum projeto de reparos ou manutenção deve ser elaborado antes de uma completa e minuciosa vistoria.

Hislop \& Ritter (1996) puderam acompanhar durante os dois anos de monitoramento realizado na ponte connell Lake, no Alaska, o desempenho da ponte recuperada depois de sua reconstrução. Houve necessidade de prevenção contra o acúmulo de solo sobre o tabuleiro que, seguramente, resultariam em deterioração da madeira uma vez que o solo armazena e transfere umidade para a madeira. Verificaram que o desempenho do CCA (cromo-cobre-arsênico) utilizado no tratamento preservante foi satisfatório, que a estabilidade dimensional da madeira tratada utilizada dependia da insolação e da umidade local e que a vegetação abundante existente ao redor da ponte não promovia ciclos rápidos de ganho e perda de umidade pela madeira. 
A madeira utilizada em pontes possui, geralmente, um alto teor de umidade. A umidade de equilíbrio média para - Brasil varia entre 13 a 19\% segundo Galvão (1975) . Portanto é recomendável que a madeira a ser utilizada em estruturas de grande responsabilidade, apresente um teor de umidade máximo de 18\%, para reduzir-se, substancialmente, os problemas decorrentes das deformações que ocorre durante - processo de secagem.

$$
\text { Segundo Nascimento (1993), além das mudanças no }
$$
teor de umidade provocadas pelo desequilíbrio com o meio, podem ocorrer acúmulos de umidade na superfície do tabuleiro devido, principalmente, à falta de um sistema de drenagem eficiente ou de um revestimento impermeabilizante como por escolha a manta bidim complementado por uma camada de asfalto. 


\section{MATERIAI E MÉTODOS}

\subsection{Madeira}

A madeira utilizada nesta experimentação foi proveniente da Estação Experimental de Anhembi, da ESALQ/USP, retirada de um plantio de Eucalyptus citriodora 19 anos de idade com espaçamento de $3 \mathrm{~m}$ x $2 \mathrm{~m}$. Esta espécie foi escolhida porque apresenta, de acordo com dados obtidos na literatura, resistência mecânica pertencente à classe C40, recomendada para estruturas em geral.

As árvores foram derrubadas e seccionadas em toras de aproximadamente 8 metros de comprimento (postes). $\mathrm{Na}$ extremidade de cada poste foi aplicada uma placa dentada para atenuar os efeitos das rachaduras de ponta (Figura 17). Posteriormente os postes foram transportados para o Laboratório de Engenharia da Madeira do Departamento de Ciências Florestais da ESALQ/USP e acondicionados para secagem ao ar (Figura 18). 


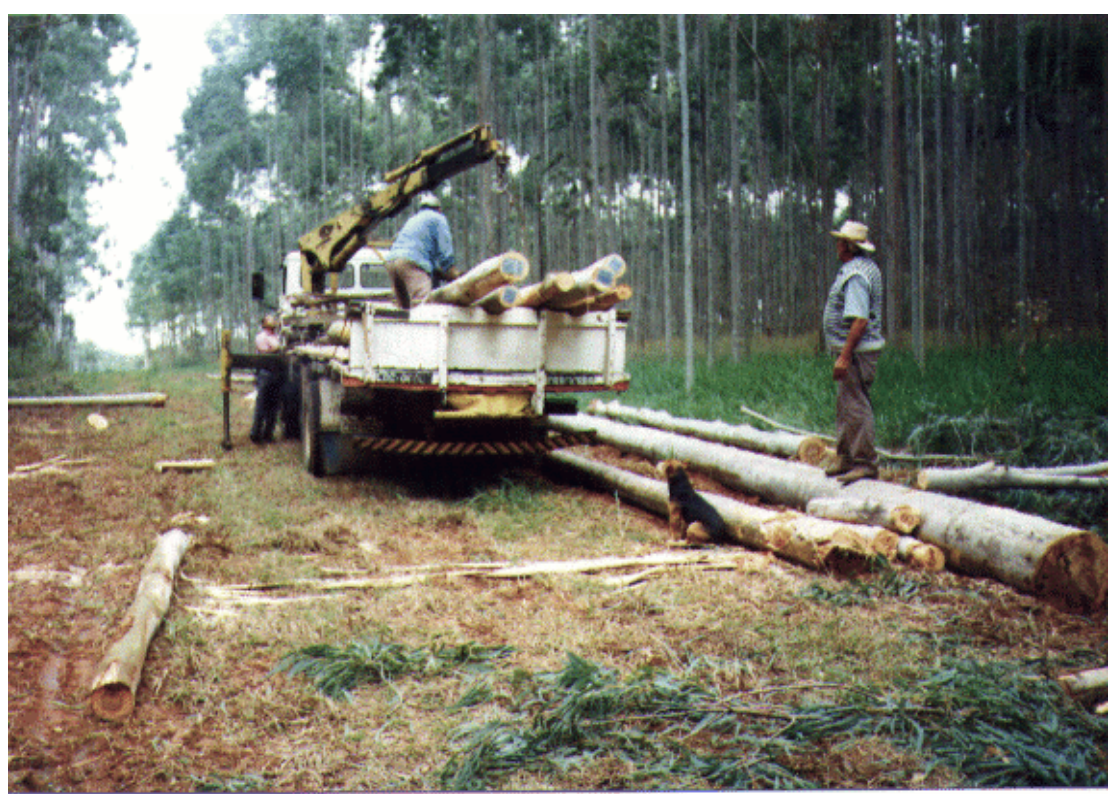

Figura 17 - Postes, já com placa dentadas aplicadas em sua extremidade, sendo removidos da Estação Experimental de Anhembi da ESALQ/USP.

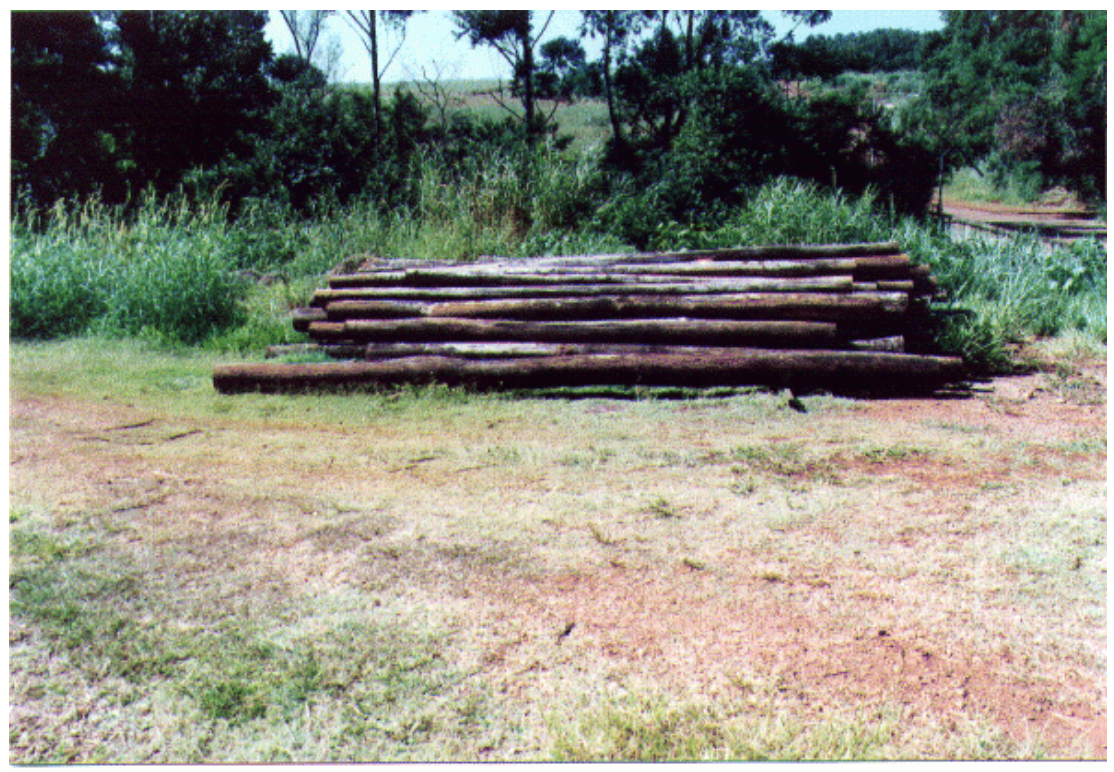

Figura 18 - Postes de Eucalipto citriodora acondicionados para secagem ao ar. 
Seria ideal para a experimentação a utilização de postes homogêneos tanto em termos de dimensões quanto de módulo de elasticidade. Entretanto essa exigência for desconsiderada porque demandaria uma quantidade muito maior de árvores para escolha dos postes ideais, o que tornaria o experimento muito mais oneroso. Por outro lado, procurou-se seguir o procedimento usual de execução de pontes rurais, no qual os postes são simplesmente coletados e utilizados.

\subsection{Anéis Metálicos}

A consideração da hiperestaticidade das estruturas somente pode ser aceita se as ligações de seus componentes de madeira apresentarem um certo grau de rigidez.

A Norma Brasileira NBR 7190/97 admite, no seu item 8.5.1, a utilização de ligações com anéis metálicos de diâmetros de 64 e $102 \mathrm{~mm}$ e espessura de $4 \mathrm{~mm}$ e $5 \mathrm{~mm}$ respectivamente, fabricados com aço submetidos às prescrições da NBR 8800, considerando-as rígidas.

A viga - tipo de seção composta adotada no presente trabalho foi construída a partir do arranjo de dois postes de oito metros de comprimento solidarizados por anéis metálicos fechados de diâmetro de $150 \mathrm{~mm}$ e espessura de $5 \mathrm{~mm}$ formando uma viga de seção bi-circular sendo o topo de um poste voltado para a base do outro. Os anéis metálicos foram obtidos de um tubo de aço (Figura 19) não tendo sido objeto do estudo a verificação da sua resistência. 
$\mathrm{Na}$ ligação das peças circulares componente foram utilizados parafusos tipo barra rosca $\left(\phi=1 / 2{ }^{\prime \prime}\right.$ e comprimento de $70 \mathrm{~cm}$, mais porcas e arruelas) para apenas manter as peças solidarizadas entre si e permitir o pleno desenvolvimento dos efeitos dos anéis. Não foi considerada a influência da rigidez do parafuso na transmissão de esforços.

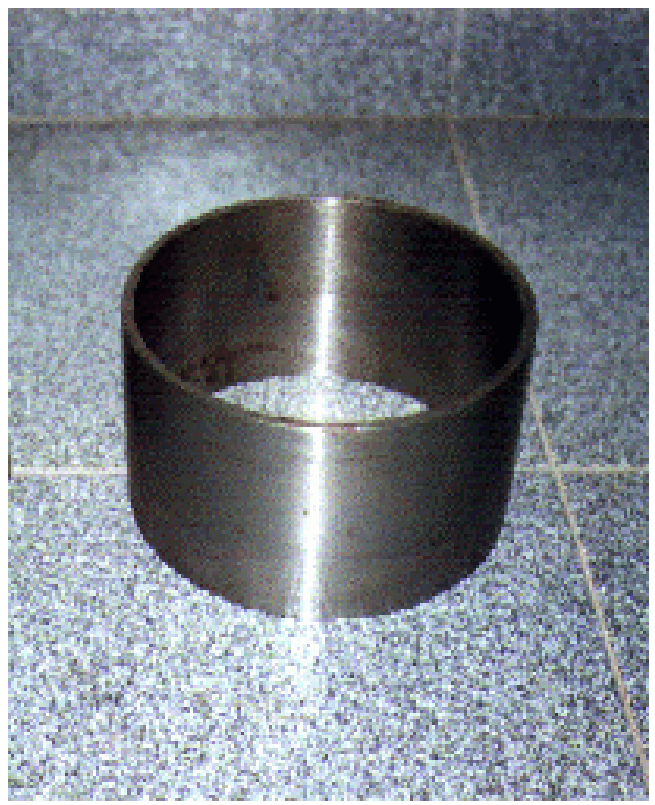

Figura 19 - Anel metálico de diâmetro de $150 \mathrm{~mm}$.

\section{3 Ferramentas}

Tendo em vista o interesse em simularem-se situações de trabalho de campo, a moto serra foi a ferramenta básica utilizada para procederem-se as operações de corte, furação e sulcagem. Para as operações de corte foi usado o sabre tradicional e para as operações de 
furação e sulcagem foi utilizada uma furadeira acoplável, facilmente, na própria motoserra. Os sulcos na madeira foram feitos através de uma serra-copo fabricada de um dos próprios anéis o qual foi transformado numa serra copo (Figura 20).
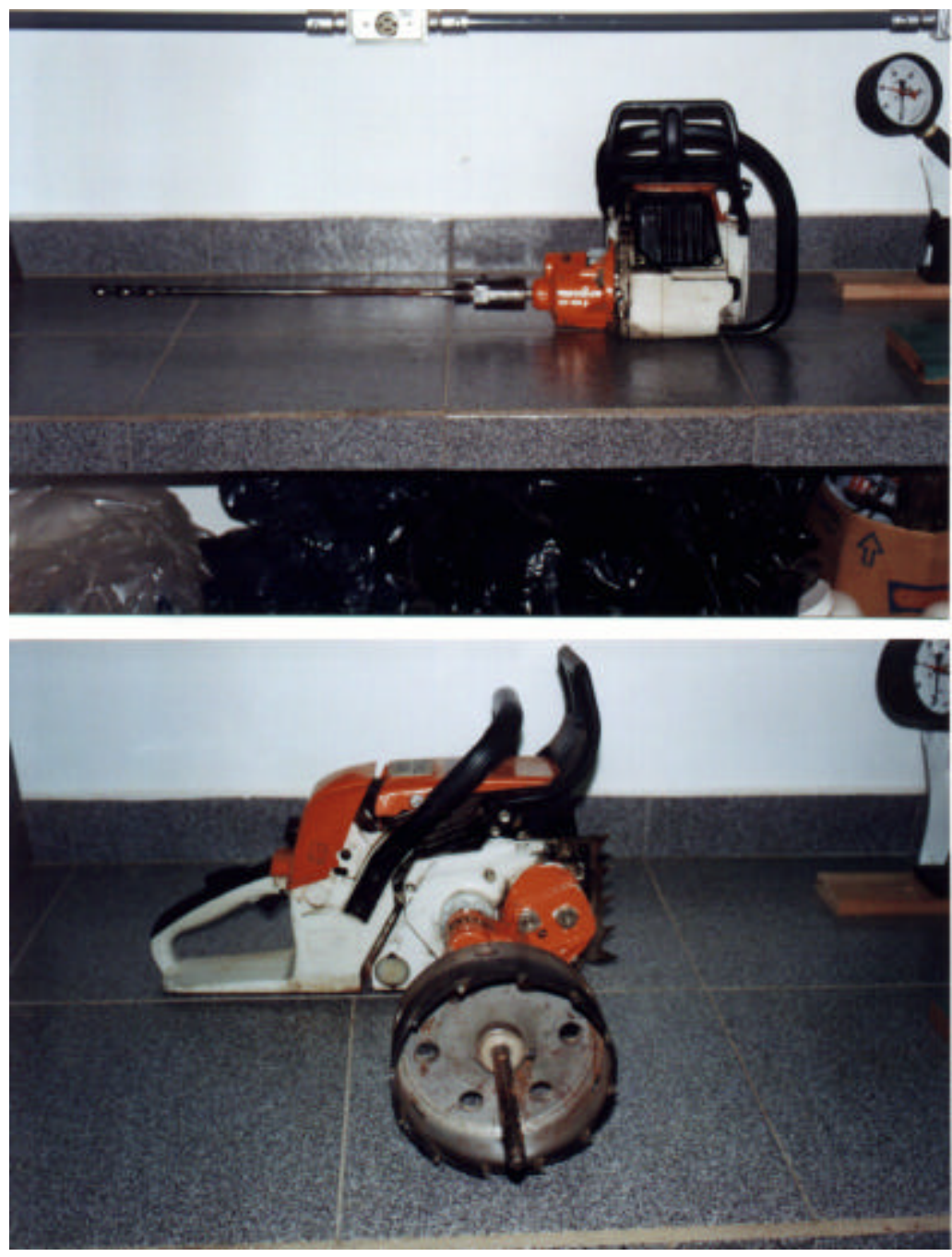

Figura 20 - Furadeira acoplada na própria motoserra portando a broca (a) ou a serra-copo com sua haste guia (b) . 


\subsection{Determinação das propriedades físico-mecânicas da madeira}

No presente trabalho utilizou-se a caracterização simplificada da madeira das espécies usuais (item 6.33 da NBR 7190/97). As dimensões especificadas de alguns corpos de prova foram alterados para ficarem compatíveis com as dimensões físicas e capacidade de carga da máquina de ensaio do Laboratório de Engenharia de Madeira da ESALQ/USP.

Do lote de ensaio foram retiradas, aleatoriamente, 3 toras que foram desdobradas conforme a Figura 21, para obterem-se os corpos de prova para a qualificação do material utilizado nas seguintes propriedades: resistência à compressão paralela às fibras, resistência ao cisalhamento, módulo de elasticidade na compressão paralela às fibras, umidade, densidade básica e densidade aparente.

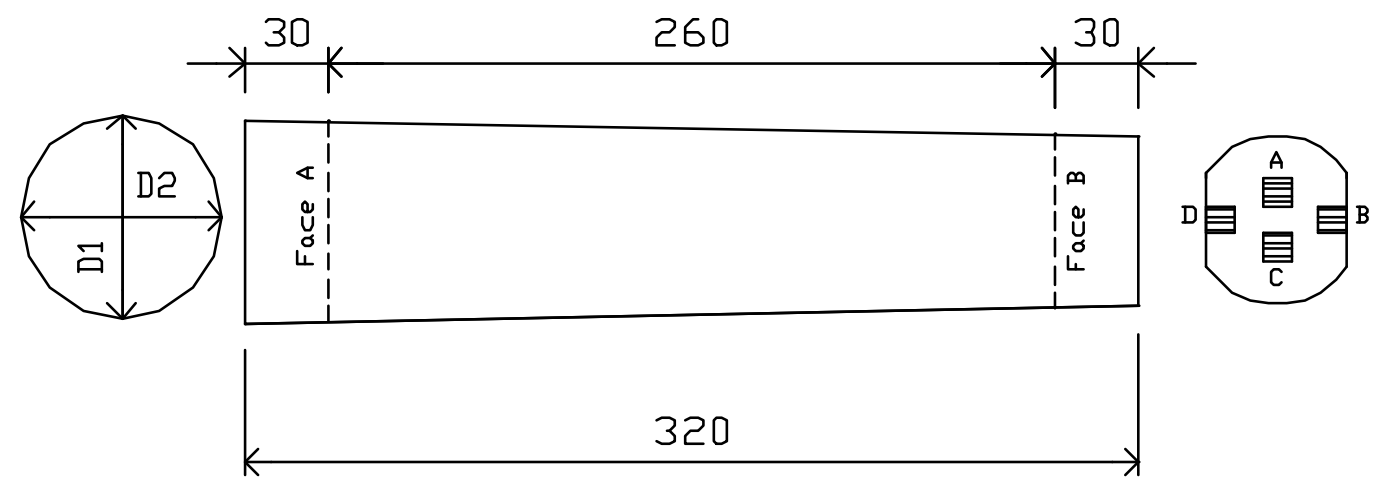

Figura 21 - Peças amostradas da tora para confecção de corpos de prova. 
Na Tabela 8 encontram-se as dimensões das três toras colhidas para a retirada dos corpos de prova.

Tabela 8. Dimensões das toras amostradas para ensaios.

\begin{tabular}{|c|c|c|c|c|c|}
\hline Tora & $\begin{array}{c}D_{1} \\
(\text { face } A) \\
(\mathrm{cm})\end{array}$ & $\begin{array}{c}\mathrm{D}_{2} \\
(\mathrm{face} A) \\
(\mathrm{cm})\end{array}$ & $\begin{array}{c}D_{1} \\
(\text { face } B) \\
(\mathrm{cm})\end{array}$ & $\begin{array}{c}\mathrm{D}_{2} \\
(\mathrm{face}) \\
(\mathrm{cm})\end{array}$ & $\begin{array}{c}\text { Comprimento } \\
(\mathrm{cm})\end{array}$ \\
\hline $\bar{I}$ & 23,00 & 20,90 & 24,10 & 21,30 & 320 \\
\hline I I & 21,10 & 21,40 & 23,00 & 21,90 & 320 \\
\hline III & 22,90 & 21,10 & 23,50 & 20,20 & 320 \\
\hline
\end{tabular}

$D_{1}$ - diâmetro do poste na face considerada; $\mathrm{D}_{2}$ - diâmetro perpendicular a $\mathrm{D}_{1}$.

Antes da retirada dos corpos de prova foi feito o descarte de $30 \mathrm{~cm}$ de cada extremidade da tora, restando portanto, o comprimento final de $260 \mathrm{~cm}$.

A densidade básica foi obtida pelo método da balança hidrostática utilizando-se cunhas retiradas de discos amostrados nas toras.

Da tora utilizada para a confecção dos corpos de prova da ligação madeira - anel metálico, foram retiradas doze cunhas para a realização do ensaio de densidade básica.

\subsection{Determinação da rigidez e resistência do conjunto de duas peças de seção circular unidas por um anel metálico}


Para determinar-se a capacidade de carga efetiva da ligação madeira - anel metálico e compara-la com a expressão admitida pela Norma Brasileira NBR 7190/97, item 8.5.3, foram ensaiados três corpos de prova de especialmente construídos para esse fim (Figura 22).
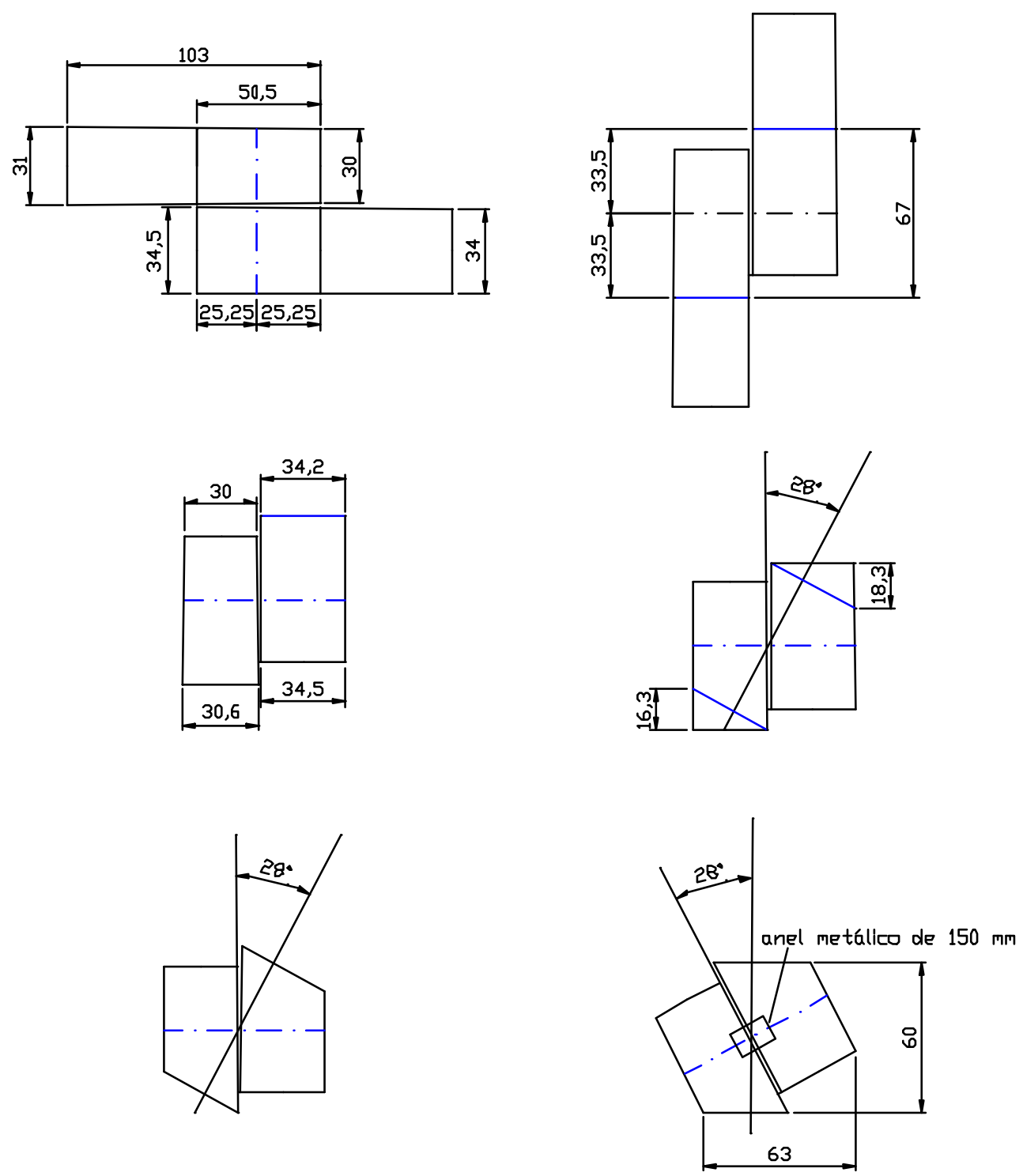

Figura 22 - Corpo de prova idealizado para o ensaio da ligação de peças roliças por anel metálico. 
O corpo de prova proposto foi idealizado para estar o mais próximo possível da realidade. Para tanto utilizou -se um poste de diâmetro médio de $32 \mathrm{~cm}$ diâmetro semelhante ao utilizado para a montagem da viga bi-circular (Figura 23).

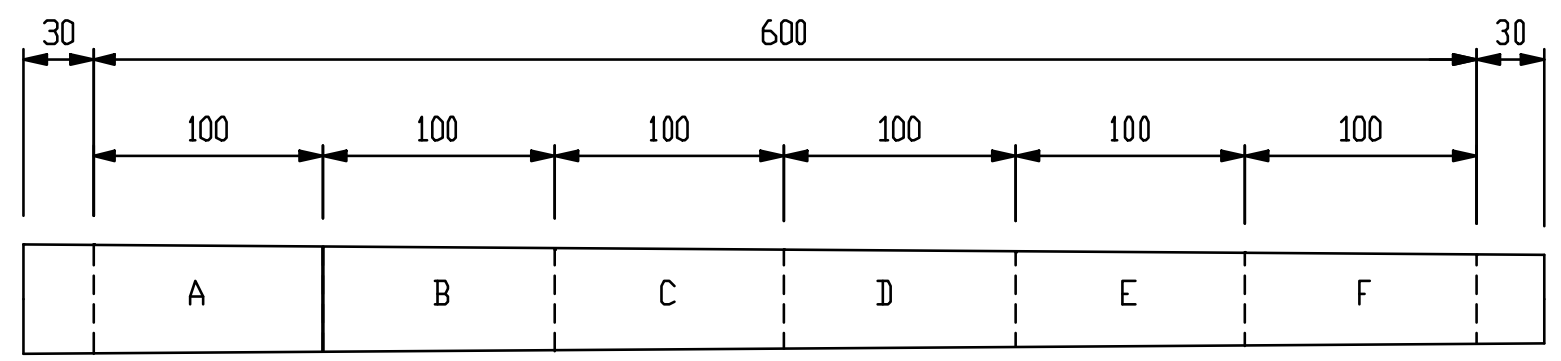

Figura 23 - Distribuição, na tora, das peças componentes do corpo de prova especial de ensaio da ligação madeira - anel metálico.

Os toretes "A" e " $F$ " formaram o primeiro corpo de prova que representa a ligação na extremidade da viga onde se tem a base de um poste ligada ao topo do outro. Os toretes "B" e "E" formaram O segundo corpo de prova que representa uma seção intermediária e as toras "C" $e$ " $D$ " formaram o terceiro corpo de prova representando a seção central onde os dois postes ligados têm aproximadamente a mesma seção (Figura 24). 


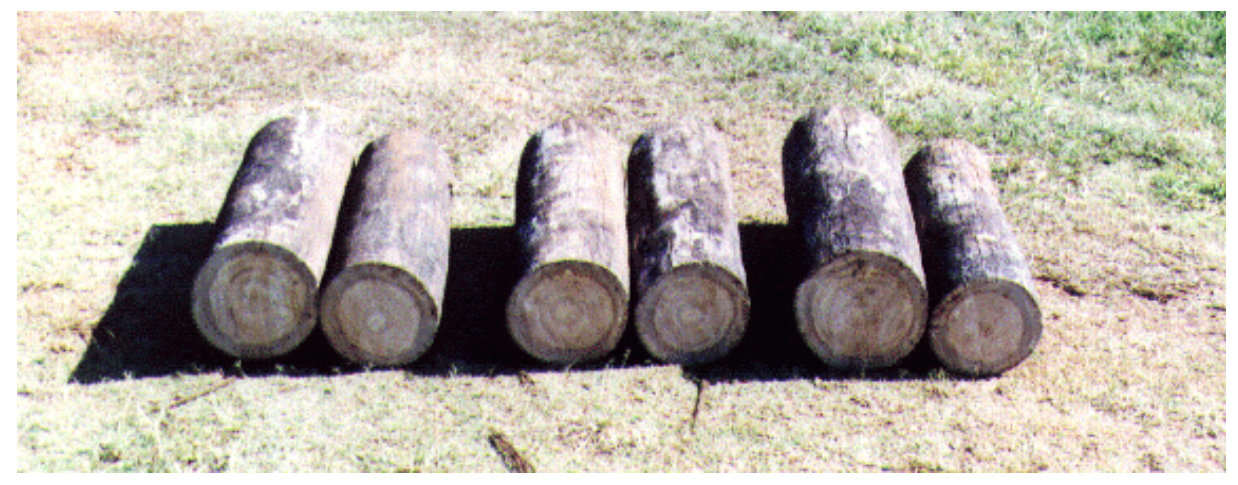

Figura 24 - Pares de toretes para a confecção dos corpos de prova da ligação madeira - anel metálico.

Esses toretes foram levemente desbastados (Figura 25) com moto-serra para permitir melhorar o ajuste de um torete ao outro.

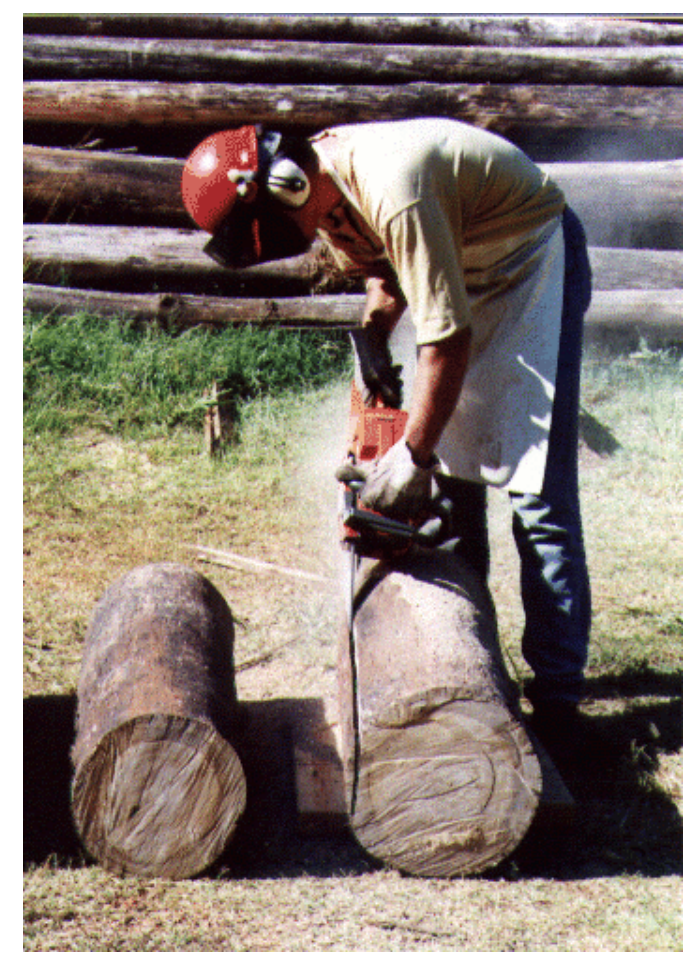

Figura 25 - Desbaste lateral dos toretes. 
As Figuras 26 a 30 mostram as etapas seguidas para montagem dos corpos de prova. Na figura 29 os dois toretes que formam, um corpo de prova, estão colocados um sobre o outro para serem furados de uma só vez. A continuidade do furo é muito importante porque o mesmo servirá de guia para a ferramenta de sulcagem. Nessa operação utilizou-se uma broca de diâmetro de 9/16", um pouco maior que o diametro de $1 / 2$ " do parafuso.

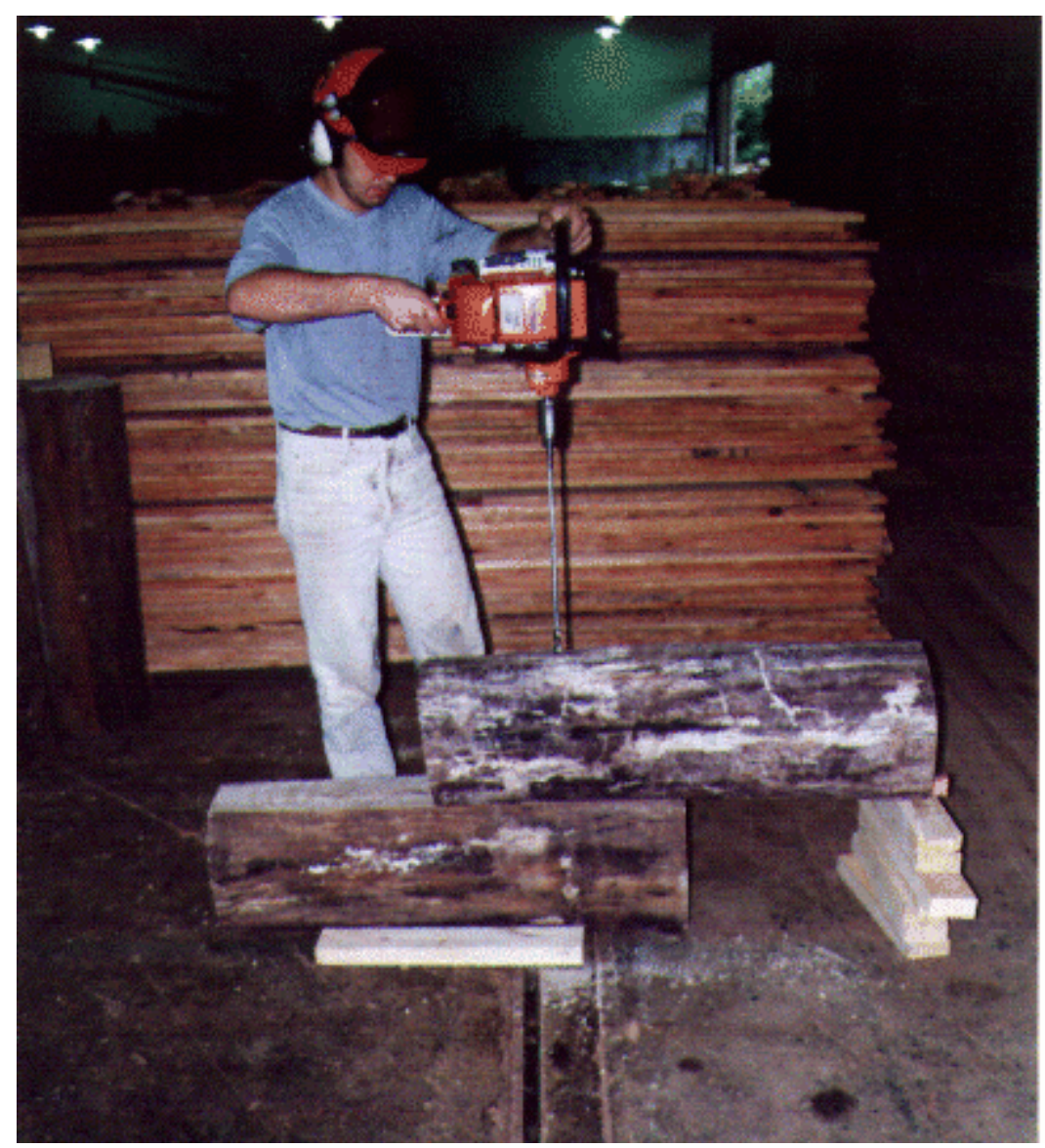

Figura 26 - Toretes componentes do corpo de prova sendo furados de forma contínua e perpendicularmente à face desbastada. 
A Figura 27 mostra a serra copa fazendo o sulco na madeira, com sua haste guia trabalhando no furo efetuado na operação anterior para proporcionar, ao mesmo tempo, a perfeita orientação do sulco, a necessária estabilidade da ferramenta e a necessária segurança do operador.

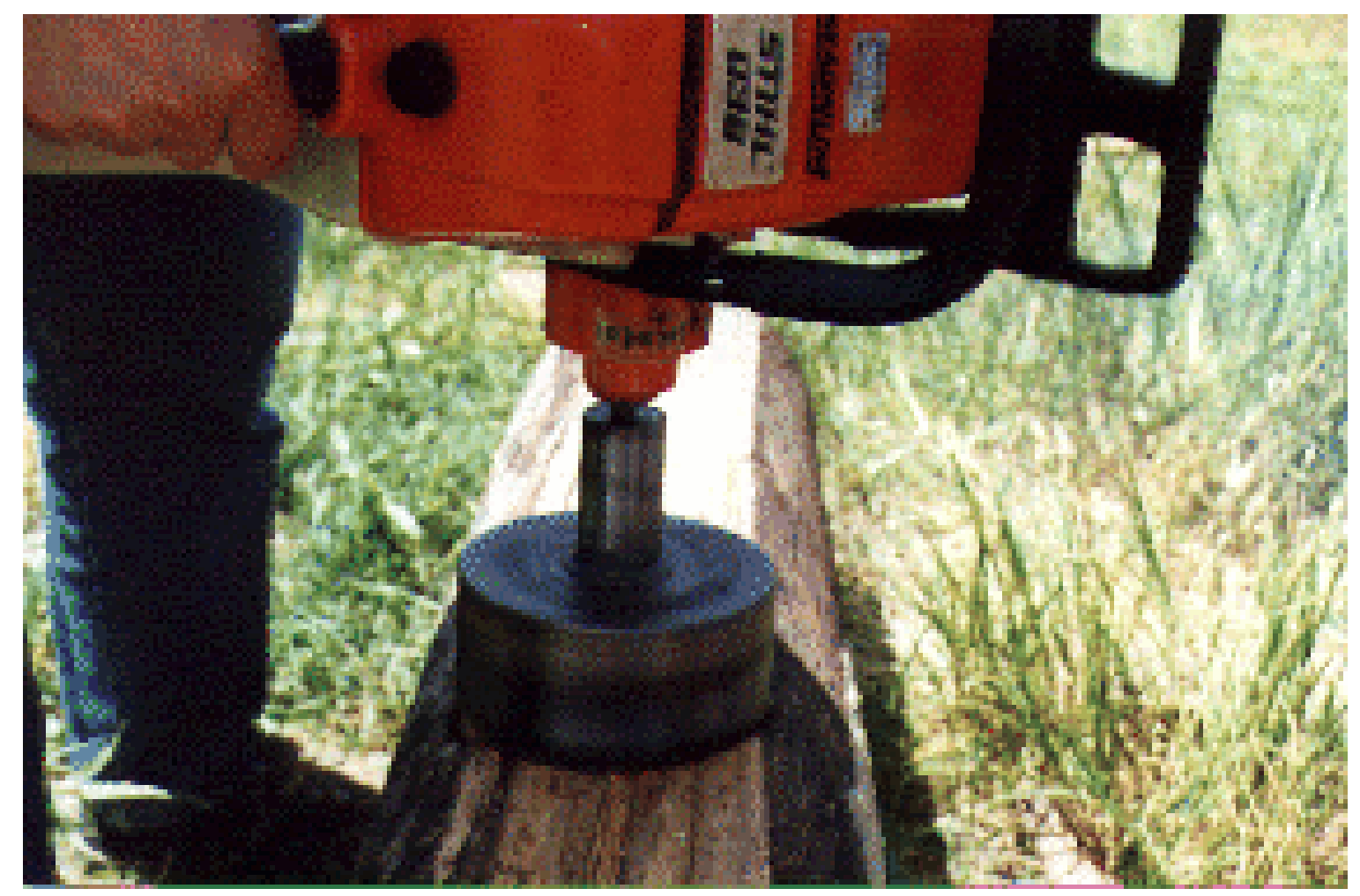

Figura 27 - Serra-copo sendo utilizada para fazer o sulco de alongamento do anel na madeira.

As figuras 28 e 29 mostram, respectivamente, o anel já alojado no sulco e o parafuso responsável pela justaposição dos dois toretes componentes do corpo de prova. 


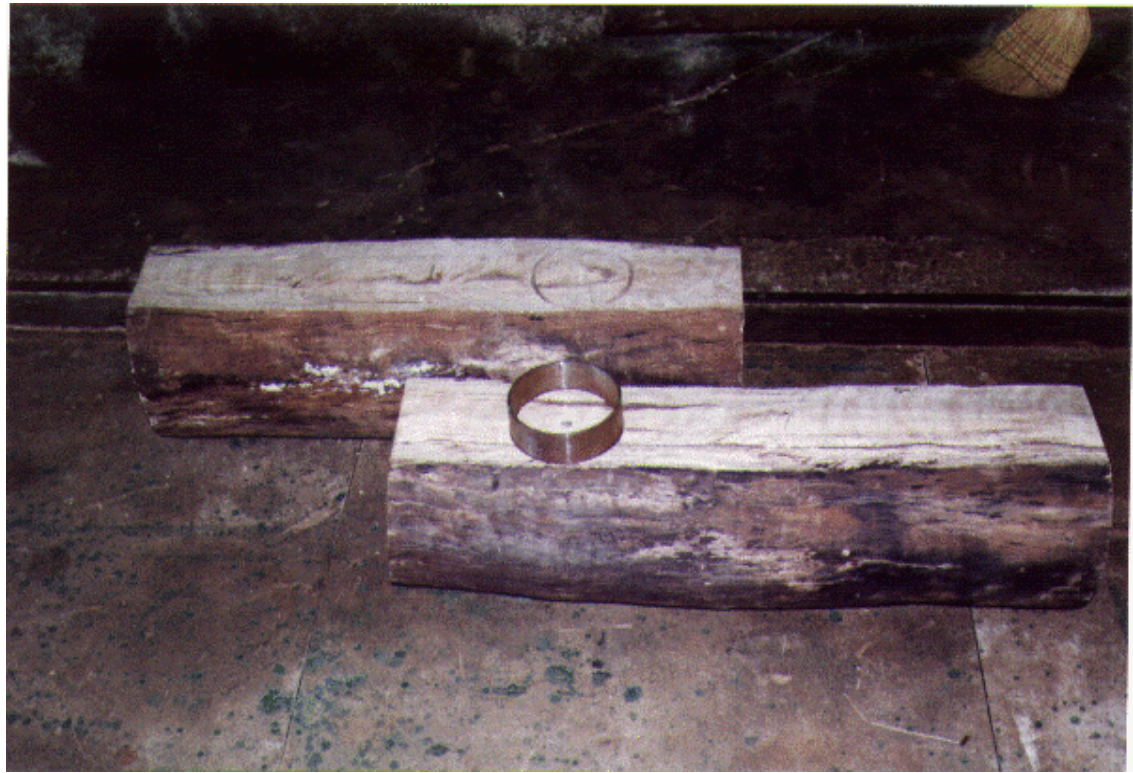

Figura 28 - Encaixe do anel no torete.

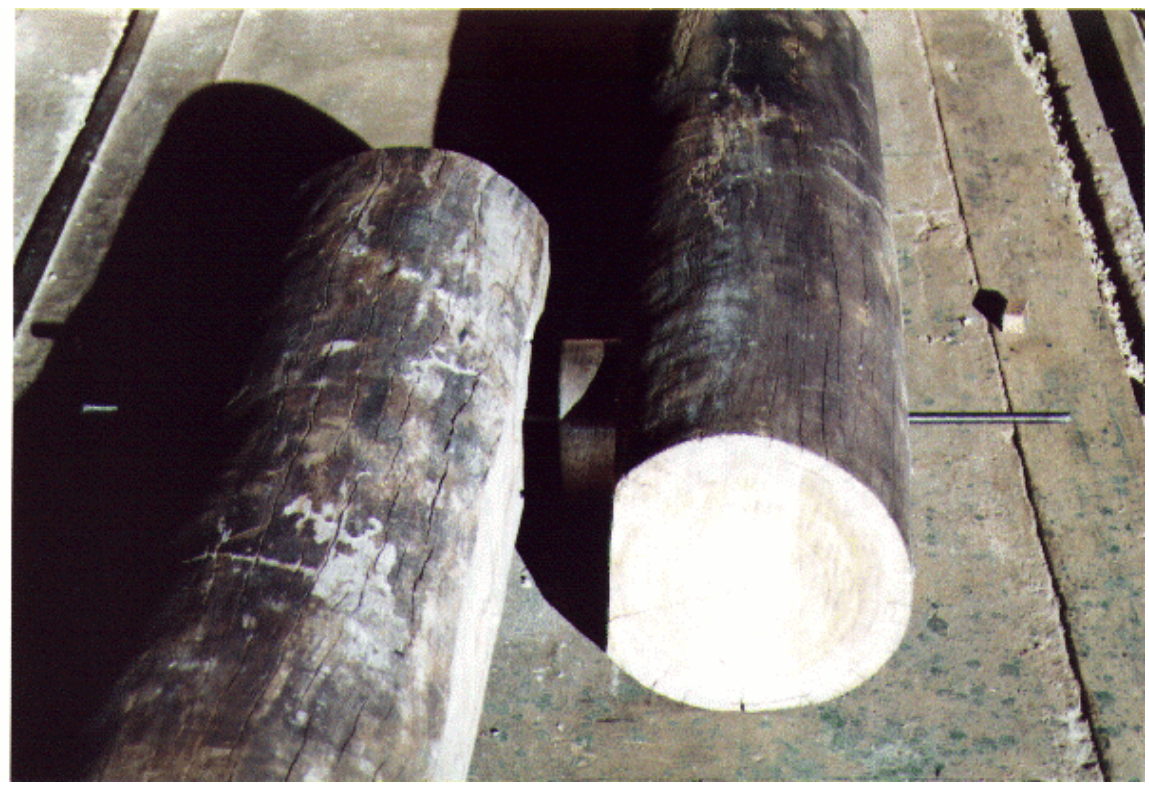

Figura 29 - Justaposição dos toretes pelo parafuso.

A Figura 30 (a) mostra a operação de corte da extremidade de um dos toretes segundo um ângulo calculado 
para propiciar a estabilidade do corpo de prova, mesmo sob carga, uma vez que o mesmo foi projetado, como mostra a Figura 30 (b) para que a linha de ação da carga de ensaio passasse pelo centro geométrico da ligação. O aperto nas porcas foi feito apenas manualmente para minimizar a contribuição do parafuso na resistência e rigidez da ligação projetada.

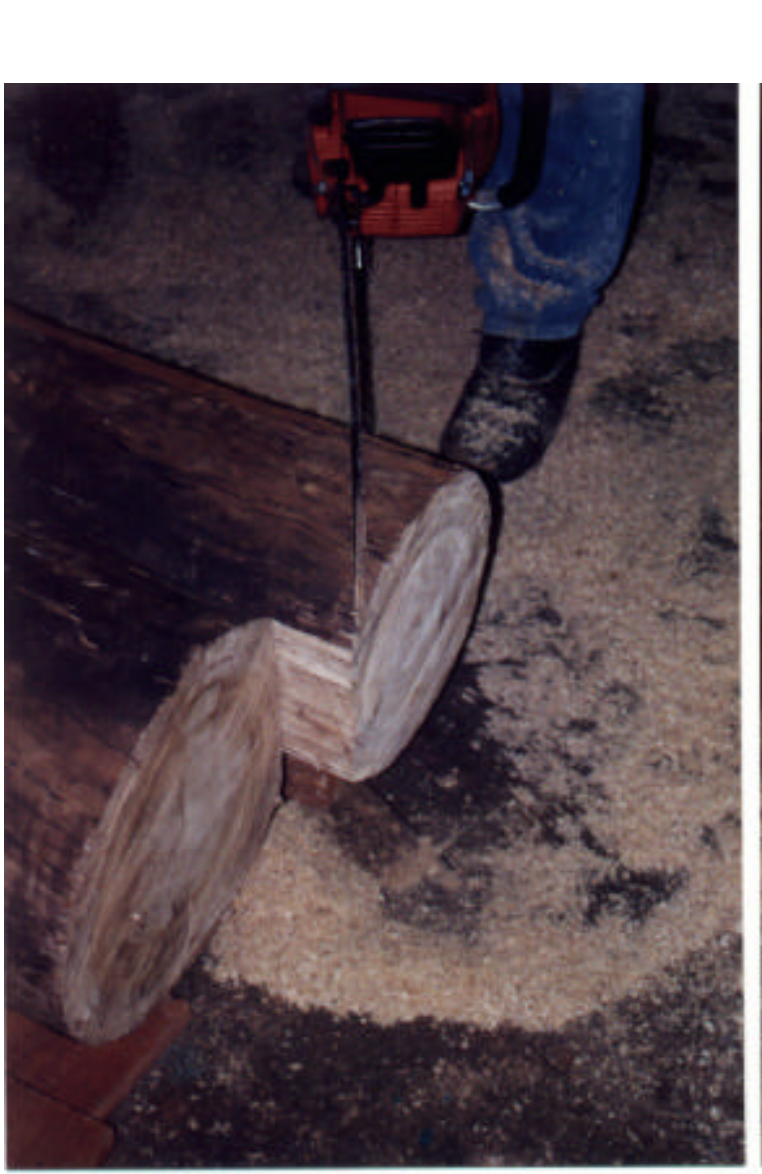

( a )

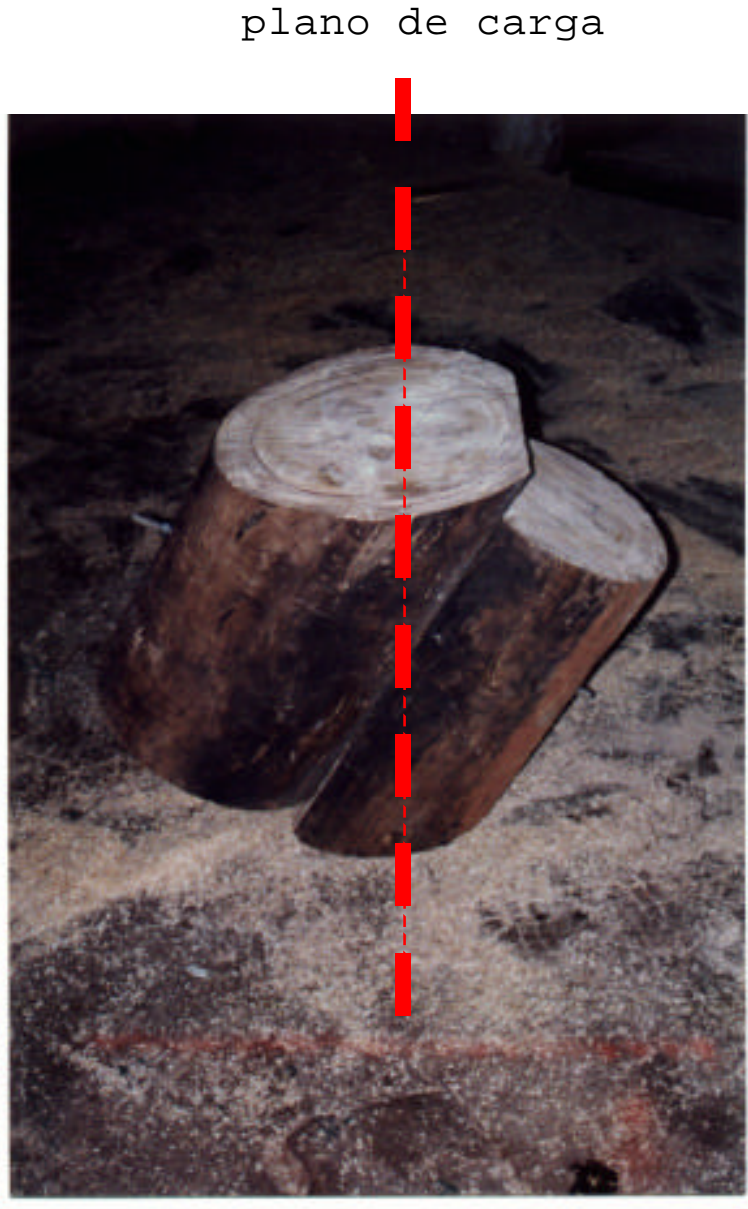

( b )

Figura 30 - Corpo de prova da ligação madeira - anel metálico de $150 \mathrm{~mm}$. Vista do corte angularmente orientado, da extremidade do torete (a) para estabilizar o corpo de prova na posição vertical (b), mesmo sob carga. 
Os ensaios de compressão desses corpos de prova na posição vertical foram realizados no I.P.T. (Instituto de Pesquisas Tecnológicas) numa máquina universal de capacidade para 40.000 daN. A velocidade de aplicação da carga foi de 1200 daN/min monitorada a cada 20 segundos. Para a obtenção dos deslocamentos relativos entre as peças, foram instalados em lados opostos do corpo de prova dois relógios comparadores presos em suportes metálicos, fixados na madeira por intermédio de pequenos pregos (Figura 31).

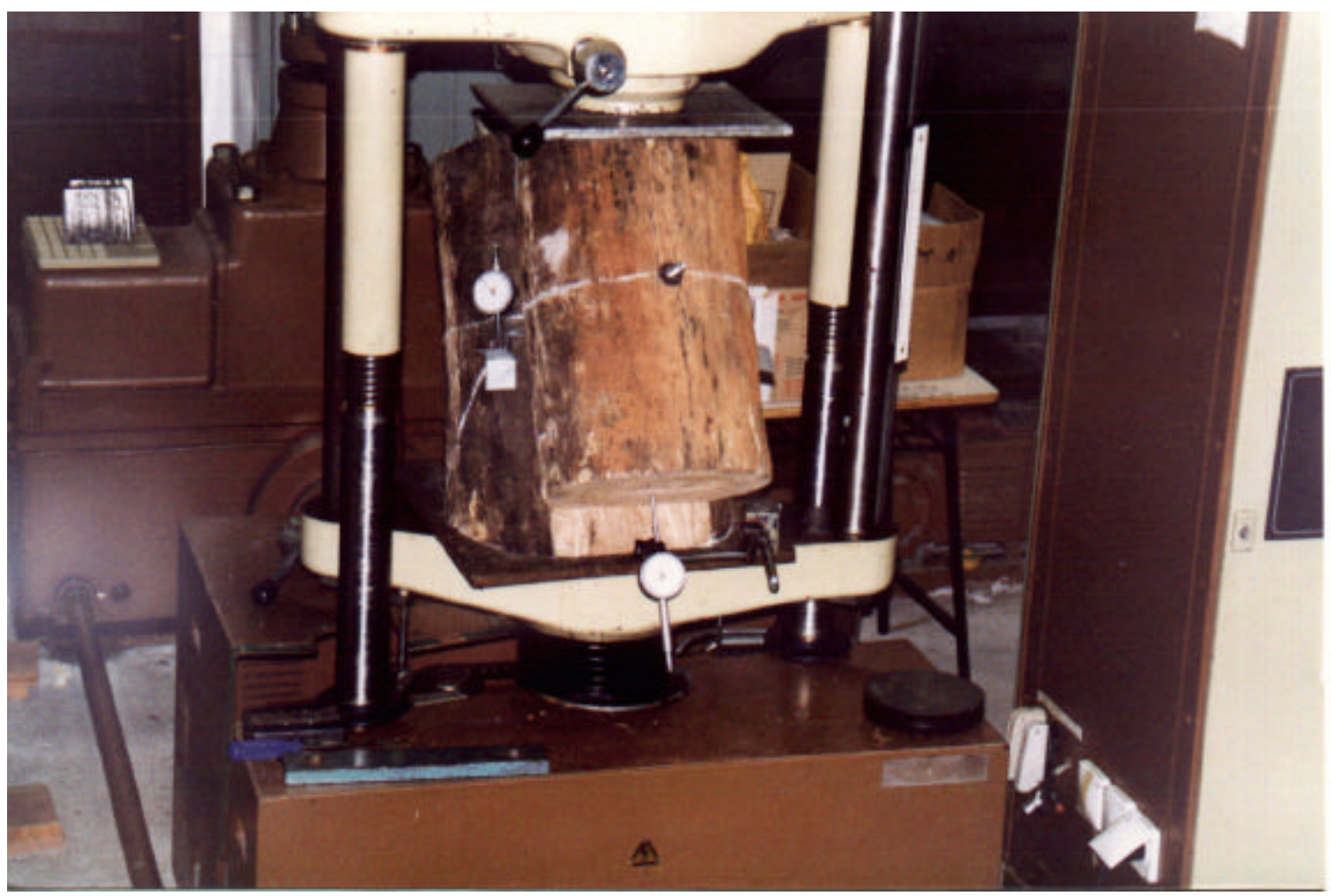

Figura 31 - Ensaio de compressão do corpo de prova para a obtenção dos deslocamentos relativo entre as duas peças roliças ligadas por um anel metálico. 
Os relógios comparadores utilizados tinham precisão de centésimo de milímetro e todas as leituras foram realizadas, sem a interrupção do carregamento, a cada 400 daN.

\subsection{Montagem e ensaio da Viga bi-circular}

Antes da execução do corpo de prova do ensaio à flexão da viga bi-circular foi necessário que todos os ensaios descritos anteriormente já tivessem sido executados uma vez que os resultados deles obtidos foram utilizados no cálculo das vigas bi-circular.

A viga bi-circular foi obtida através da composição de dois postes solidarizados por anéis metálicos fechados de diâmetro de $150 \mathrm{~mm}$ e altura de $10 \mathrm{~cm}$. Foram ensaiadas duas vigas nas mesmas condições de vinculação nos apoios previamente estabelecidas em cálculo, ou seja de vigas simplesmente apoiada.

Os apoios que garantiram a condição de contorno da experimentação foram conseguidos através da confecção de quatro garfos. Cada garfo foi constituído de três peças de madeira roliça solidarizadas por quatro anéis metálicos (Figura 32 ). 

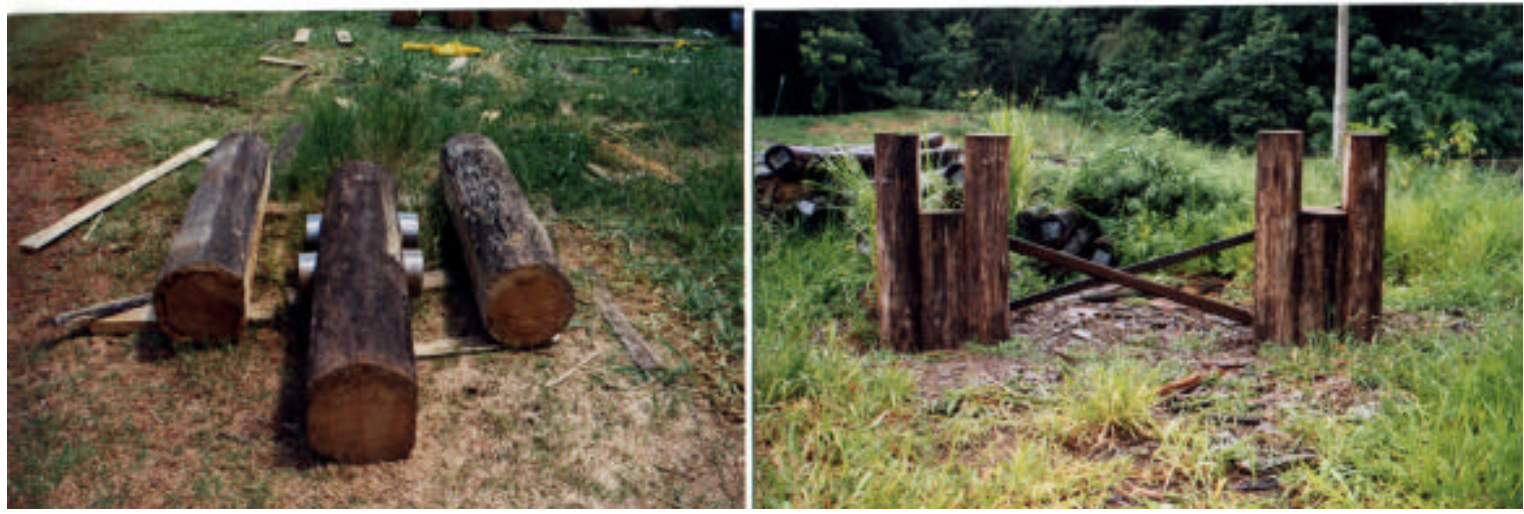

Figura 32 - Garfos de madeira para apoio das vigas bicirculares no contexto da paisagem rural.

Os quatro garfos foram cravados no solo deixandose um vão livre de 7,50 m. Após serem cravados os apoios foram travados dois a dois.

Os postes a serem utilizados na vigas bicirculares foram previamente selecionados aos pares para facilitar o preparo das faces de acomodação entre eles (Figura 33) .
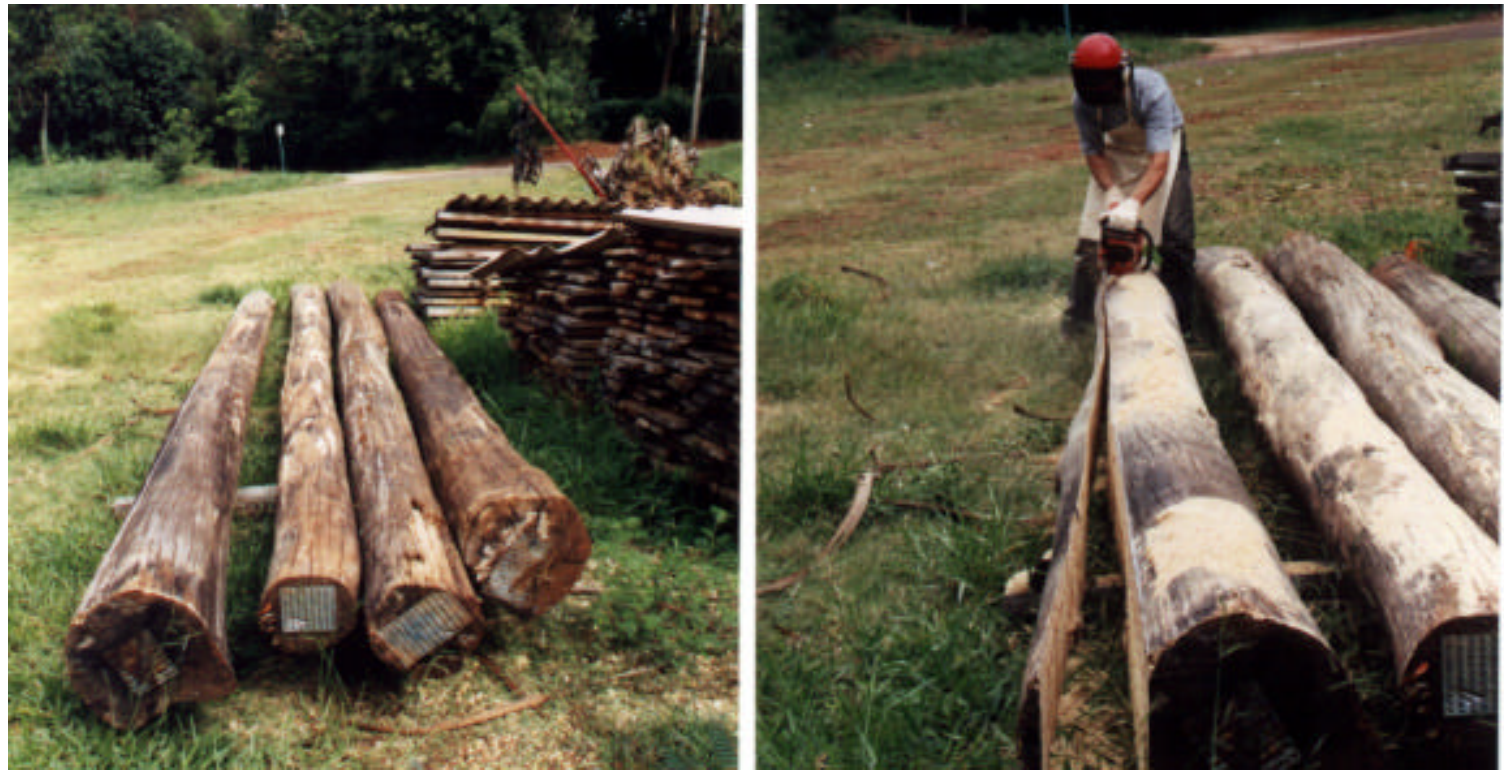

Figura 33 - Face do poste sendo preparada para melhor justaposição com o seu par. 
Primeiramente as vigas foram ensaiadas à flexão sem estarem conectadas e para tanto elas foram içadas e posicionadas nos apoios. Para o registro das deformações foi instalado um relógio comparador, de precisão de centésimo de milímetro, em cada uma das vigas. Para posiciona-los no meio do vão das vigas utilizaram dois tripés fixados sobre uma plataforma de madeira (Figura 34).
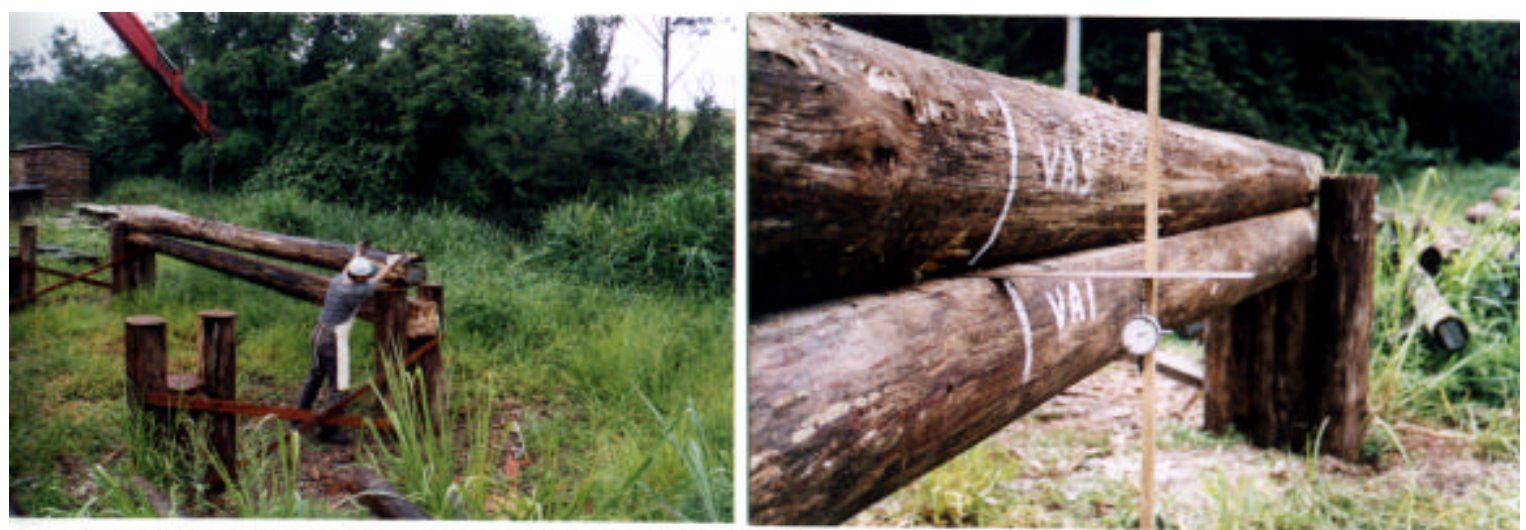

Figura 34 - Vigas bi-circulares sendo posicionadas sem conexão entre seus postes componentes (a) e preparada para o ensaio a flexão (b) com um relógio comparador posicionado no meio do vão livre.

Três toras de madeira previamente pesadas foram posicionadas nas proximidades do meio do vão das vigas. Os pontos de apoio das toras nas vigas foram bem demarcados para que a posterior reposição das toras fosse facilitada (Figura 35). 


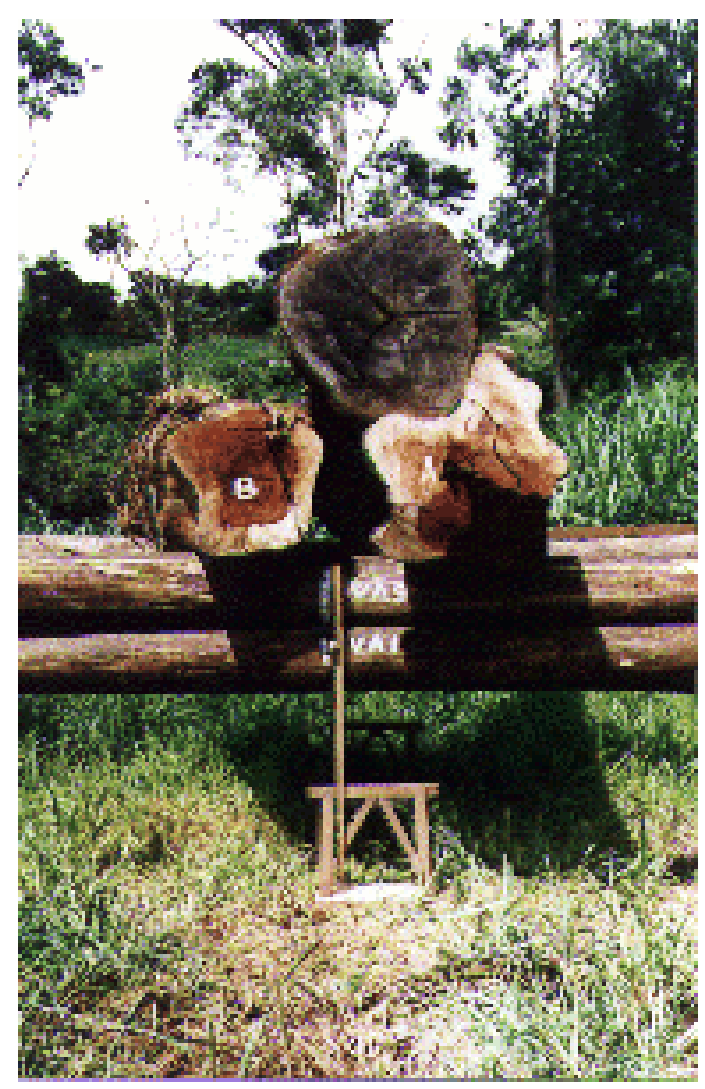

Figura 35 - Carregamento não destrutivo das vigas bicirculares de seção composta de peças circulares independentes.

Após as medições dos deslocamentos verticais (um valor para cada tora colocada sobre a viga) as toras foram retiradas para proceder-se a montagem das definitivas. Todas as recomendações feitas durante a execução dos corpo de prova das ligações por anel metálico foram aqui utilizadas para a colocação dos anéis ao longo da viga. Primeiramente os furos guias foram executados para que a parte superior das duas vigas fosse retiradas (Figura 36). Depois que todos os furos guias foram finalizados os postes superiores foram retirados, e os sulcos na madeira foram executados. 


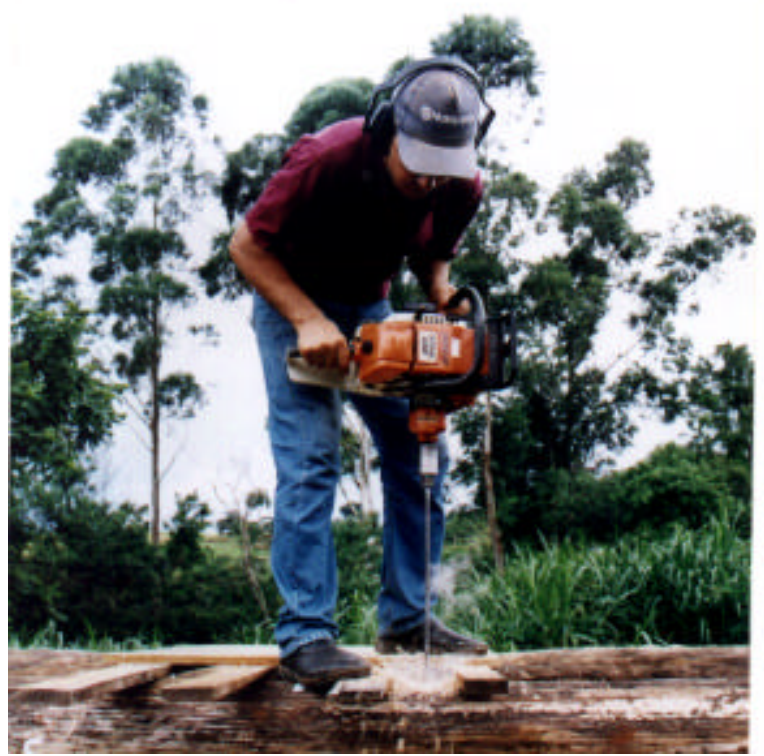

Figura 36 - Execução dos furos sulcos na madeira

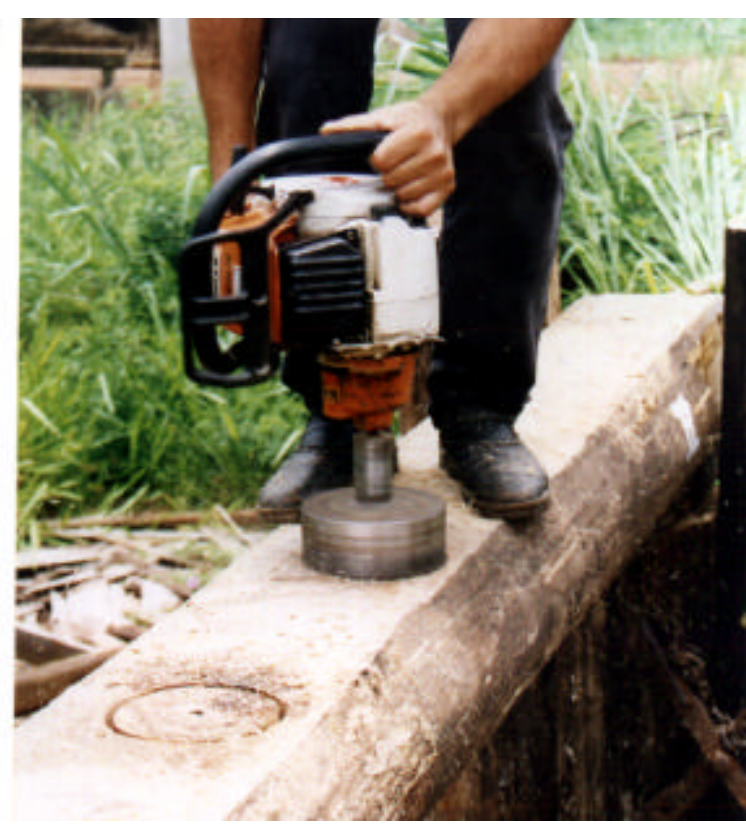

(a) e confecção dos (b) .

Os anéis metálicos foram posicionados para que o poste superior da viga pudesse ser novamente içado e encaixado no inferior (Figuras 37).

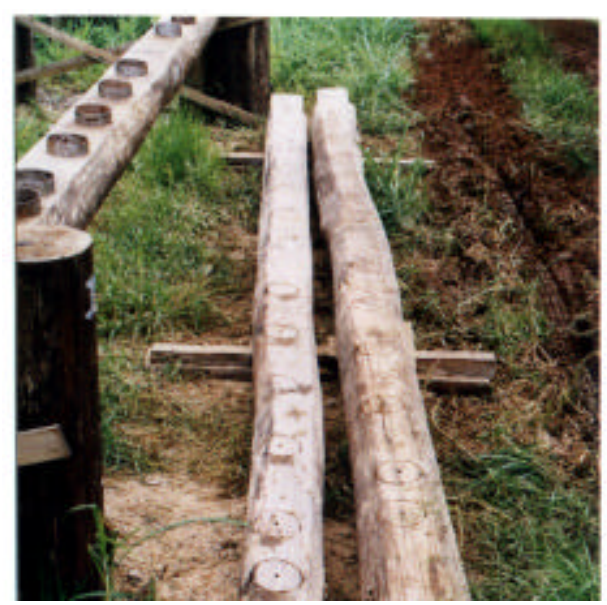

(a)

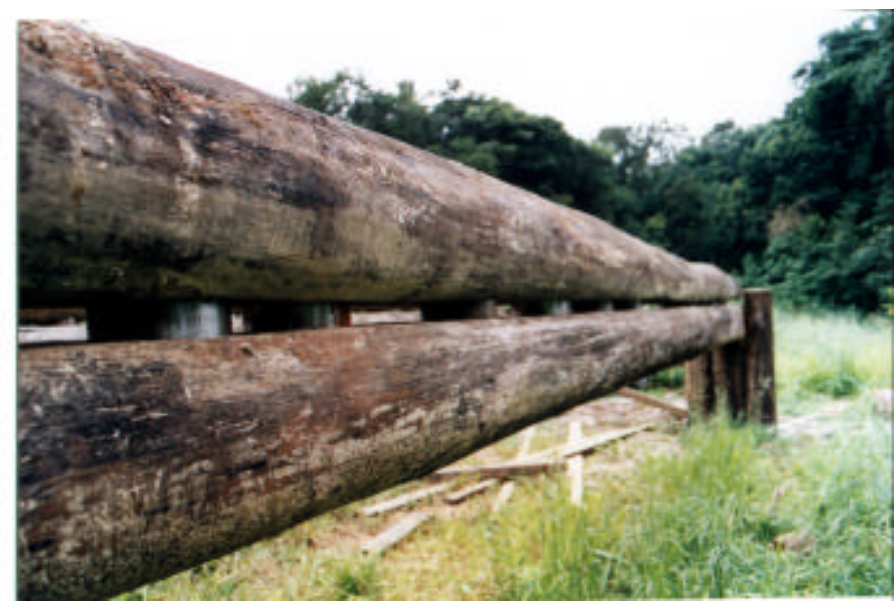

(b)

Figura 37 - Posicionamento dos anéis (a) e justaposição final dos postes constituintes da viga bicircular (b) . 
Depois de finalizada a composição das vigas bicirculares as toras - cargas foram reposicionadas para obterem-se os novos deslocamentos verticais dos postes centrais da viga (Figura 38). Como no ensaio anterior, porém, com duas medidas adicionais sendo uma para cada uma das toras adicionadas àquela do primeiro ensaio.

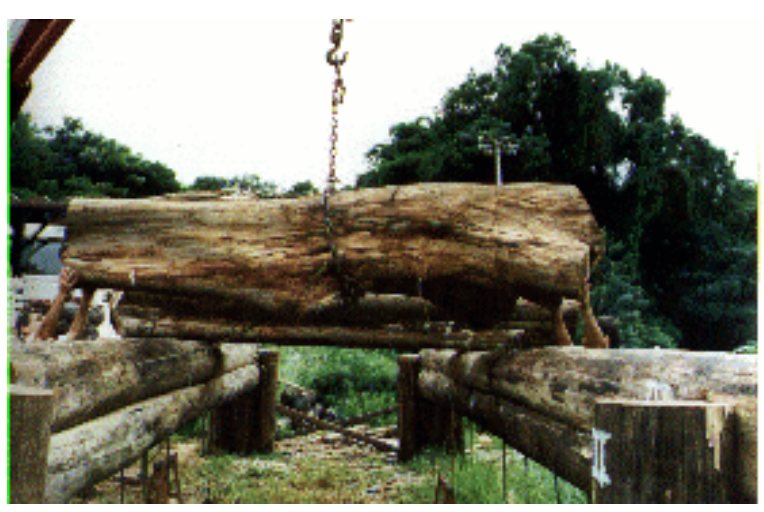

(a)

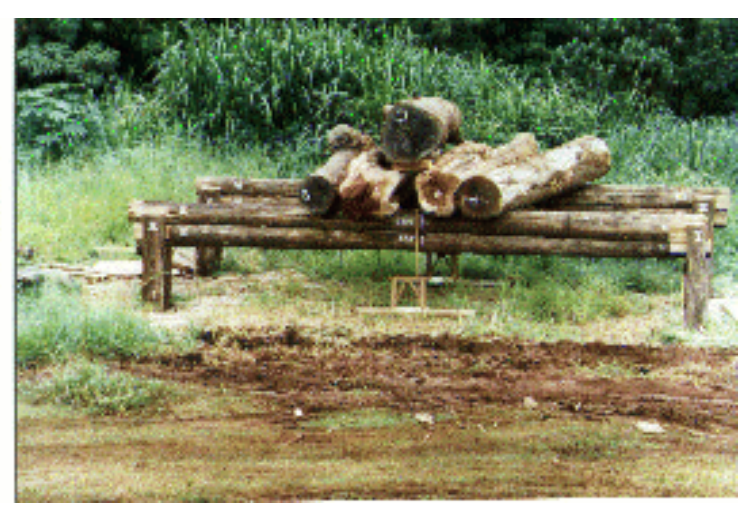

(b)

Figura 38 - Posicionamento equilibrado da tora para distribuir a sua carga eqüitativamente nas duas vigas bi-circulares (a) e carregamento final do ensaio de flexão (b) . 


\section{RESULTADOS E DISCUSSÃO}

Neste capítulo são apresentados os resultados das características físicas e mecânicas do material escolhido para a pesquisa, do ensaio e da teoria de cálculo da ligação por anéis metálicos, do ensaio de flexão da longarina de seção bi-circular e dos cálculos da ponte.

\subsection{Propriedades físico - mecânicas da madeira}

Nas Tabelas 9 a 13 encontram-se as dimensões dos corpos de prova utilizados para cada ensaio, os valores das forças de ruptura e os respectivos valores médios e característicos das propriedades mecânicas em questão.

- valor característico da resistência da madeira foi estimado pela eq. (2) conforme o item 6.4 .8 da NB7190/97. Para tanto os resultados foram colocados em ordem crescente $\mathrm{f}_{1}<\mathrm{f}_{2}<\ldots<\mathrm{f}_{\mathrm{n}}$ desprezando-se o valor mais alto se o número de corpos de prova for ímpar e não se tomando para $f_{\mathrm{wk}}$ valor inferior a $f_{1} \mathrm{e}$ nem a 0,70 do valor médio.

$f_{\mathrm{wk}}=\left(2 \frac{\mathrm{f}_{1}+\mathrm{f}_{2}+\ldots+\mathrm{f}_{\frac{\mathrm{n}}{2}}-1}{\frac{\mathrm{n}}{2}-1}-\frac{f_{\mathrm{n}}}{2}\right) \times 1,1$

onde: 
$f_{\mathrm{wk}}=$ resistência característica

$f_{i}=$ valores da resistência colocados em ordem crescente $\mathrm{n}=$ números de amostras computadas

Tabela 9. Resistência à compressão paralela às fibras obtidos nos ensaios de corpos de prova de Eucalyptus citriodora de 19 anos de idade.

\begin{tabular}{|c|c|c|c|c|c|}
\hline C.P. & $\begin{array}{c}\mathrm{a} \\
(\mathrm{mm})\end{array}$ & $\begin{array}{c}\mathrm{b} \\
(\mathrm{mm})\end{array}$ & $\begin{array}{c}\mathrm{F}_{\mathrm{C} 0, \max } \\
(\mathrm{N})\end{array}$ & $\begin{array}{c}f_{\mathrm{wc} 0} \\
(\mathrm{MP} a)\end{array}$ & $\mathrm{f}_{\mathrm{wC} 0}$ \\
\hline IA & 20,12 & 20,38 & 32.000 & 78,0 & \\
\hline IB & 20,40 & 20,42 & 31.000 & 74,4 & \\
\hline IC & 21,24 & 21,64 & 26.000 & 56,6 & هـ \\
\hline ID & 20,23 & 20,32 & 28.200 & 68,6 & $\sigma$ \\
\hline IIA & 21,07 & 20,35 & 32.200 & 75,1 & $\succ$ \\
\hline IIB & 19,99 & 20,50 & 31.700 & 77,4 & 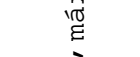 \\
\hline IIC & 19,45 & 20,02 & 28.600 & 73,4 & i \\
\hline IID & 20,30 & 20,08 & 30.300 & 74,3 & 山 \\
\hline IIIA & 19,91 & 20,06 & 26.800 & 67,1 & 10 \\
\hline IIIB & 20,18 & 20,22 & 34.600 & 84,8 & $4^{3}$ \\
\hline IIIC & 20,94 & 21,17 & 35.300 & 79,6 & \\
\hline IIID & 21,17 & 19,96 & 30.800 & 72,9 & \\
\hline$f_{\text {wc0 médio }}$ & desv. padrão & $\mathrm{f}_{1}$ & $0,70 f_{\text {wc } 0 \text { médio }}$ & $f_{\mathrm{wk}}$ & $f_{\mathrm{wc} 0, \mathrm{k}}$ \\
\hline 73,52 & 7,11 & 56,66 & 51,46 & 67,22 & 67,22 \\
\hline
\end{tabular}

a : lado 1 da seção transversal comprimida do corpo de prova;

b : lado 2 da seção transversal comprimida do corpo de prova;

$\mathrm{F}_{\mathrm{C} 0 \text {, Max }}$ : força máxima de compressão aplicada no c.p. durante os ensaio;

$\mathrm{f}_{\mathrm{wC} 0}$ : resistência à compressão paralela às fibras;

$f_{\mathrm{wk}}$ : resistência característica dada eq. (2);

$\mathrm{f}_{\mathrm{wc} 0, \mathrm{k}}$ : resistência característica à compressão paralela às fibras. 
Tabela 10. Resistência ao cisalhamento paralelo às fibras obtidos nos ensaios de corpos de prova de Eucalyptus citriodora de 19 anos de idade.

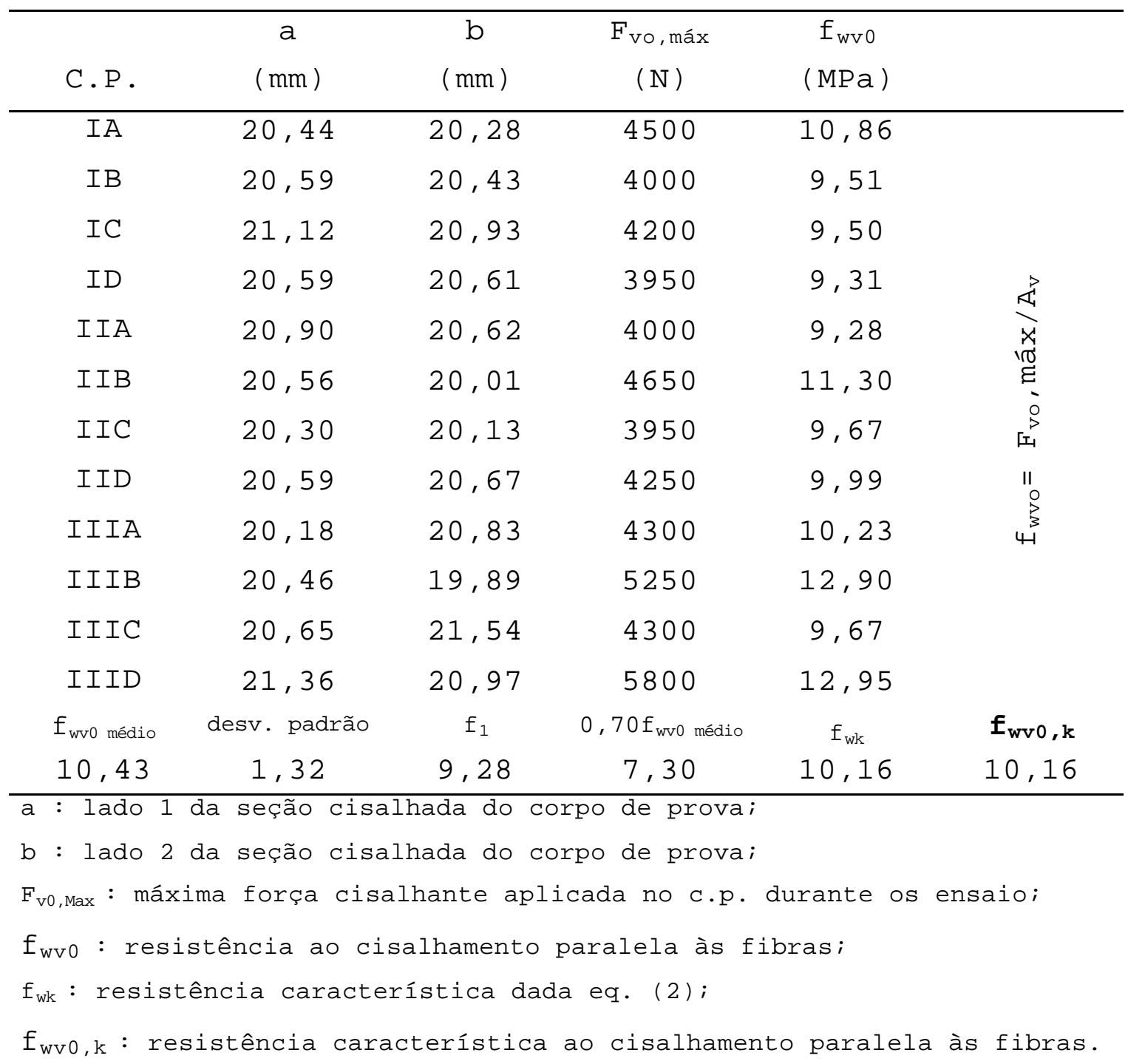

Sales et al. (1995) verificou que tanto para madeira de dicotiledônea quanto de conífera, o módulo de elasticidade nos ensaios de compressão ( $\left.E_{c 0}\right)$ e tração paralela às fibras $\left(E_{t 0}\right)$ possuem média estatisticamente iguais ao nível de probabilidade de 99\%. Já para o módulo 
de elasticidade obtido no ensaio da flexão ( $\left.E_{M}\right)$, com a relação 1/h igual a 21, não foi encontrada equivalência estatística de $\left(E_{M}\right)$ com $\left(E_{C 0}\right)$ ou $\left(E_{t 0}\right)$. Considerando que o valor médio obtido para $\left(E_{M}\right)$ é menor que os obtidos para $\left(E_{c 0}\right)$ e $\left(E_{t 0}\right)$, a utilização de $\left(E_{M}\right)$ é viável. Pode-se estimar - módulo de elasticidade longitudinal da madeira através da realização de apenas um entre os ensaios de compressão paralela, tração paralela e flexão.

Tabela 11. Módulos de Elasticidade na compressão paralela 'as fibras obtidos nos ensaios de corpos de prova de Eucalyptus citriodora de 19 anos de idade.

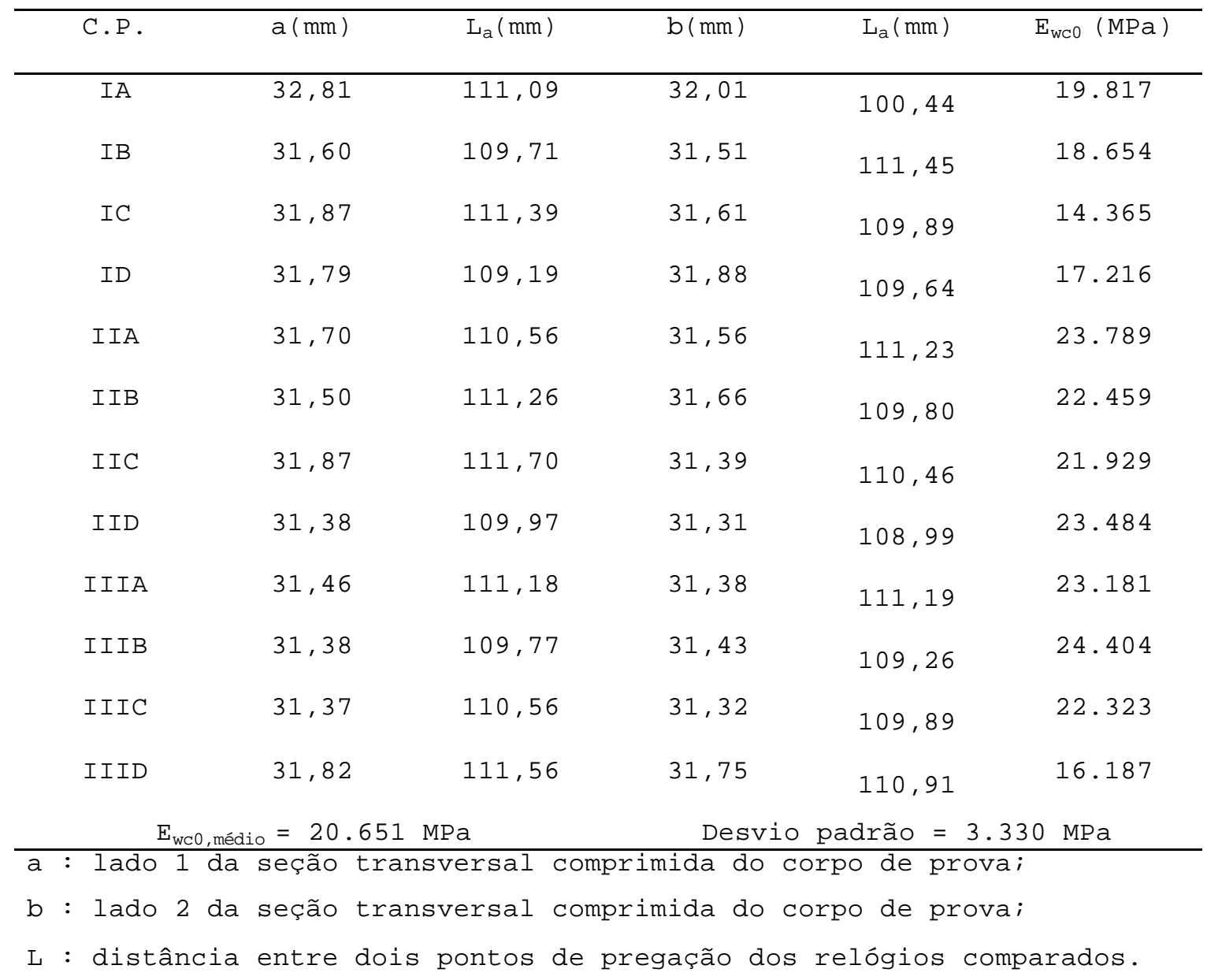


A Figura 39 mostra um exemplo (C.P.IIA) de diagramas carga - deformação elaborado para cada corpo de prova utilizado para a obtenção do $E_{\mathrm{wc} 0}$, que é numericamente igual ao coeficiente angular a reta ajustado ao trecho linear da curva.

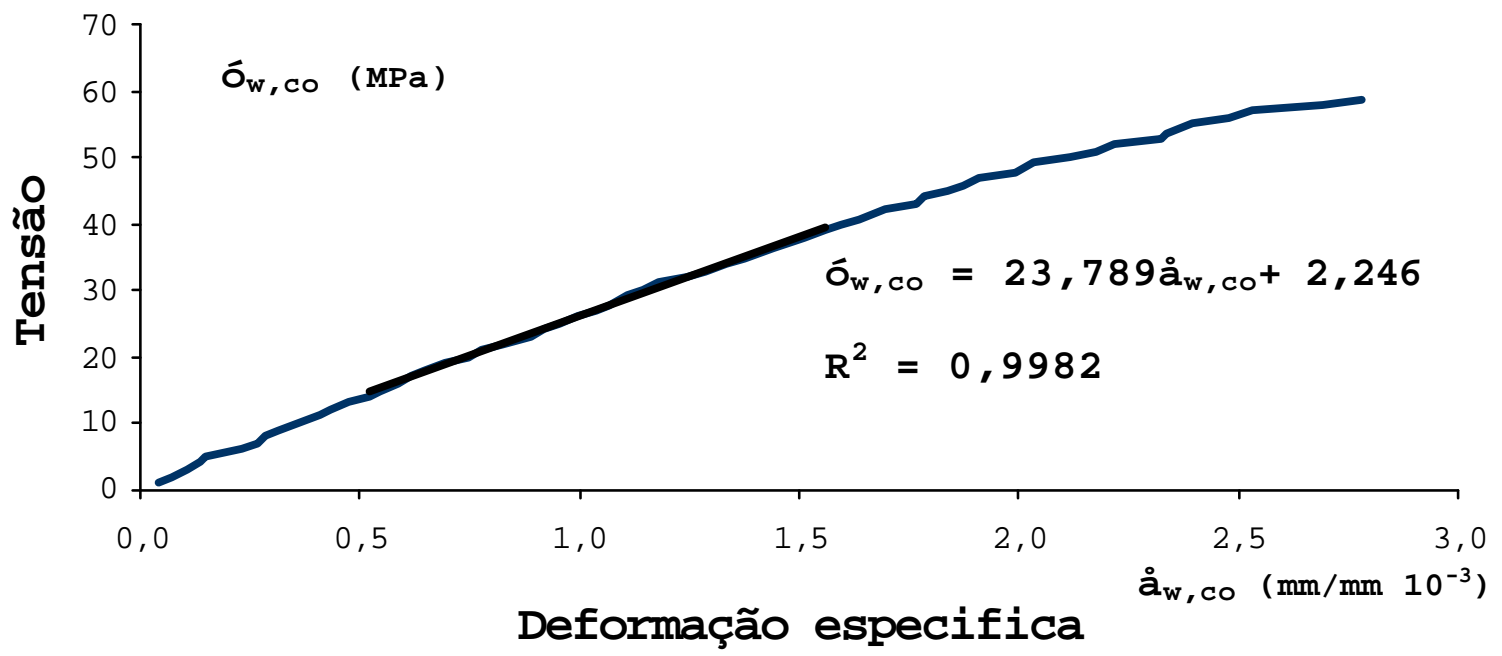

Figura 39 - Curva de tensão x deformação específica para o C.P. IIA de Eucalyptus citriodora plotada com os dados obtidos no ensaio de compressão paralela às fibras. 
Tabela 12. Propriedades Físicas - Densidades básicas e umidades obtidos de discos de Eucalyptus citriodora de 19 anos de idade.

\begin{tabular}{|c|c|c|c|c|c|}
\hline$C . P$. & $\begin{array}{c}\text { Massa } \\
\text { Imersa } \\
m_{i} \\
(g)\end{array}$ & $\begin{array}{c}\text { Massa } \\
\text { saturada } \\
\text { m sat } \\
(\mathrm{g})\end{array}$ & $\begin{array}{c}\text { massa } \\
\text { seca } \\
m_{s} \\
(g)\end{array}$ & $\begin{array}{c}\text { Densidade } \\
\text { Básica } \\
\tilde{\mathrm{n}}_{\mathrm{bas}} \\
\left(\mathrm{kg} / \mathrm{m}^{3}\right)\end{array}$ & $\begin{array}{l}\text { Umidade } \\
\mathrm{U} \quad\left(\frac{\circ}{0}\right) \\
\frac{m_{i}-m_{s}}{m_{s}} \times 100\end{array}$ \\
\hline IV-1 & 82,9 & 571,8 & 322,8 & 660 & 43,55 \\
\hline$I V-2$ & 92,3 & 721,3 & 399,2 & 635 & 44,66 \\
\hline$I V-3$ & 55,7 & 395,2 & 232,1 & 684 & 41,27 \\
\hline IV -4 & 33,4 & 257,1 & 147,6 & 660 & 42,59 \\
\hline IV -5 & 82,0 & 496,0 & 294,2 & 711 & 40,68 \\
\hline IV -6 & 70,7 & 454,2 & 265,2 & 692 & 41,61 \\
\hline IV -7 & 108,9 & 692,8 & 385,2 & 660 & 44,40 \\
\hline IV -8 & 89,5 & 577,5 & 332,4 & 681 & 42,44 \\
\hline IV -9 & 96,7 & 614,2 & 357,1 & 690 & 41,86 \\
\hline IV -10 & 79,7 & 530,3 & 304,2 & 675 & 42,64 \\
\hline IV -11 & 74,1 & 459,4 & 267,7 & 695 & 41,73 \\
\hline IV -12 & 77,6 & 521,4 & 306,1 & 690 & 41,29 \\
\hline Densidade & \multicolumn{2}{|c|}{ Básica $=677,59 \mathrm{~kg} / \mathrm{m}^{3}$} & \multicolumn{3}{|c|}{ Umidade média $=42,39 \%$} \\
\hline \multicolumn{3}{|c|}{ Desvio padrão $=20,71 \mathrm{~kg} / \mathrm{m}^{3}$} & \multicolumn{3}{|c|}{ Desvio padrão $=1,25 \%$} \\
\hline
\end{tabular}


Tabela 13. Propriedades Físicas

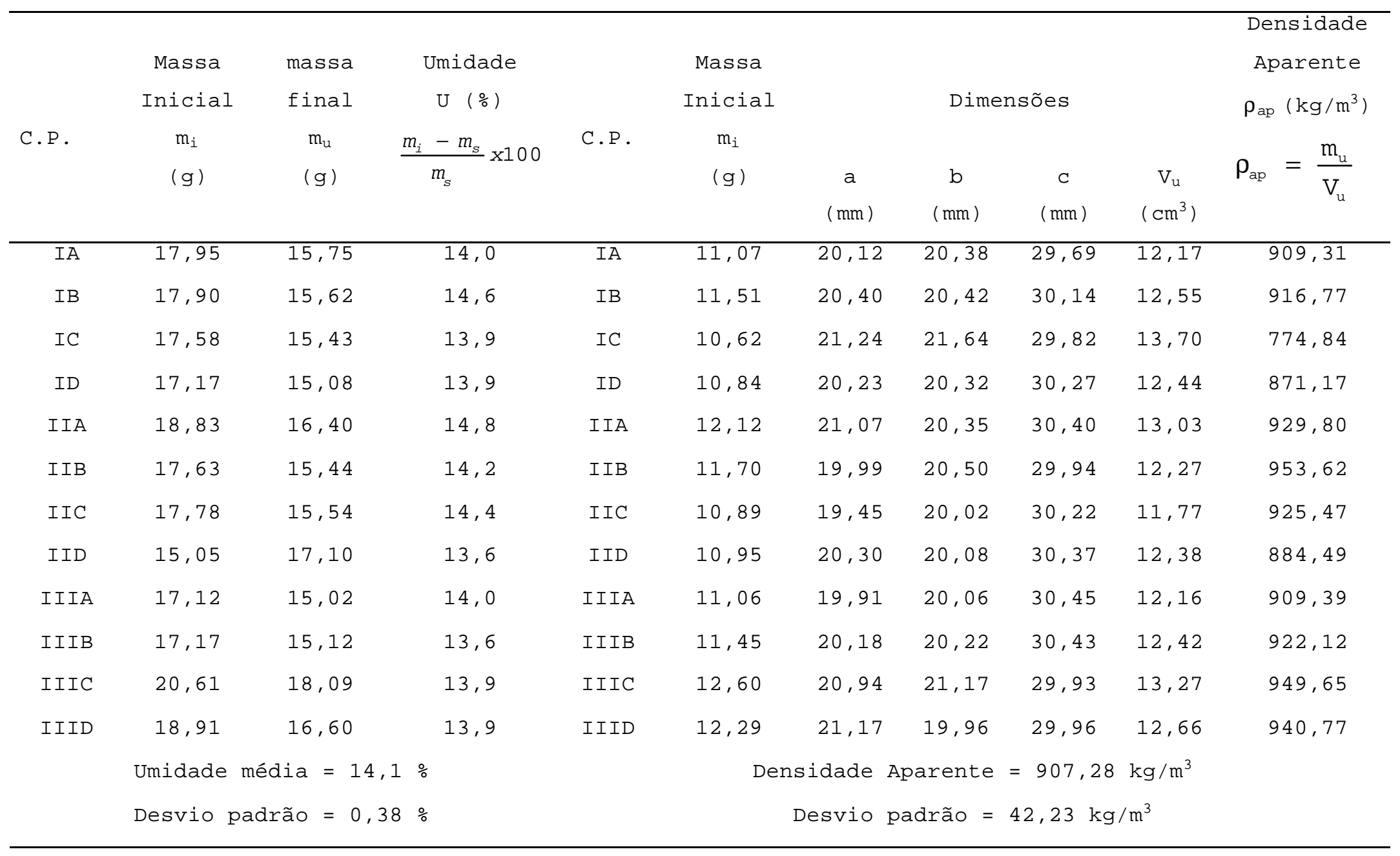


Na Tabela 14 encontram-se de uma forma concentrada os valores mais importantes das propriedades acima, que serão utilizados nos cálculos efetuados no item 4.5 .4

Tabela 14. Valores característicos das resistências mecânicas e valor médio do módulo de elasticidade para $U=14,01 \%$

\begin{tabular}{|c|c|c|c|c|c|c|}
\hline $\begin{array}{l}\text { Nome } \\
\text { Comum }\end{array}$ & $\begin{array}{c}\tilde{\mathrm{n}}_{\mathrm{ap}} \\
\left(\mathrm{kg} / \mathrm{m}^{3}\right)\end{array}$ & $\begin{array}{l}f_{\mathrm{wc} 0, \mathrm{k}} \\
(\mathrm{Mpa})\end{array}$ & $\begin{array}{l}f_{\mathrm{wV}, \mathrm{k}} \\
(\mathrm{Mpa})\end{array}$ & $\begin{array}{c}E_{\mathrm{C} 0}, \text { médio } \\
(\mathrm{Mpa})\end{array}$ & $\begin{array}{l}\mathrm{U} \\
\%\end{array}$ & $\begin{array}{c}\mathrm{n}^{\circ} \\
\mathrm{c} \cdot \mathrm{p} .\end{array}$ \\
\hline $\begin{array}{l}\text { Eucalipto } \\
\text { citriodora }\end{array}$ & 907,28 & 67,22 & 10,16 & 20.651 & 14,01 & 12 \\
\hline
\end{tabular}

Onde:

$\mathrm{U}=$ Umidade média;

$\tilde{n}_{\text {ap }}=$ densidade aparente;

$\mathrm{f}_{\mathrm{wc} 0, \mathrm{k}}=$ resistência característica à compressão paralela às fibras;

$\mathrm{f}_{\mathrm{wV}, \mathrm{k}}=$ resistência ao cisalhamento paralelo às fibras;

$\mathrm{E}_{\mathrm{wC} 0 \text {, médio }}$ módulo de elasticidade na compressão paralela às fibras.

Para $U<20 \%$ as resistências e o módulo de elasticidade devem ser corrigidos segundo NBR 7190/97 pela equação (3) e (4) respectivamente:

$$
\begin{aligned}
& f_{12}=f_{u \circ}\left[1+\frac{3(U \%-12)}{100}\right] \\
& E_{12}=E_{u \circ}\left[1+\frac{2(U \circ-12)}{100}\right]
\end{aligned}
$$


Logsdon (1998), estudando a influencia da umidade nas propriedades de resistência e rigidez concluiu que é possível utilizarem-se as expressões (5) e (6), semelhantes as anteriores mas com coeficientes diferentes (Tabela 15) para cada propriedade de resistência ou rigidez tanto para madeira de conífera quanto para madeira de dicotiledônea:

$$
\begin{aligned}
& f_{12}=f_{u \circ}\left[1+\frac{a ́(U \circ-12)}{100}\right] \\
& E_{12}=E_{u \circ}\left[1+\frac{a ́(U \circ-12)}{100}\right]
\end{aligned}
$$

Tabela 15. Valores do coeficiente de correlação á.

\begin{tabular}{lc}
\hline Propriedade de Resistência ou Rigidez & á \\
\hline Resistência à compressão paralela às fibras & 3,5 \\
Resistência à tração paralela às fibras & 2,0 \\
Resistência ao cisalhamento paralela às fibras & 2,5 \\
Módulo de elasticidade longitudinal & 2,5 \\
\hline
\end{tabular}

Embora a NBR 7109/97 não faça referência à correção da densidade aparente para a umidade pedida de 12\% obteve-se, na literatura especializada a eq. (7) que permite fazer essa correção. 
$\tilde{\mathrm{n}}_{\mathrm{apU}_{2}}=\tilde{\mathrm{n}}_{\mathrm{apU}_{1}}\left[\frac{100+\mathrm{U}_{2}}{100+\mathrm{U}_{1}} \times \frac{100-\mathrm{CV}\left(28-\mathrm{U}_{1}\right)}{100-\mathrm{CV}\left(28-\mathrm{U}_{2}\right)}\right]$

onde:

$\tilde{\mathrm{n}}_{\mathrm{apU}_{1}}=$ densidade aparente a umidade de $\mathrm{U}_{1 \%}$;

$\tilde{n}_{\mathrm{apU}_{2}}=$ densidade aparente a umidade de $\mathrm{U}_{2 \%} ;$

$\mathrm{U}_{1}=$ umidade 1 expressa em $\%$ e menor que $28 \%$;

$\mathrm{U}_{2}=$ umidade 2 expressa em $\%$ e menor que $28 \%$;

$\mathrm{CV}=$ coeficiente de variação volumétrica expresso em $\frac{0}{\mathrm{~d}} \mathrm{e}$ variação para cada $1 \%$ de variação de umidade.

Portanto, o valor de CV pode ser obtido, simplificadamente, da eq. (8), onde a constante de 28 que aparece no segundo membro representa o teor de umidade do PSF .

$\mathrm{CV}=\frac{\mathrm{RV}}{28}$

onde:

$\mathrm{RV}=$ retração volumétrica.

Por outro lado, foi verificada por Stamm (1964) \& Greenhill (1936) a existência da correlação entre a retração volumétrica (RV) e a densidade básica, mostrada na Figura 40, de onde se obtém a eq. (9).

$$
\begin{aligned}
& \tilde{\mathrm{n}}_{\text {bas }}=\frac{\mathrm{RV}}{28} \\
& \tilde{\mathrm{n}}_{\text {bas }}=\text { densidade básica }\left(\mathrm{g} / \mathrm{cm}^{3}\right) .
\end{aligned}
$$




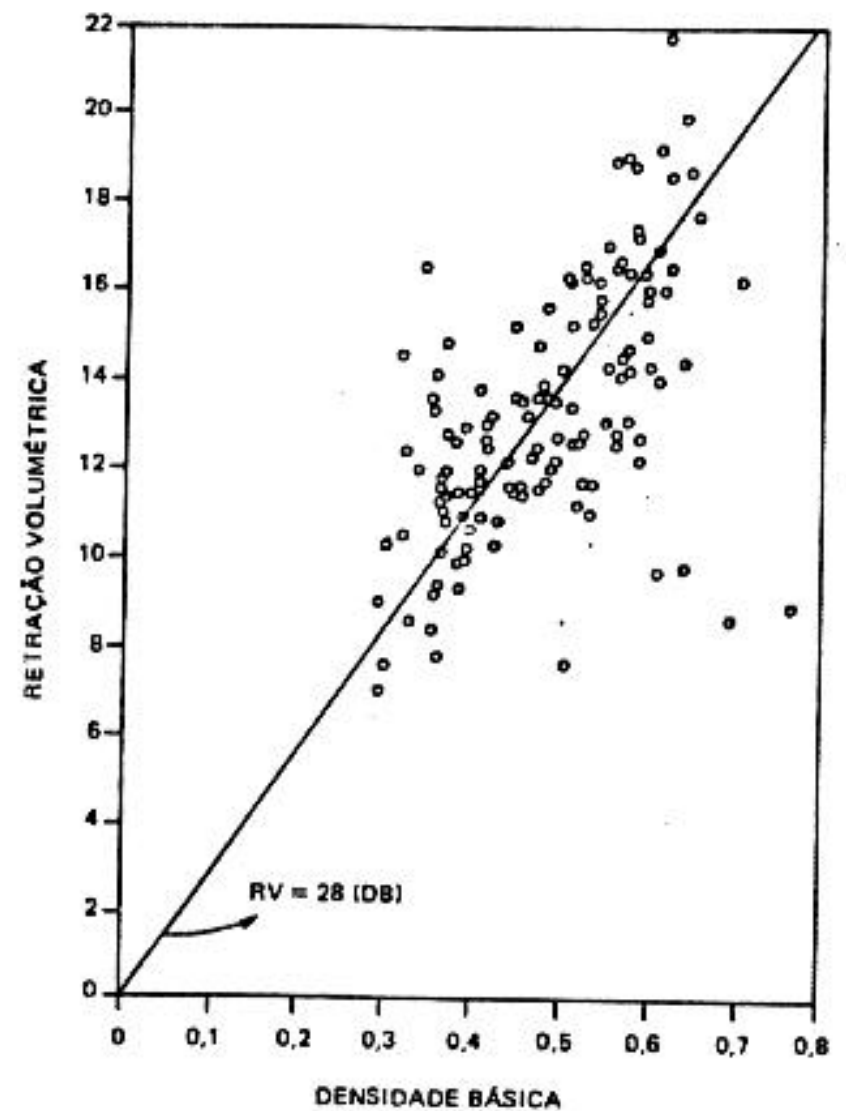

Figura 40 - Relação linear da retração volumétrica (RV) com a densidade básica $\left(\tilde{n}_{\text {bas }}\right)$.

Fonte: Jankowsky \& Galvão (1985)

Da igualdade das equações (8) e (9) deduz-se que $\mathrm{CV}=\tilde{n}_{\text {bas }}$ e portanto, a eq. (7) pode ser simplificada para a eq. (10) .

$\tilde{\mathrm{n}}_{\mathrm{apU} U_{2}}=\tilde{\mathrm{n}}_{\mathrm{apU}_{1}}\left[\frac{100+\mathrm{U}_{2}}{100+\mathrm{U}_{1}} \times \frac{100-\tilde{\mathrm{n}}_{\mathrm{bas}}\left(28-\mathrm{U}_{1}\right)}{100-\tilde{\mathrm{n}}_{\mathrm{bas}}\left(28-\mathrm{U}_{2}\right)}\right]$

A tabela 16 mostra os valores da Tabela 14 corrigidos pela eq. (3) e (4). 
Tabela 16. Valores característicos das resistências mecânicas e valor médio do módulo de elasticidade para $U=12 \%$

\begin{tabular}{cccccc}
\hline $\begin{array}{c}\text { Nome } \\
\text { comum }\end{array}$ & $\begin{array}{c}\tilde{\mathrm{n}}_{\mathrm{ap}} \\
\left(\mathrm{kg} / \mathrm{m}^{3}\right)\end{array}$ & $\begin{array}{c}\mathrm{f}_{\mathrm{wc} 0, \mathrm{k}} \\
(\mathrm{MPa})\end{array}$ & $\begin{array}{c}\mathrm{f}_{\mathrm{wv} 0, \mathrm{k}} \\
(\mathrm{MPa})\end{array}$ & $\begin{array}{c}\mathrm{E}_{\mathrm{Co}, \mathrm{m}} \\
(\mathrm{MPa})\end{array}$ & $\begin{array}{c}\mathrm{U} \\
\left(\frac{\circ}{0}\right)\end{array}$ \\
\hline $\begin{array}{c}\text { Eucalipto } \\
\text { Citriodora }\end{array}$ & 904,89 & 71,27 & 10,77 & 21.481 & 12 \\
\hline
\end{tabular}

A resistência de cálculo da madeira pode ser dada pela eq. (11) e o valor efetivo do módulo de elasticidade de elasticidade pela eq. (12) .

$$
\begin{aligned}
& f_{d}=k_{\text {mod }} \frac{f_{k}}{\gamma_{\mathrm{w}}} \\
& E_{m, \text { ef }}=k_{\text {mod }} E_{m, \text { médio }}
\end{aligned}
$$

onde:

$$
\begin{aligned}
& \mathrm{k}_{\bmod }=\text { coeficiente de modificação }=\mathrm{k}_{\bmod 1} \cdot \mathrm{k}_{\bmod 2} \cdot \mathrm{k}_{\bmod 3} ; \\
& \mathrm{k}_{\bmod 1}=0,70 \text { (carregamento de longa duração); } \\
& \left.\mathrm{k}_{\bmod 2}=1,00 \text { (classe de umidade } 1 \text { e } 2\right) ; \\
& \mathrm{k}_{\text {mod } 3}=0,80 \text { (madeira de } 1^{\text {a }} \text { ou } 2^{\text {a }} \text { categoria) } . \\
& \mathrm{k}_{\bmod }=\mathrm{k}_{\bmod 1} \cdot \mathrm{k}_{\bmod 2} \cdot \mathrm{k}_{\bmod 3}=0,70.1,00.0,80=0,56
\end{aligned}
$$


O coeficiente de ponderação para estados limites últimos decorrentes de tensões de compressão paralelas às fibras $\tilde{a}_{\mathrm{c}}$ tem o valor básico $\tilde{a}_{\mathrm{wc}}=1,4$.

O coeficiente de ponderação para estados limites últimos decorrentes de tensões de cisalhamento paralelas às fibras ã tem o valor básico $\tilde{a}_{\mathrm{wv}}=1,8$.

Na Tabela 17 encontram-se os valores de cálculo para a resistência da madeira e o valor efetivo para o módulo de elasticidade.

Tabela 17. Valores de cálculo das resistências mecânicas e efetivo do módulo de elasticidade.

\begin{tabular}{cccccc}
\hline $\begin{array}{c}\text { Nome } \\
\text { comum }\end{array}$ & $\begin{array}{c}\tilde{\mathrm{N}}_{\mathrm{ap}} \\
\left(\mathrm{kg} / \mathrm{m}^{3}\right)\end{array}$ & $\begin{array}{c}\mathrm{f}_{\mathrm{wc} 0, \mathrm{~d}} \\
(\mathrm{Mpa})\end{array}$ & $\begin{array}{c}\mathrm{f}_{\mathrm{wvo}, \mathrm{d}} \\
(\mathrm{Mpa})\end{array}$ & $\begin{array}{c}\mathrm{E}_{\mathrm{Co}, \mathrm{ef}} \\
(\mathrm{Mpa})\end{array}$ & $\begin{array}{c}\mathrm{U} \\
\left(\frac{\circ}{0}\right)\end{array}$ \\
\hline $\begin{array}{c}\text { Eucalipto } \\
\text { Citriodora }\end{array}$ & 904,90 & 28,51 & 3,35 & $12.029,36$ & 12 \\
\hline
\end{tabular}

\subsection{Rigidez e resistência da ligação por anel}

Os resultados dos três ensaios idênticos àquele mostrado na Figura 31 estão apresentados nos gráficos carga - deslocamento da Figura 41. 

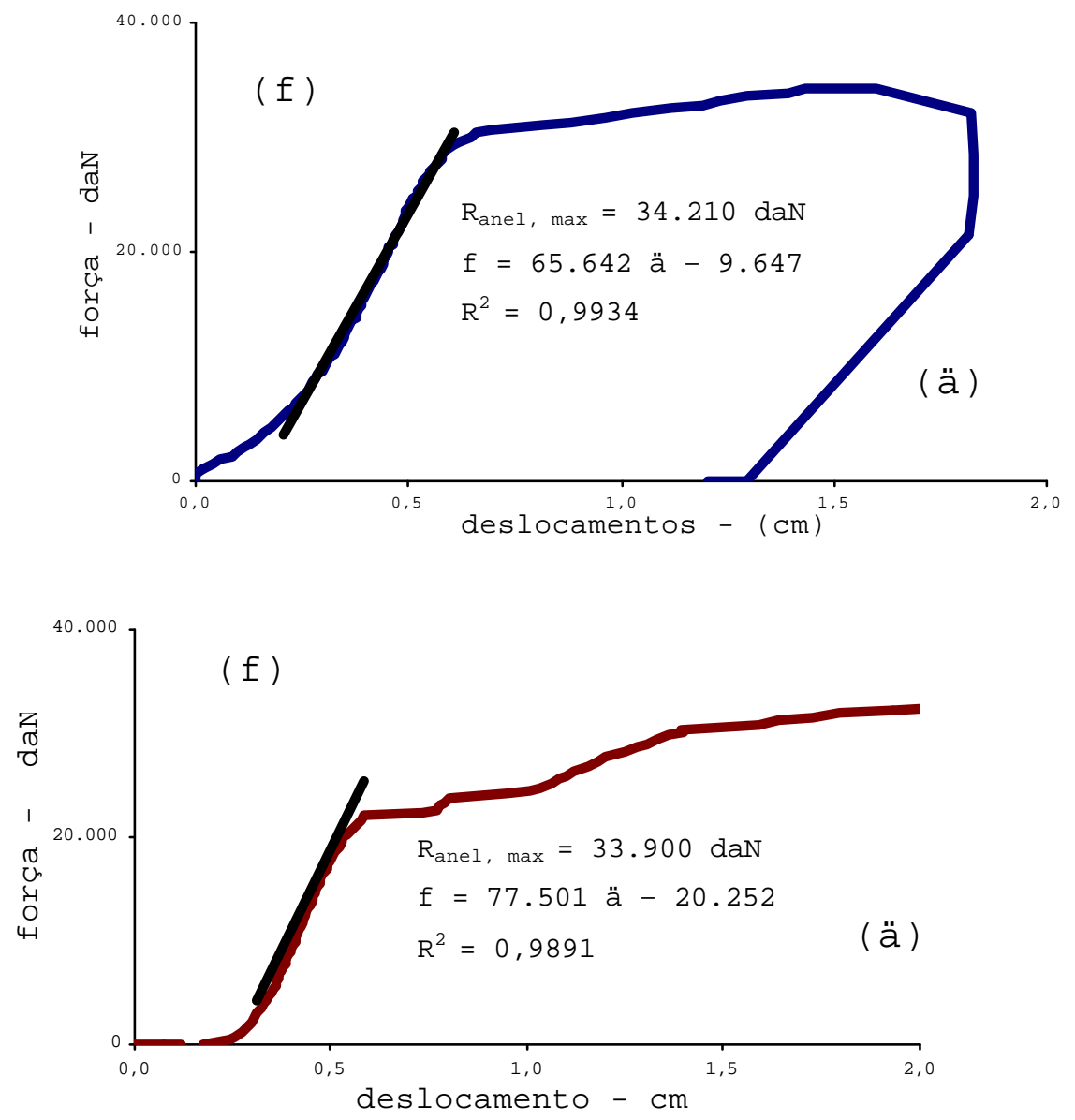

(b)

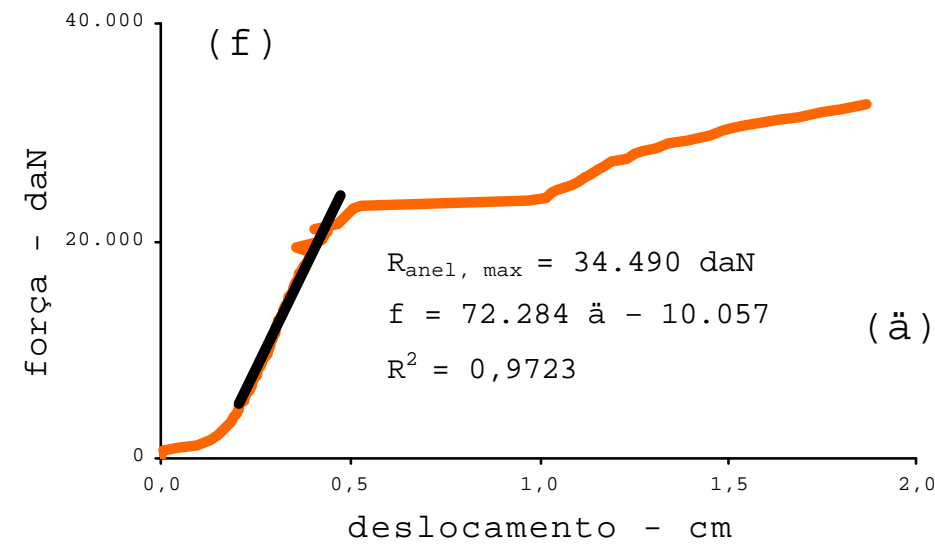

(c)

Figura 41 - Diagramas carga x deslocamento dos CP I (a), CP II (b) e CP III (c). 
A Tabela 18 concentra os dados importantes dessa figura que serão utilizados nos cálculos do item 4.5 .4

Tabela 18. Resistências e Rigidezes ao cisalhmaneto da ligação de peças de madeira de E. citriodora de seção circular unidas por um anel metálico de $150 \mathrm{~mm}$ de diâmetro.

\begin{tabular}{ccc}
\hline CP & $R_{\text {anel,máx }}($ daN $)$ & $f / \ddot{a}^{1}$ \\
\hline 1 & 34.210 & 65.642 \\
3 & 33.900 & 77.501 \\
média & 34.490 & 72.284 \\
\hline
\end{tabular}

$\mathrm{R}_{a n e l, m a ́ x}=$ resistência máxima da ligação ao cisalhamento;

$1=\operatorname{as}$ retas $\mathrm{f} \times$ ä foram transportadas para a origem; $\mathrm{f} / \ddot{a}$ = relação carga deslocamento relativo entre as peças. 
4.3 Espaçamento entre anéis e elástica da viga bicircular

Para levar em conta as contribuições das deformações das ligações, por anel, que vinculam as peças componentes da viga bi-circualar (Figura 41) entre si, foi desenvolvida a teoria detalhada a seguir. Essa teoria, embora simplificada ao nível da teoria de primeira ordem, permite calcularem-se o momento de inércia real, o espaçamento entre anéis e a flecha da viga.
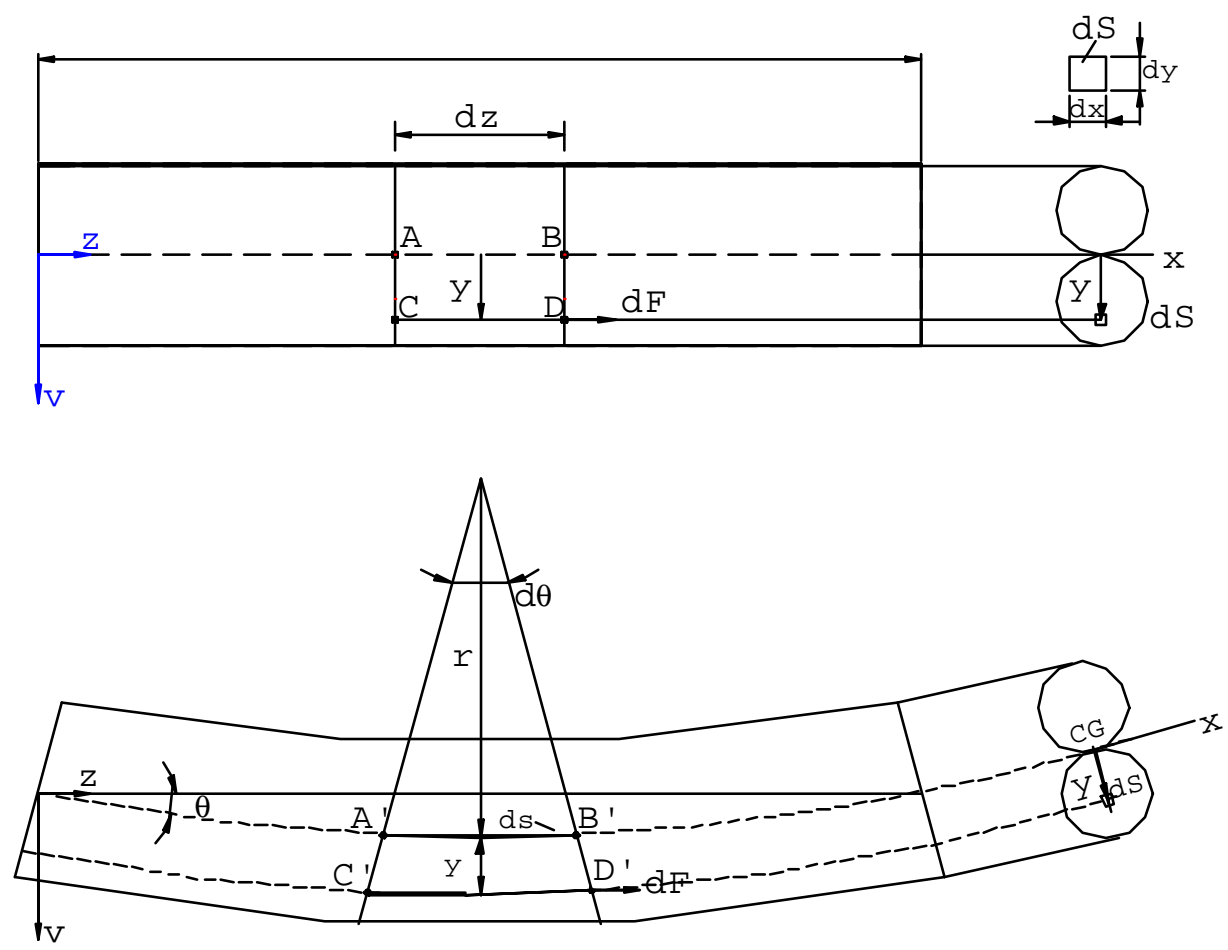

Figura 41 - Viga de seção bi-circular indeformada (a) e fletida (b) . 
O segmento $A B$ é igual a dz e $r$ é o raio de curvatura da elástica da viga monolítica. A distância da fibra CD à linha neutra está representada pela variável y e - raio de curvatura dessa fibra é, portanto, r+y. A elástica da viga deformada será dada pela variável v.

Sabe-se que $\frac{d v}{d z}=$ tgè e como, na prática, o ângulo è é um ângulo muito pequeno pode-se admitir que a tgè é igual ao próprio ângulo è. A eq. (14) mostra essa $1^{a}$ aproximação.

$\frac{d v}{d z}=$ tgè $\approx$ è

O arco ds que se encontra na linha neutra da viga fletida é calculado pela eq. (15).

$\mathrm{ds}=\mathrm{r}$ dè

Quando a viga está fletida o segmento CD passa a ser o arco C' $\mathrm{D}^{\prime}$, que é calculado pela eq. (16).

$C^{\prime} D^{\prime}=(r+y) d e ̀ ~$

Assim, o valor da deformação será: 


$$
\begin{aligned}
& \stackrel{\mathrm{a}}{=}=\frac{\ddot{\mathrm{A}} \mathrm{l}}{\mathrm{l}}=\frac{(\mathrm{r}+\mathrm{y}) \text { dè }-r \text { dè }}{r \text { dè }}=\frac{\mathrm{v}}{\mathrm{r}} \\
& \frac{\mathrm{a}}{\mathrm{y}}=\frac{1}{\mathrm{r}}
\end{aligned}
$$

Como $2^{\text {a }}$ aproximação pode-se admitir que 0 segmento curvo ds seja igual ao segmento retilíneo dz, ou seja:

$\mathrm{ds}=\mathrm{dz}$

Portanto, a eq. (15) se transforma na eq. (18), donde se obtém a eq. (19) .

$\mathrm{dz}=\mathrm{rdè}$

$\frac{\mathrm{dè}}{\mathrm{dz}}=\frac{1}{\mathrm{r}}$

O momento da força dF, de tração, aplicada longitudinalmente na fibra $C D$ e em relação ao eixo $x$ é dado pela eq. (20).

$\mathrm{dM}=\mathrm{dF} \cdot \mathrm{Y}$

Substituindo-se a eq. (21) na eq. (20) obtém-se a eq. (22) . 
Ó $=\frac{d F}{d S}$

$\mathrm{dM}=$ ÓdS $\cdot \mathrm{Y}$

onde:

dS = áreada seçãotransversal da fibra.

Derivando-se ambos os membros da eq. (14) em relação a z, obtém-se a eq. (23) :

$\frac{d^{2} v}{d z^{2}}=\frac{d e ̀ ~}{d z}$

Da identidade das equações (17), (19) e

obtém-se a eq. (24).

$\frac{\mathrm{d}^{2} \mathrm{v}}{\mathrm{dz}^{2}}=\frac{\mathrm{a}}{\mathrm{y}}$

Substituindo-se as equações (25) e (26) na eq. (24) como mostra a eq. (27) obtém-se a equação diferencial da linha elástica dada pela eq. (28), que é idêntica à eq. (2) e que é idêntica à eq. (17).

Ó $=\mathrm{E} \cdot \stackrel{\mathrm{a}}{ }$

ó $=\frac{M}{I} \cdot y$ 


$$
\begin{aligned}
& \frac{d^{2} v}{d z^{2}}=\frac{\stackrel{\circ}{y}}{y}=\frac{\frac{O}{E}}{y}=\frac{o ́}{E \cdot y}=\frac{\frac{M}{I} \cdot y}{E \cdot y} \\
& \frac{d^{2} v}{d z^{2}}=\frac{1}{r}=\frac{M}{I E}
\end{aligned}
$$

$$
\text { As equações (29) a (31) mostram o desenvolvimento }
$$

efetuado para o cálculo de espaçamento entre anéis metálico dado pela eq. (32).

$$
\hat{o}=\frac{\mathrm{Q} \cdot \mathrm{M}_{\mathrm{S}}}{\mathrm{b} \cdot \mathrm{I}_{\text {real }}}
$$

$\hat{\mathrm{o}} \cdot \mathrm{b}=\frac{\mathrm{Q} \cdot \mathrm{M}_{\mathrm{S}}}{\mathrm{I}_{\text {real }}}=\mathrm{F}$

$F=\frac{R_{\text {anel }}}{S}$

$$
S=\frac{R_{\text {anel }}}{F}=\frac{R_{\text {anel }}}{\frac{Q \cdot M_{s}}{I_{\text {real }}}}
$$

Onde:

$\mathrm{s}=$ espaçamento entre anéis, medido paralelamente ao eixo da viga;

$\mathrm{R}_{\mathrm{anel}}=$ Resistência da ligação por anel ao cisalhamento;

$\mathrm{Q}=$ cortante máximo na viga bi-circular;

$\mathrm{M}_{\mathrm{S}}=$ momento estático de área $=\frac{\partial \mathrm{d}^{3}}{8}$;

$I_{\text {real }}=$ momento de inércia real da viga bi-circular. 
A eq. (32) mostra que o espaçamento entre anéis (de qualquer material) ao longo de uma viga de seção composta depende do momento de inércia real dessa viga, que por sua vez, depende da rigidez da ligação das peças componentes pelo anel. Portanto, a deformação total da viga real pode ser considerada como a soma da deformação da viga composta suposta monolítica com a deformação da ligação eq. (33) .

$$
\stackrel{\circ}{\text { total }}^{=} \stackrel{\circ}{\text { monolítica }}+\stackrel{\circ}{\text { ligação }}
$$

A deformação da viga composta suposta monolítica é facilamente calculada pela eq. (34), obtida da eq. (17).

$$
\stackrel{\circ}{\text { monolítica }}=\frac{y}{r_{\text {monolítico }}}
$$

onde:

$y=$ distancia do centro geométrico da seção até a borda; $r$ = raio de curvatura da viga suposta monolítica calculado pela eq. (35).

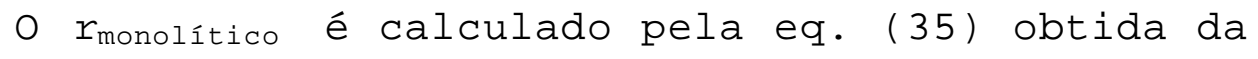
eq. (28) .

$r_{\text {monolítico }}=\frac{E \cdot I_{\text {teórico }}}{M}$

onde:

$\mathrm{M}=$ momento fletor. 
A deformação da ligação é calculada pela eq. (36).

$\stackrel{\circ}{\text { ligação }}=\frac{\ddot{a}_{\text {ligação }}}{\ell}$

onde:

$\ddot{a}_{\text {ligação }}=$ deslocamento relativo entre as peças componentes de seção composta determinada em ensaios de ligação; = comprimento da viga.

Obtida a deformação total, coloca-se o raio de curvatura da viga composta real pela eq. (37), obtida da eq. (17).

$r_{\text {total }}=\frac{y}{\stackrel{g}{a}_{\text {total }}}$

Finalmente calcula-se o momento de inércia real pela eq. (38), obtida pela eq. (28) .

$I_{\text {real }}=\frac{M \cdot r_{\text {total }}}{E}$

Para a dedução da elástica da viga composta, procedeu-se a integração da eq. (28) substituindo-se a variável r genérica pela variável conhecida rtotal, como mostra a eq. (39). Obtiveram-se, então, as equações (40) e (41), respectivamente da primeira e segunda integração. 


$$
\begin{aligned}
& \iint \frac{d^{2} v}{d z^{2}} d z d z=\iint \frac{1}{r_{\text {total }}} d z d z \\
& \frac{d v}{d z}=\frac{1}{r_{\text {total }}} z+C_{1} \\
& v=\frac{1}{r} \frac{z^{2}}{2}+C_{1} z+C_{2}
\end{aligned}
$$

Tendo em vista a simetria de carregamento tanto de peso próprio quanto do trem de carga, pois a situação crítica é aquela em que a carga central do trem de carga coincide com a seção central da viga, foram tomadas as condições de contorno dadas pelas equações (42) e (43).

$\mathrm{v}(0)=0$

$\frac{\mathrm{dv}}{\mathrm{dz}}\left(\frac{\ell}{2}\right)=0$

Substituindo a eq. (42) na equação (41) obtém-se da constante $\mathrm{C}_{2}$ dada pela eq. (44).

$$
\begin{aligned}
& \mathrm{V}=\frac{1}{\mathrm{r}} \frac{\mathrm{z}^{2}}{2}+\mathrm{C}_{1} \mathrm{z}+\mathrm{C}_{2} \\
& 0=\frac{1}{r} \frac{(0)^{2}}{2}+\mathrm{C}_{1}(0)+\mathrm{C}_{2} \\
& \mathrm{C}_{2}=0
\end{aligned}
$$


Analogamente, substituindo-se a eq. (43) na eq. (40) obteve-se o valor da constante $\mathrm{C}_{2}$, dada pela eq. (45).

$$
\begin{aligned}
& \frac{d v}{d z}=0=\frac{1}{r} z+C_{1} \\
& C_{1}=\frac{1}{r} \times\left(\frac{\ell}{2}\right)=\frac{\ell}{2 r}
\end{aligned}
$$

Substituindo-se as eq. (44) e (45) obteve-se a eq. (46) da elástica da viga de seção composta, escrita em função do seu raio de curvatura, para z variando de 0 a :

$$
\mathrm{v}(\mathrm{z})=\frac{\mathrm{z}^{2}}{2 r}-\frac{\ell \mathrm{z}}{2 r}
$$




\subsection{Projeto da Ponte}

A Figura 42 mostra a planta de uma ponte de uma única direção de tráfego pertencente à classe 30, com pista de rolamento constituído de troncos dispostos transversalmente e de forma alternada para compensar a conicidade. O tabuleiro é revestido parcialmente e longitudinalmente com vigas de $6 \times 16 \mathrm{~cm}$, posicionadas com a finalidade de direcionar o tráfego e promover conforto na passagem dos veículos. Na Figura 43 pode-se observar o esquema estático das longarinas que trabalham como vigas bi-apoiadas e o das transversinas que desempenham, em conjunto, o papel de tabuleiro.

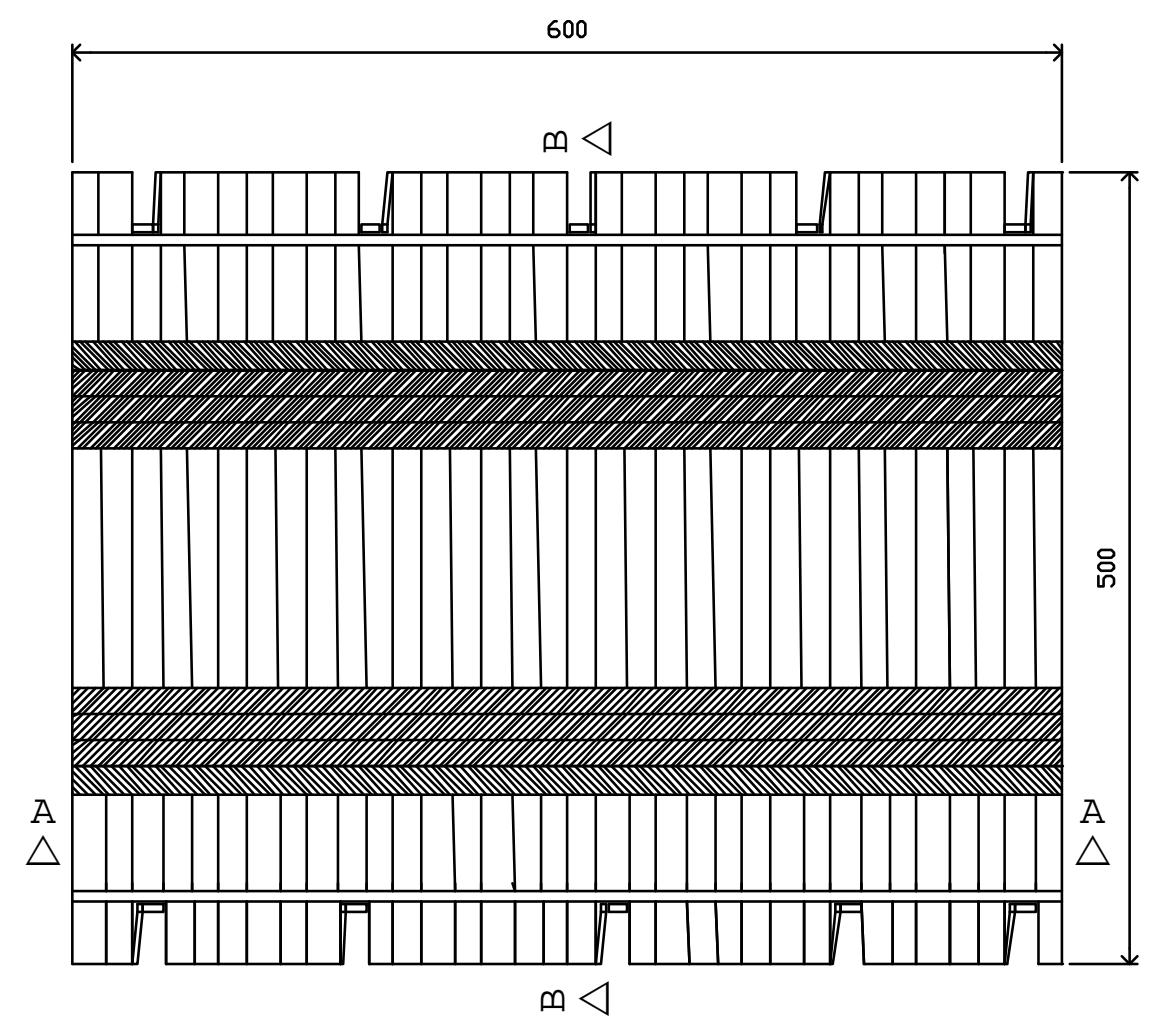

Figura 42 - Planta baixa da ponte (medidas em $\mathrm{cm}$ ). 

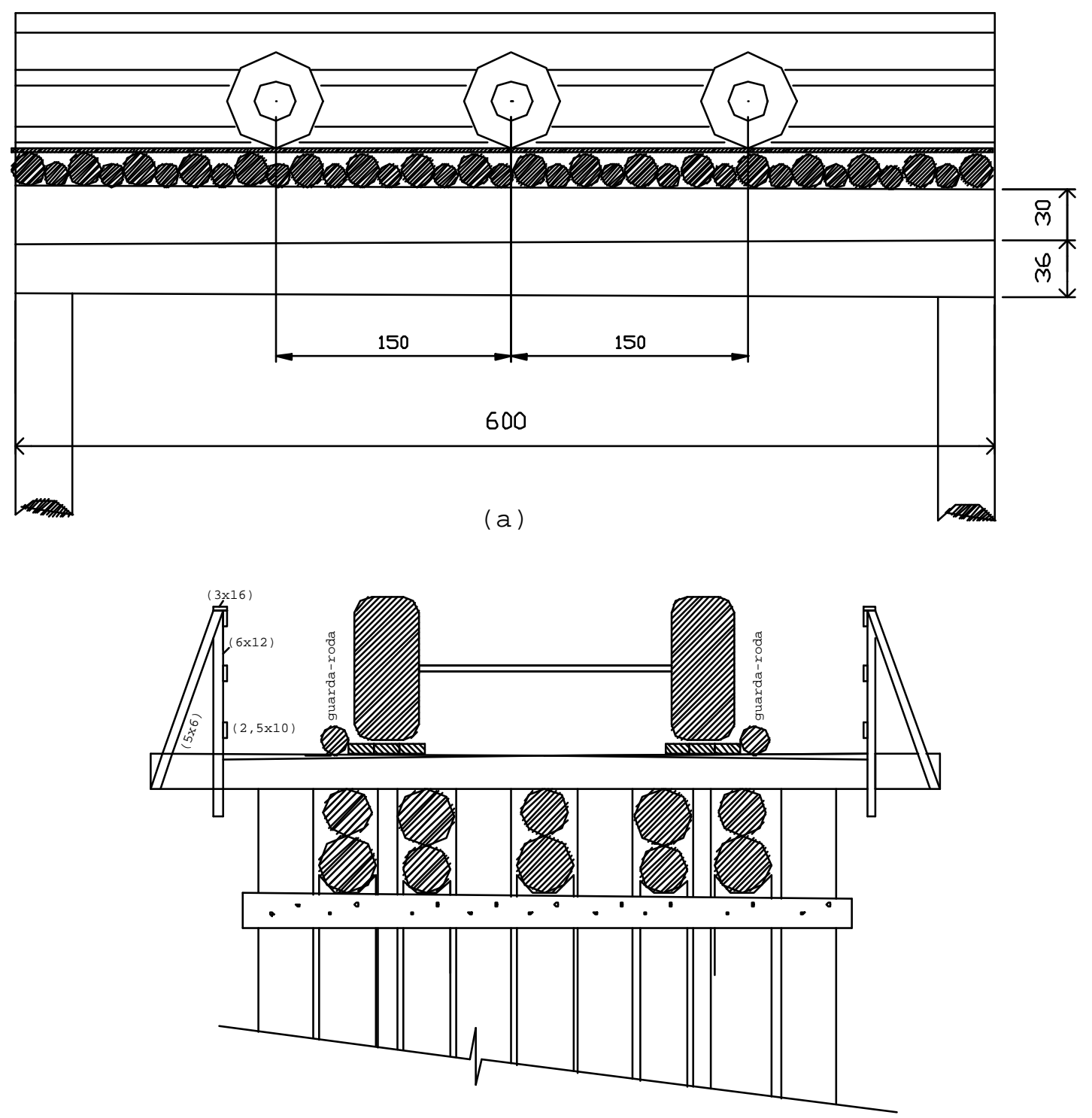

(b)

Figura 43 - Cortes AA, longitudinal (a) e BB, transversal (b) da ponte (medidas em $\mathrm{cm}$ ) . 


\title{
4.5 Cálculo da Ponte por analogia de grelhas
}

\begin{abstract}
O cálculo da ponte por analogia de grelha é mais trabalhoso mas leva a obter-se uma melhor distribuição de esforços nas longarinas. Para simplificar os cálculos a grelha completa pode ser substituída por uma grelha de menor número de elementos, que absorvem as rigidezes dos elementos que foram omitidos.
\end{abstract}

A ponte pode, então, ser considerada formada por um número bem menor de transversinas. O número mínimo de transversinas deve ser aquele que possibilite, dentro de uma determinada confiabilidade, a transferência dos esforços oriundo das cargas aplicadas nas transversinas para as longarinas.

No presente trabalho a ponte de 5 longarinas e 33 transversinas foi calculado como sendo grelha de 1,3 e 33 transversinas. Os cálculos foram feitos através do programa SAP 90 mas para a ponte até 3 transversinas foi utilizado também um programa próprio baseado no método dos esforços e desenvolvido numa planilha eletrônica.

\subsubsection{Grelha de uma transversina idealizada}

Quando se idealiza a estrutura da ponte como uma grelha, essa estrutura passa a ser hiperestática e assim as três equações de equilíbrio não são suficientes para o cálculo de todos os esforços internos. Há, portanto, a necessidade de estabelecerem-se equações de compatibilidade de deslocamentos. 
A solução da estrutura hiperestática pode ser obtida através do Processo dos Esforços onde, dentro do princípio da superposição dos efeitos, substitui-se cada incógnita hiperestática por uma carga unitária.

A estrutura da grelha formada por 5 longarinas e apenas 1 transversina é três vezes hiperestática. A Figura 44 mostra o esquema estático montado com a eliminação das 3 incógnitas hiperestático dados pelas reações da transvesina.
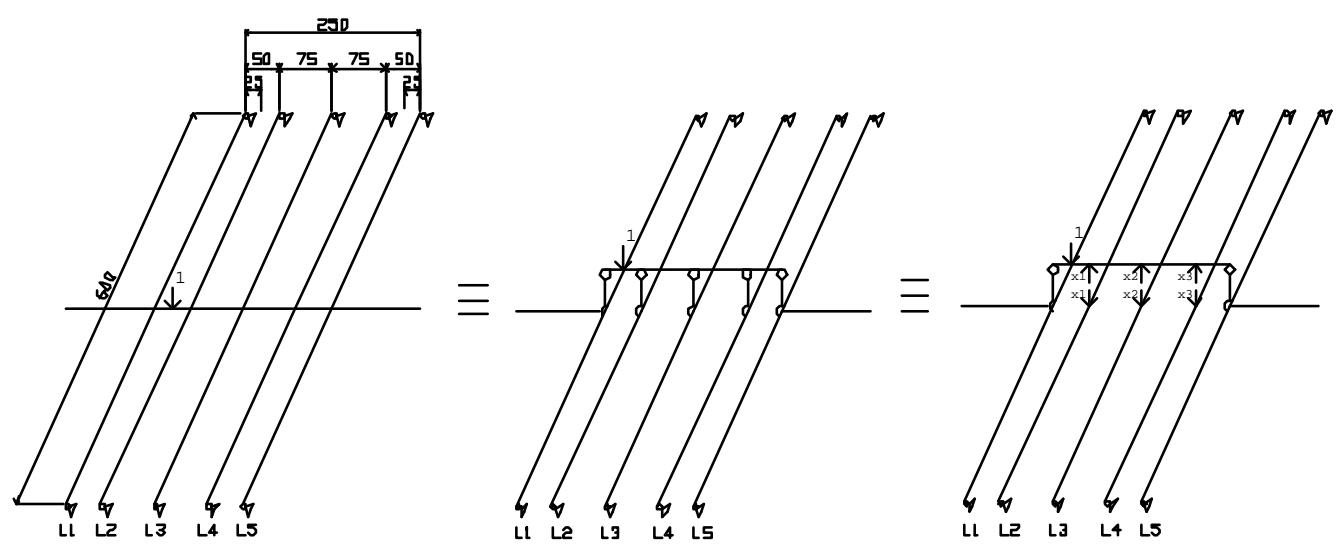

$(r)$

Figura 44 - Incógnitas hiperestáticas para a grelha simplificada sendo a única transversina posicionada no meio do vão da longarina.

A Figura 45 mostra, no problema (0) que a transversina idealizada transforma-se numa viga isostática apoiada nas longarinas 1 e 5 (longarinas externas) e nos problemas (1) a (3) a substituição da incógnita respectiva, pela carga unitária. Dessa superposição de efeito obtém-se a eq. (47) que permite calcular qualquer esforço ou deslocamento da estrutura real como numa conf... linear dos esforços obtidos nas estruturas isostáticas componentes. 
$(r)=(0)+x_{1}(1)+x_{2}(2)+x_{3}(3)$

Aplicando a eq. (47) para os deslocamentos dos pontos de aplicação das incógnitas adotadas tem-se o sistema de equações de compatibilidade de deslocamentos dados pela eq. (48).

$$
\Delta_{1 \mathrm{r}}=\Delta_{10}+\mathrm{x}_{1} \delta_{11}+\mathrm{x}_{2} \delta_{12}+\mathrm{x}_{3} \delta_{13}=0
$$

$\Delta_{2 \mathrm{r}}=\Delta_{20}+\mathrm{x}_{1} \boldsymbol{\delta}_{21}+\mathrm{x}_{2} \boldsymbol{\delta}_{22}+\mathrm{x}_{3} \boldsymbol{\delta}_{23}=0$

$\Delta_{3 \mathrm{r}}=\Delta_{30}+\mathrm{x}_{1} \delta_{31}+\mathrm{x}_{2} \delta_{32}+\mathrm{x}_{3} \delta_{33}=0$

Como o efeito do momento fletor na deformação é, quase sempre preponderante em relação aos efeitos dos esforços cortante e normal, utilizou-se como, mostra a Figura 46, apenas os diagramas de momento para o cálculo dos deslocamentos dados pela integral do produto de duas quaisquer funções de momento $\int_{\ell} \frac{M_{r} M_{i}}{E I} d x$.

Para o cálculo da grelha adotou-se para o momento de inércia, da longarina bi-circular, o valor do momento de inércia teórico e o momento de inércia da transversina idealizada foi obtido à partir da soma dos momentos de inércia das transversinas que ela representa de acordo com a Figura 47 e eq. (49).

$$
I t_{\text {idealizada }}=\frac{\mathrm{n} \times I t}{\ell} \times \ell_{\mathrm{t}}
$$

onde:

It $_{\text {idealizada }}=$ momento de inércia da transversina idealizada; $\mathrm{n}=$ número total de transversinas da ponte completa;

$$
\text { = vão da ponte; }
$$

$t=$ vão referente à área de influencia sobre a transversina idealizada. 


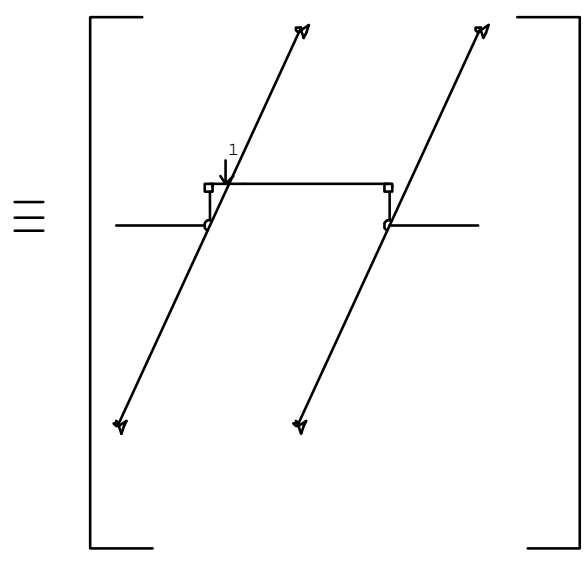

(0)

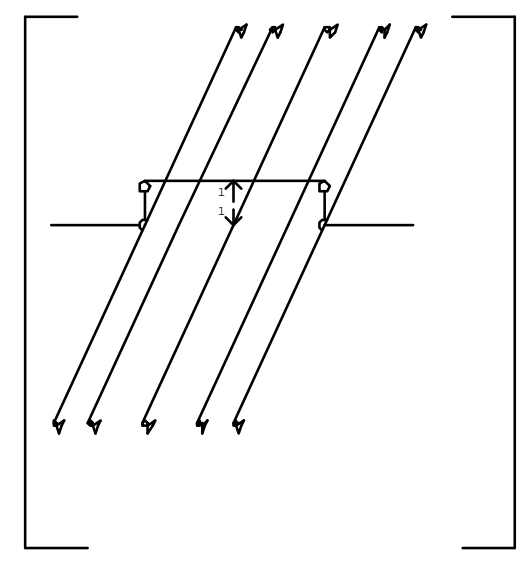

(2)

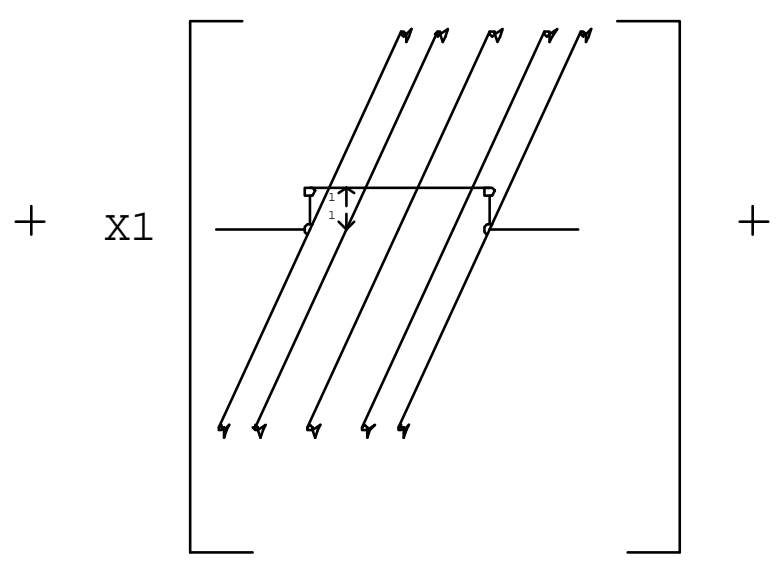

(1)

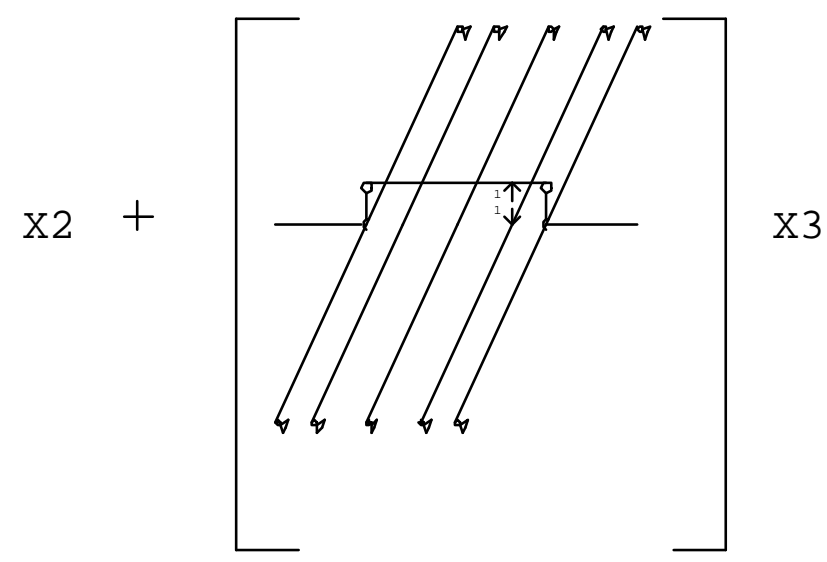

(3)

Figura 45 - Esquema estático da superposição de efeitos, mostrando a carga unitária na posição de carregamento do trem - tipo a $25 \mathrm{~cm}$ da longarina 1 . 


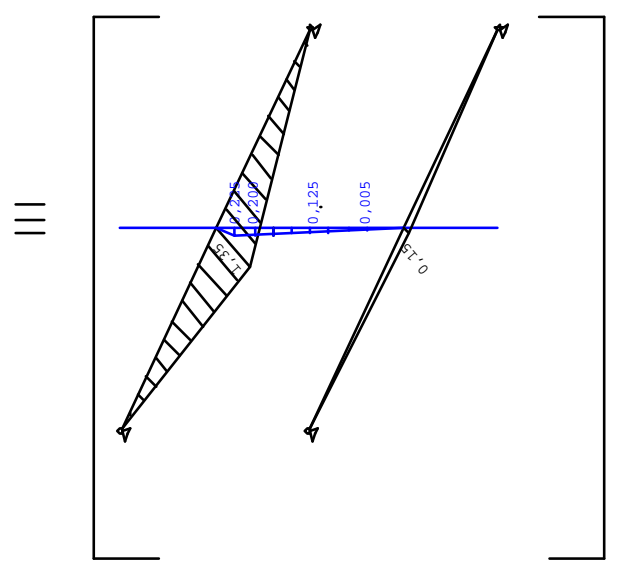

( $\mathrm{MO})$

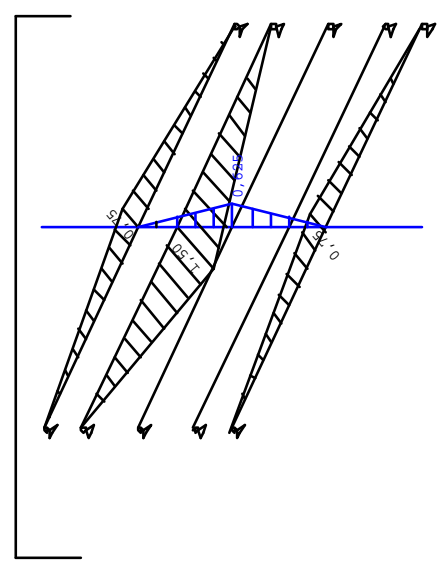

(M2)
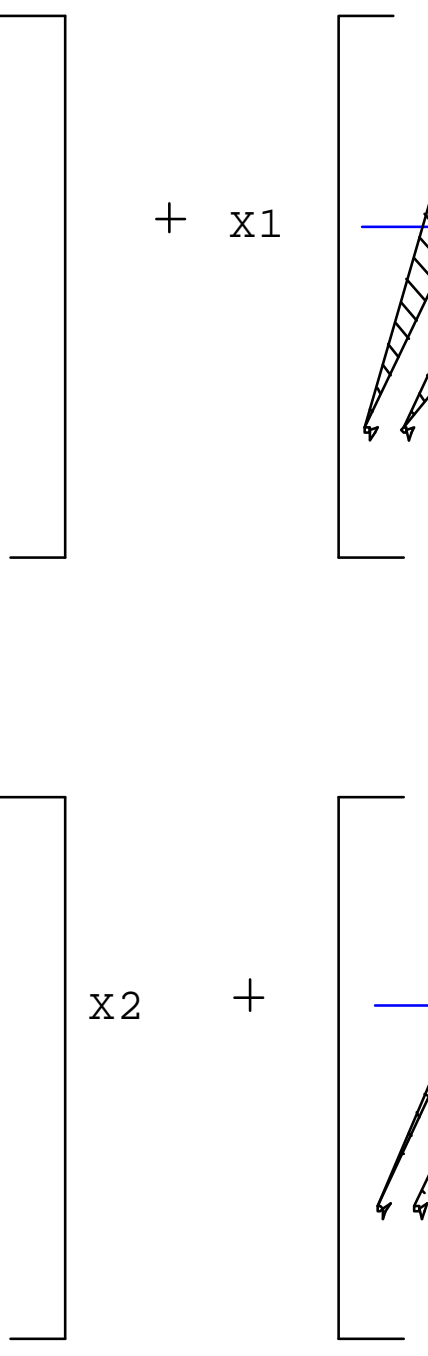

$+$

(M1)
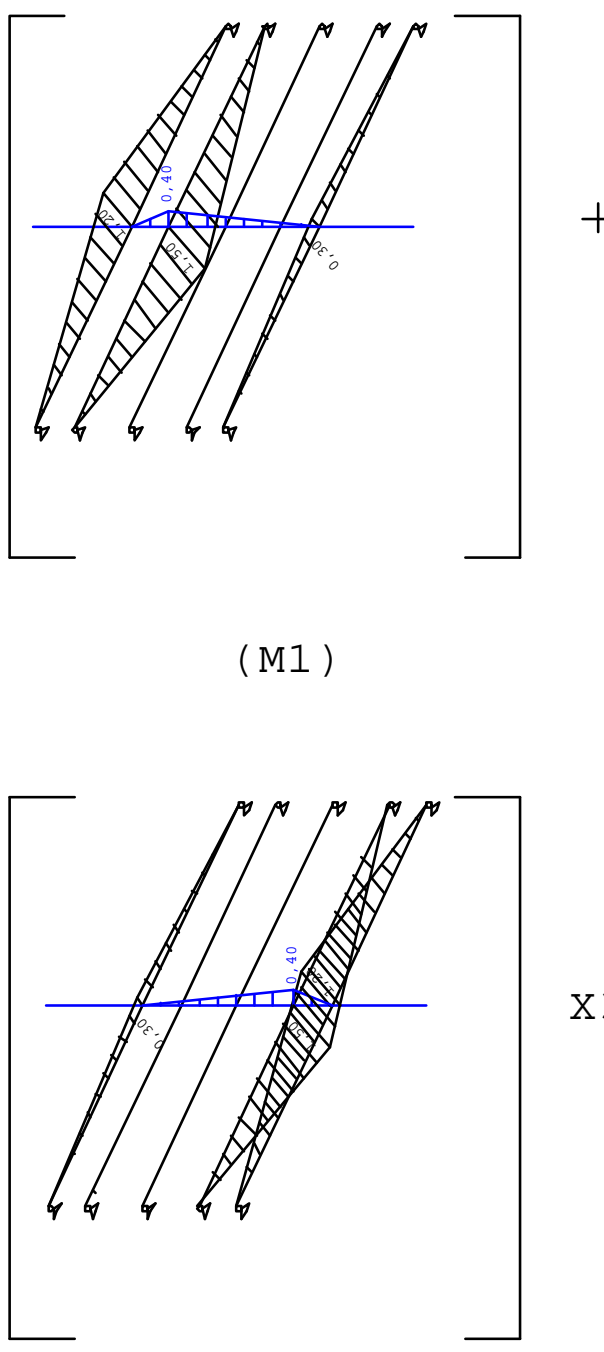

(M3)

Figura 46 - Diagramas de momentos das estruturas isostáticas dadas pelos problemas (0), (1), (2) e (3).

Na Tabela 19 estão os valores dos momentos de inércia calculados. 


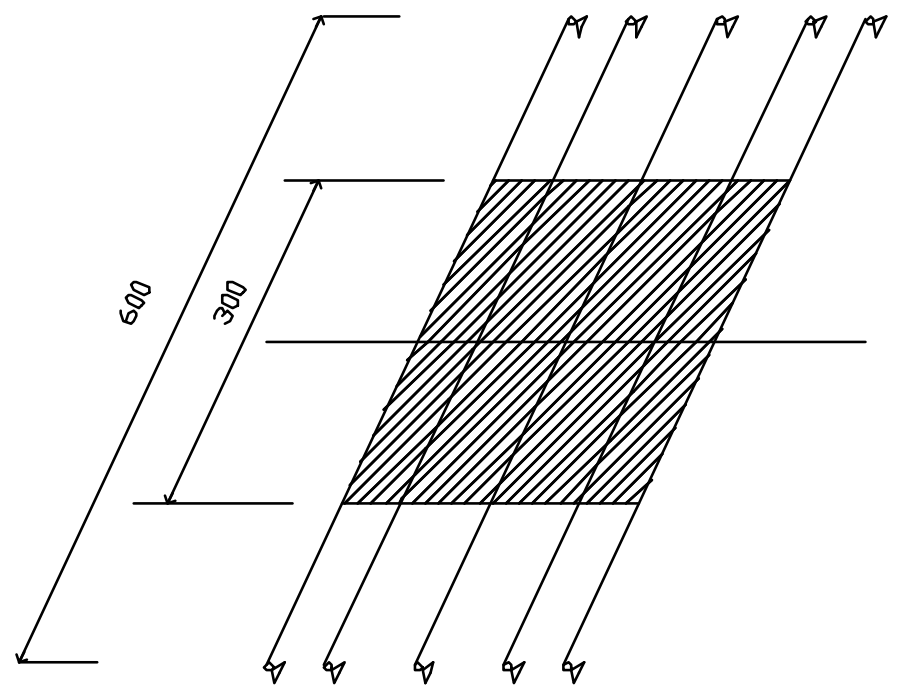

Figura 47 - Faixa de influência da transversina idealizada.

Tabela 19. Rigidezes à flexão dos elementos estruturais.

\begin{tabular}{|c|c|c|c|}
\hline $\begin{array}{l}\text { Elemento } \\
\text { Estrutural }\end{array}$ & $\begin{array}{c}\text { momento de } \\
\text { inércia teórico } \\
I \mathrm{I}=\left(\mathrm{cm}^{4}\right)\end{array}$ & $\begin{array}{c}\text { módulo de } \\
\text { elasticidade } \\
\mathrm{E}=(\mathrm{MPa})\end{array}$ & $\begin{array}{c}\text { rigidez à } \\
\text { flexão } \\
\text { EI }\left(\text { daN. } \mathrm{cm}^{2}\right)\end{array}$ \\
\hline longarina & 514.457 & 12.029 & $\mathrm{EI}_{1}=6,05 \mathrm{EI_{t }}$ \\
\hline transversina & 84.975 & 12.029 & $E I_{t}$ \\
\hline
\end{tabular}

Os comprimentos fictícios das longarinas e das transversinas, calculados pela eq. (50), encontram-se na Figura 48 .

$$
\ell^{\prime}=\ell_{i} \frac{I_{1}}{I_{i}}
$$

onde:

'= vão fectício;

$i=$ vão do elemento estrututal i;

$I_{1}=$ menor momento de inércia dos elementos estruturais; 
$I_{i}=$ momento de inércia do elemento estrutural i.
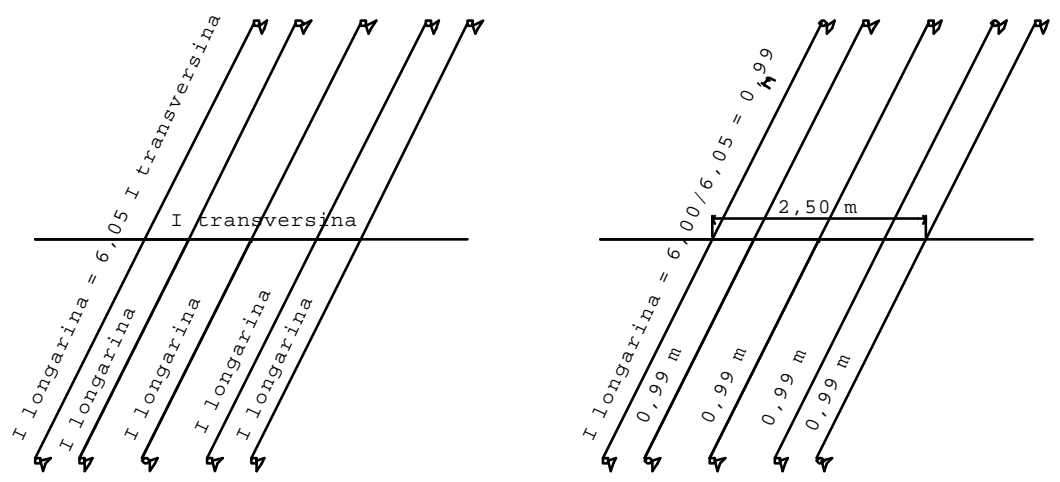

Figura 48 - Comprimentos fictícios dos elementos estruturais da grelha simplificada.

Tabela 20. Deslocamentos ampliados calculados no programa desenvolvido numa planilha eletrônica.

\begin{tabular}{lrrrrrrrr}
\hline & long 1 & long 2 & long 3 & long & long & transv & $\Sigma$ \\
\hline$E I_{t} \ddot{A}_{10}$ & $-0,536$ & 0,000 & 0,000 & 0,000 & $-0,015$ & $-0,012$ & $-0,562$ \\
$E I_{t} \ddot{A}_{20}$ & $-0,335$ & 0,000 & 0,000 & 0,000 & $-0,004$ & $-0,016$ & $-0,354$ \\
$E I_{t} \ddot{A}_{30}$ & $-0,015$ & 0,000 & 0,000 & 0,000 & $-0,536$ & $-0,008$ & $-0,559$ \\
$E I_{t} \ddot{a}_{11}$ & 0,476 & 0,744 & 0,000 & 0,000 & 0,030 & 0,022 & 1,272 \\
$E I_{t} \ddot{a}_{12}$ & 0,298 & 0,000 & 0,000 & 0,000 & 0,074 & 0,031 & 0,402 \\
$E I_{t} \ddot{a}_{13}$ & 0,119 & 0,000 & 0,000 & 0,000 & 0,119 & 0,016 & 0,254 \\
$E I_{t} \ddot{a}_{22}$ & 0,186 & 0,000 & 0,744 & 0,000 & 0,186 & 0,054 & 1,170 \\
$E I_{t} \ddot{a}_{23}$ & 0,074 & 0,000 & 0,000 & 0,000 & 0,298 & 0,031 & 0,402 \\
$E I_{t} \ddot{a}_{33}$ & 0,030 & 0,000 & 0,000 & 0,744 & 0,476 & 0,022 & 1,272 \\
\hline
\end{tabular}

Substituindo-se os dados da última coluna desta Tabela nas equações (48) e resolvendo-se o sistema obtido pelo programa desenvolvido, como mostra a Tabela 21, obtém- 
se os valores de $x_{1}, x_{2}$ e $x_{3}$ que eram as incógnitas procuradas.

Tabela 21. Valores de $\mathrm{X}_{1}, \mathrm{X}_{2}$ e $\mathrm{X}_{3}$ (última coluna) calculados no programa desenvolvido pelo método de Gauss.

\begin{tabular}{ccccccccc}
\hline $\mathrm{X}_{1}$ & $\mathrm{X}_{2}$ & $\mathrm{X}_{3}$ & $\ddot{\mathrm{A}}$ & & & & & \\
\hline 1,272 & 0,402 & 0,254 & $-0,562$ & $\mathrm{X}_{1}$ & 0,562 & $-0,006$ & $-0,078$ & 0,376 \\
0,402 & 1,170 & 0,402 & $-0,388$ & $\mathrm{X}_{1}$ & 0,388 & $-0,009$ & $-0,228$ & 0,376 \\
0,254 & 0,402 & 1,272 & $-0,202$ & $\mathrm{X}_{1}$ & 0,202 & $-0,028$ & $-0,078$ & 0,376 \\
& 1,325 & 0,410 & $-0,267$ & $\mathrm{X}_{2}$ & 0,267 & $-0,009$ & 0,258 & 0,195 \\
& 0,410 & 1,552 & $-0,114$ & $\mathrm{X}_{2}$ & 0,114 & $-0,034$ & 0,080 & 0,195 \\
& & 1,889 & $-0,041$ & $\mathrm{X}_{3}$ & 0,022 & & & \\
\hline
\end{tabular}

A Figura 49 mostra que a rigidez da transversina idealizada promoveu uma razoável distribuição de cargas para as longarinas. Ressalta-se portanto a grande importância de se verificar a rigidez do tabuleiro real com a rigidez dessa transversina.

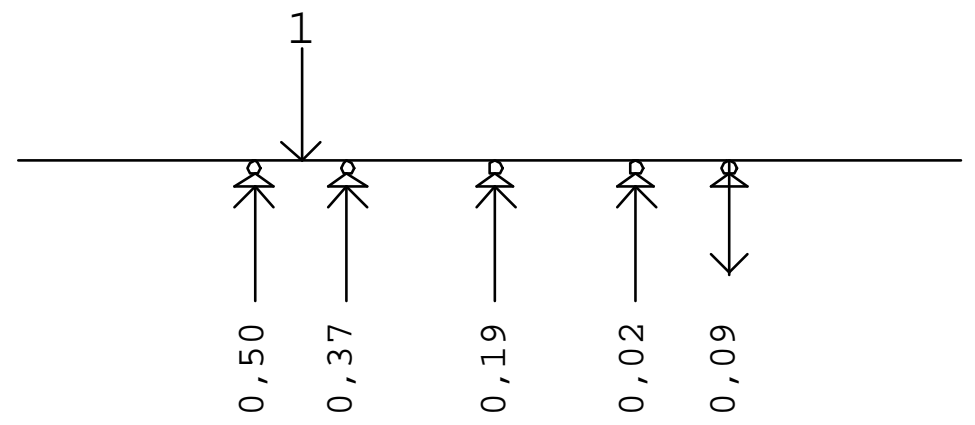

Figura 49 - Quinhões de carga distribuídos às longarinas, pela transversina idealizada. 
Na Tabela 22 tem-se o cálculo do momento resultante no meio do vão das longarinas e em 4 pontos da transversina. A Figura 50 mostra os diagramas de momento e cortante resultante na grelha de uma transversina.

Tabela 22. Momentos resultantes da transversina no meio do vão das longarinas e ao longo da transversina.

\begin{tabular}{|c|c|c|c|c|c|c|c|c|c|}
\hline & \multicolumn{5}{|c|}{ Longarinas } & \multicolumn{4}{|c|}{ Transversina } \\
\hline & L1 & L2 & L3 & L4 & L5 & $\begin{array}{c}0,25 * \\
(\mathrm{~m})\end{array}$ & $\begin{array}{c}0,50 * \\
(\mathrm{~m})\end{array}$ & $\begin{array}{c}1,25 * \\
(\mathrm{~m})\end{array}$ & $\begin{array}{c}2,00 * \\
(\mathrm{~m})\end{array}$ \\
\hline MO & 1,35 & 0,00 & 0,00 & 0,00 & 0,15 & 0,23 & 0,20 & 0,13 & 0,05 \\
\hline $\mathrm{x} 1 \mathrm{M} 1$ & $-0,45$ & 0,56 & 0,00 & 0,00 & $-0,11$ & $-0,08$ & $-0,15$ & $-0,09$ & $-0,04$ \\
\hline $\mathrm{x} 2 \mathrm{M} 2$ & $-0,15$ & 0,00 & 0,29 & 0,00 & $-0,15$ & $-0,02$ & $-0,05$ & $-0,12$ & $-0,05$ \\
\hline x3M3 & $-0,01$ & 0,00 & 0,00 & 0,03 & $-0,03$ & 0,00 & 0,00 & $-0,01$ & $-0,01$ \\
\hline $\mathrm{Mr}$ & 0,75 & 0,56 & 0,29 & 0,03 & $-0,14$ & 0,12 & 0,00 & $-0,10$ & $-0,05$ \\
\hline
\end{tabular}

* distância da longarina 1 .

Resolvendo-se a mesma estrutura pelo programa SAP 90 obtiveram-se os diagramas de momento e cortante mostrados na Figura 51. Comparando-se as Figuras 50 e 51 observa-se que o programa desenvolvido, facilmente acessivel por engenheiros agrônomos e florestais, permitiu - cálculo da grelha de uma transversina com a mesma precisão alcançado no programa SAP 90 . 

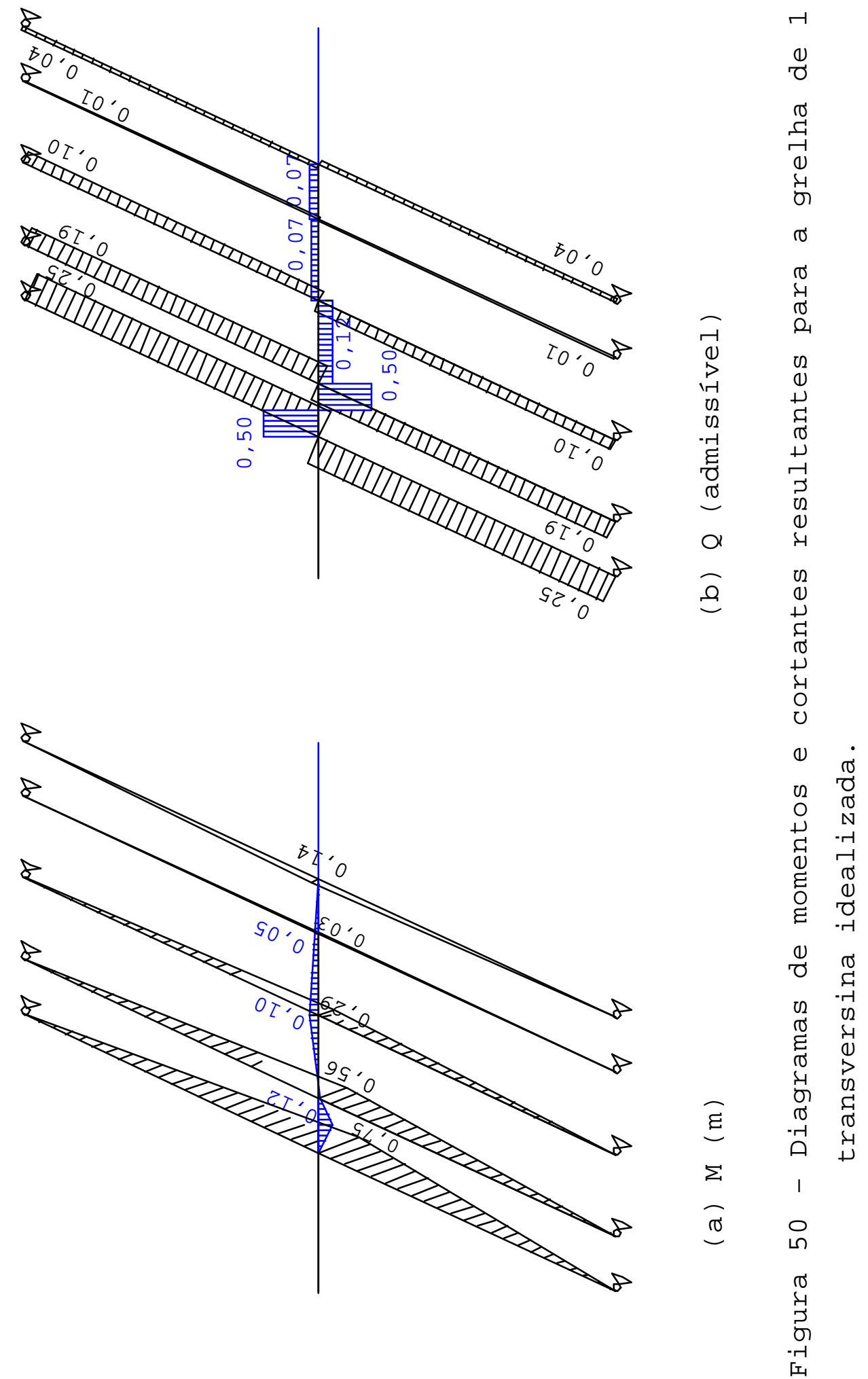


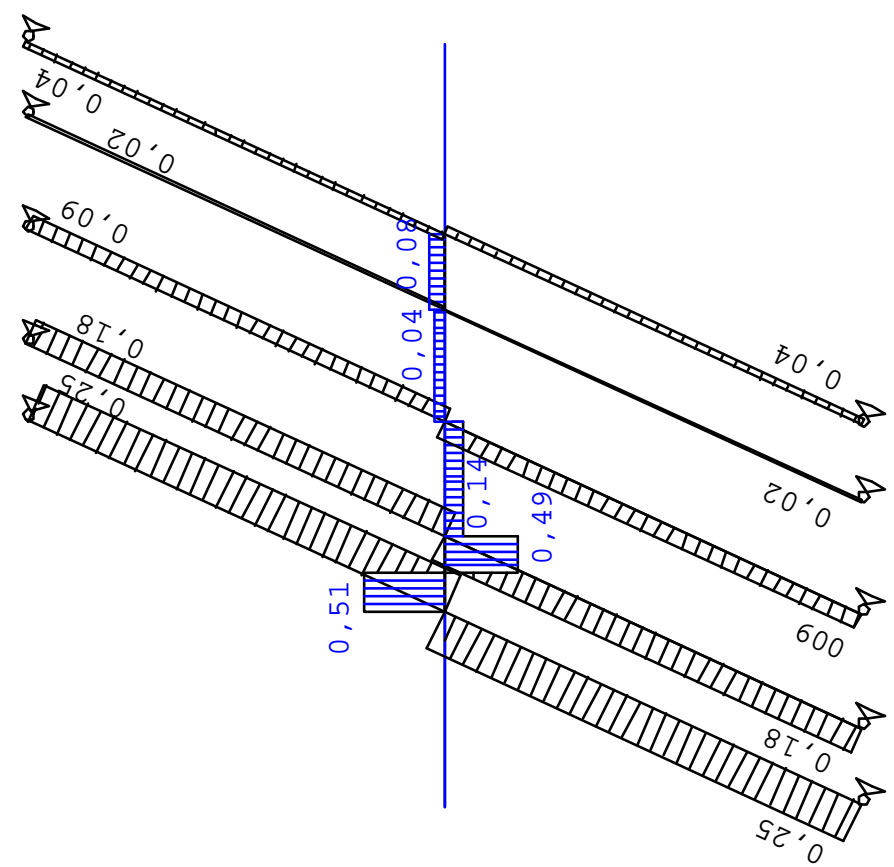

0
$C$
-7
0
1
0
0
0
0
0
1
1
+1

$-1$

ర)

(

O1
0
0
0
0
0
02
-1
5
0
0
0
0
0
0
0

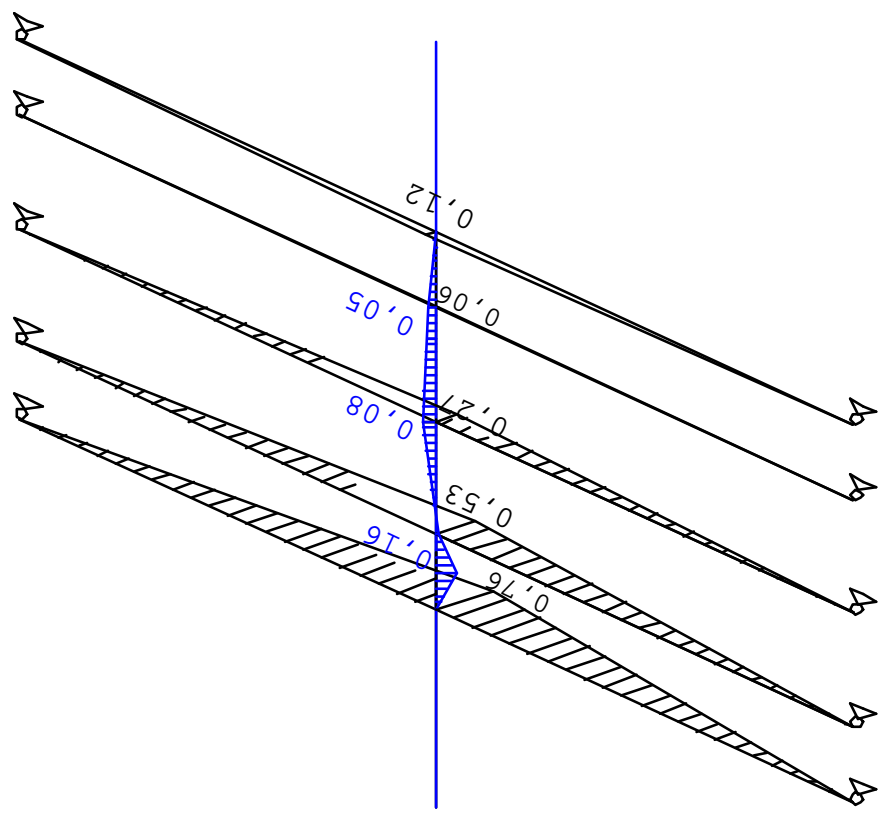




\subsubsection{Grelha de 3 transversinas idealizadas}

Utilizando-se o mesmo procedimento empregado para no cálculo da grelha de uma transversina idealizada calculou-se também, através do programa desenvolvido, a grelha de 3 transversinas idealizadas, mostrada na Figura 52 .
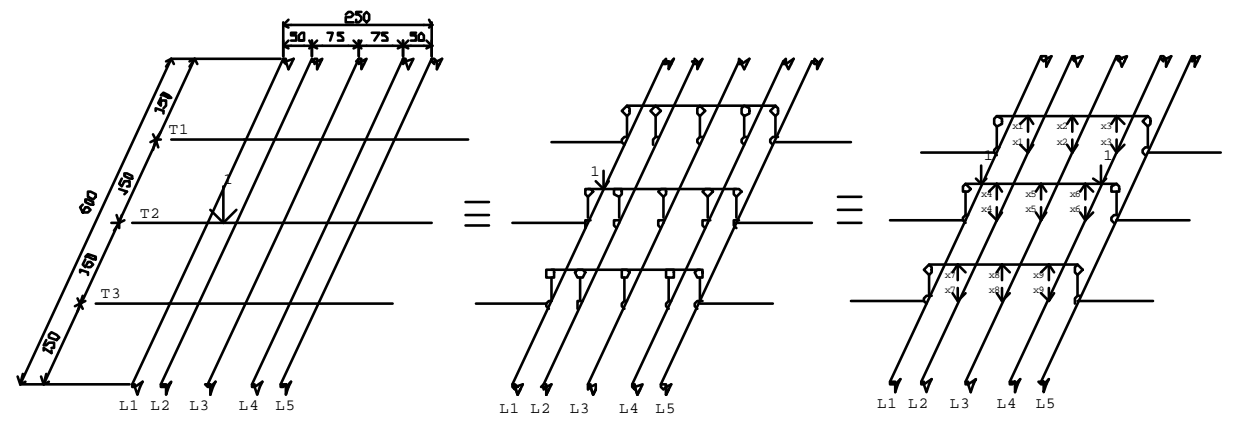

$(r)$

Figura 52 - Incógnitas hiperestáticas para a grelha simplificada de três transversinas idealizadas regularmente espaçadas.

A estrutura da grelha formada por 5 longarinas e 3 transversinas idealizadas é nove vezes hiperestática, como mostra o esquema de superposição de efeitos mostrado na Figura 53. Os diagramas de momento dos problemas (0) a (9) encontram-se nas Figuras 54 a 56.

As rigidezes à flexão dos elementos estruturais encontram-se na Tabela 23. 


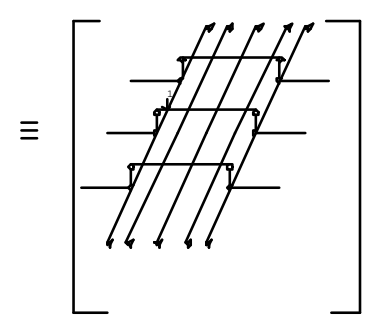

(0)

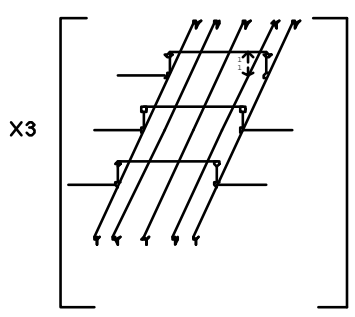

(3)

(6)

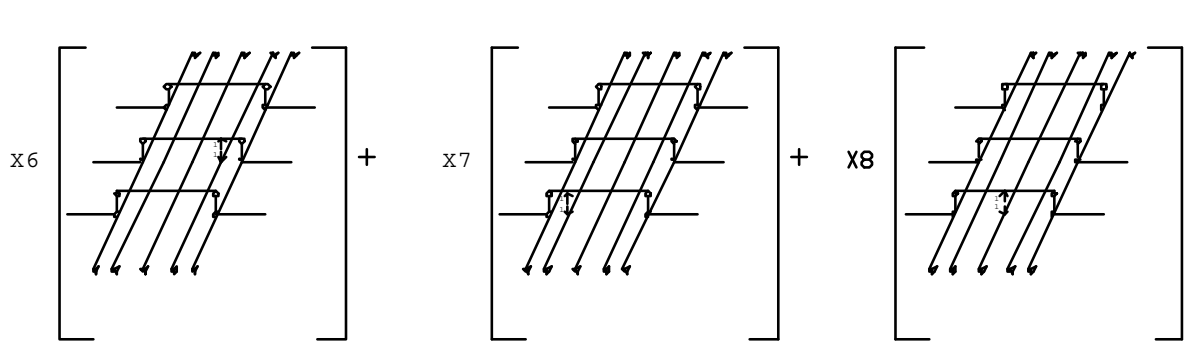

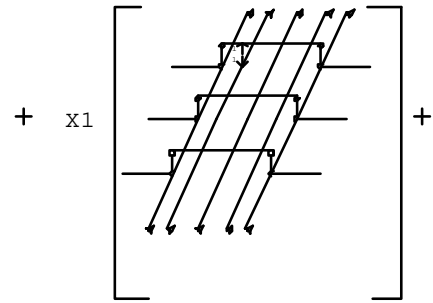

(1)

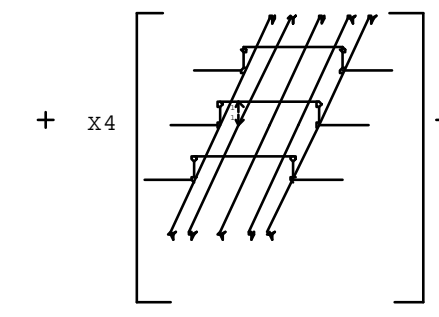

(4)

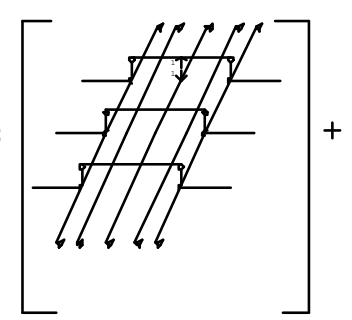

(2)

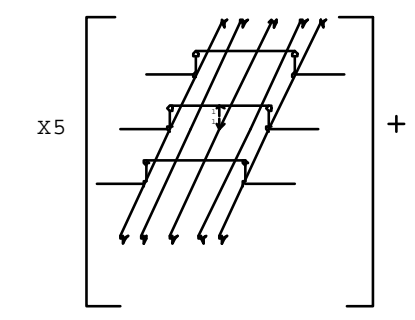

(5)

(7)

(8)

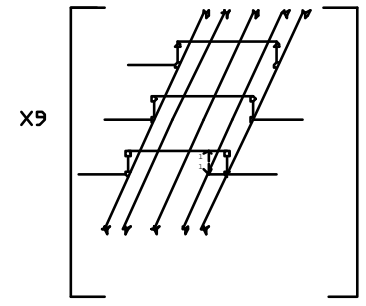

(9)

Figura 53 - Esquema estático da superposição de efeitos, mostrado a carga unitária aplicado a carga unitária aplicada na transversina 2 a $25 \mathrm{~cm}$ da longarina 1 . 


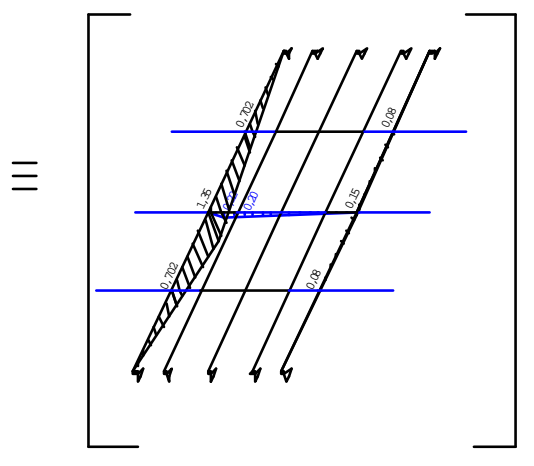

(M0)

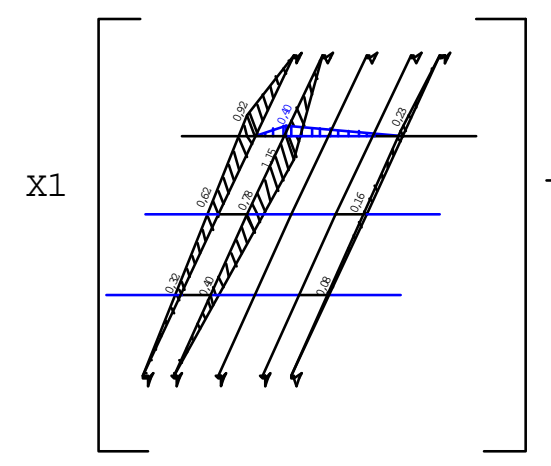

(M1)

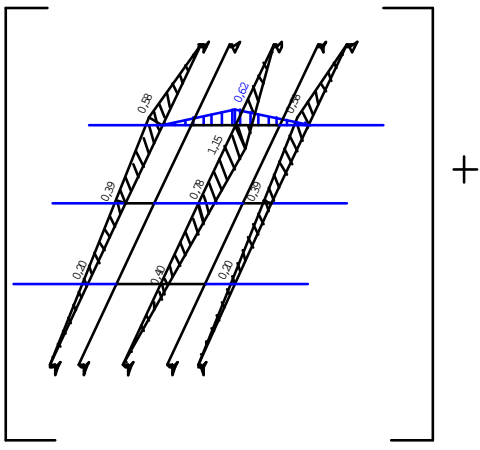

(M2)

Figura 54 - Diagrama de momento para os problemas (0), (1), (2) . 


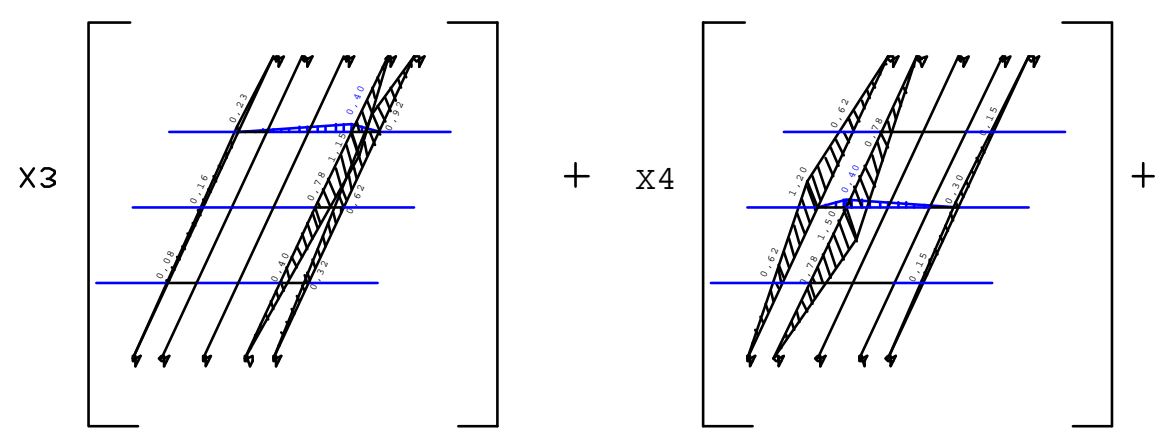

(M3)

(M4)

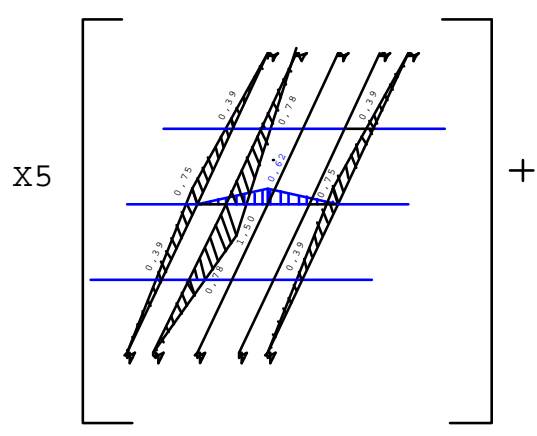

(M5)

Figura 55 - Diagrama de momento para os problemas (3), (4), (5). 


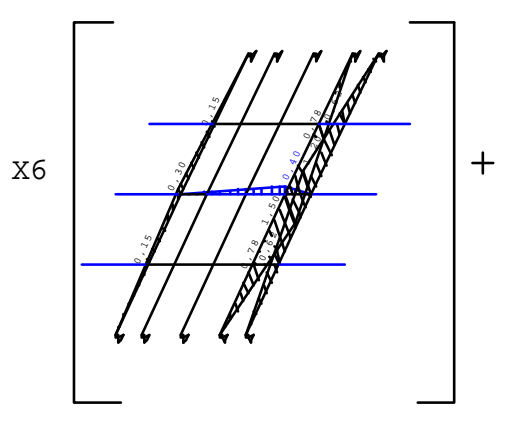

(M6)

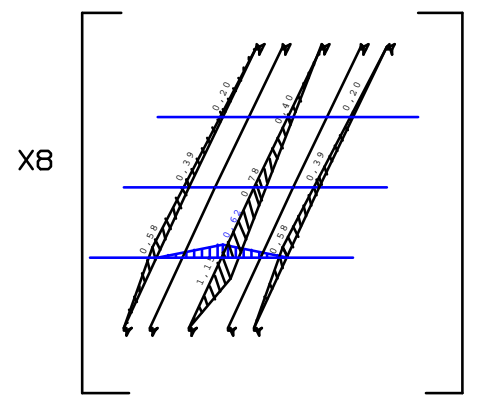

(M8)

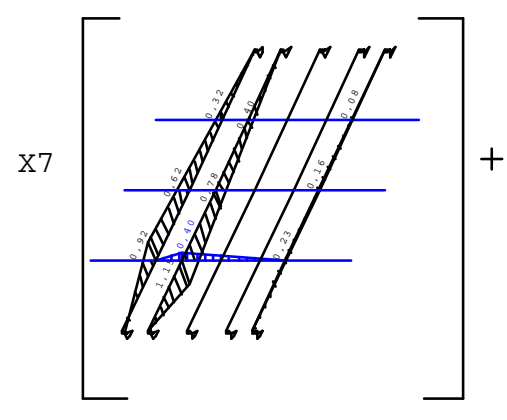

(M4)

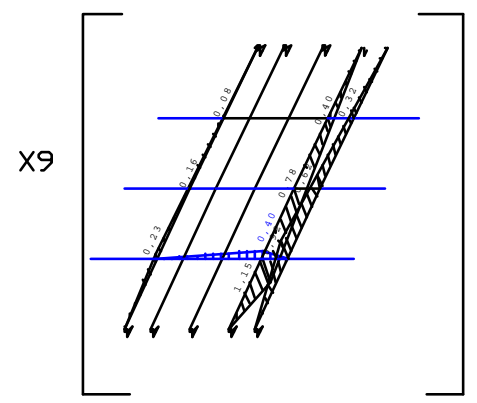

(M9)

Figura 56 - Diagrama de momento para os problemas (6), (7), (8), (9).

Tabela 23. Rigidezes à flexão dos elementos estruturais.

\begin{tabular}{lccc}
\hline Elemento & momento de & módulo de & rigidez à \\
Estrutural & inércia teórico & elasticidade & $\begin{array}{c}\text { flexão } \\
\end{array}$ \\
\hline longarina & 514.457 & $\mathrm{E}=(\mathrm{MPa})$ & $\mathrm{EI}\left(\right.$ daN. $\left.\mathrm{cm}^{2}\right)$ \\
transversina & 40.788 & 12.029 & $\mathrm{EI}_{\mathrm{l}}=12,61 \mathrm{EI}_{\mathrm{t}}$ \\
\hline
\end{tabular}

Portanto para grelha de 3 transversinas idealizada a rigidez à flexão da longarina é 12,61 vezes maior que a rigidez à flexão da transversina. 
$\mathrm{Na}$ Tabela 24 encontram-se os deslocamentos ampliados calculados para grelha de 3 transversinas, de diâmentro médio de $18 \mathrm{~cm}$.

Tabela 24. Deslocamento ampliados da grelha de 3 transversinas calculados no programa desenvolvido numa planilha eletrônica.

\begin{tabular}{lccccccccc}
\hline & long 1 & long 2 & long 3 & long 4 & long 5 & T 1 & T 2 & T 3 & $\Sigma$ \\
\hline$E I_{t} \ddot{A}_{10}$ & $-0,18$ & 0,00 & 0,00 & 0,00 & $-0,01$ & 0,00 & 0,00 & 0,00 & $-0,19$ \\
$E I_{t} \ddot{A}_{20}$ & $-0,11$ & 0,00 & 0,00 & 0,00 & $-0,01$ & 0,00 & 0,00 & 0,00 & $-0,13$ \\
$E I_{t} \ddot{A}_{30}$ & $-0,05$ & 0,00 & 0,00 & 0,00 & $-0,02$ & 0,00 & 0,00 & 0,00 & $-0,07$ \\
$E I_{t} \ddot{A}_{40}$ & $-0,26$ & 0,00 & 0,00 & 0,00 & $-0,01$ & 0,00 & $-0,07$ & 0,00 & $-0,34$ \\
$E I_{t} \ddot{A}_{50}$ & $-0,16$ & 0,00 & 0,00 & 0,00 & $-0,02$ & 0,00 & $-0,10$ & 0,00 & $-0,27$ \\
$E I_{t} \ddot{A}_{60}$ & $-0,06$ & 0,00 & 0,00 & 0,00 & $-0,03$ & 0,00 & $-0,05$ & 0,00 & $-0,14$ \\
$E I_{t} \ddot{A}_{70}$ & $-0,06$ & 0,00 & 0,00 & 0,00 & $-0,03$ & 0,00 & 0,00 & 0,00 & $-0,09$ \\
$E I_{t} \ddot{A}_{80}$ & $-0,18$ & 0,00 & 0,00 & 0,00 & $-0,01$ & 0,00 & 0,00 & 0,00 & $-0,19$ \\
$E I_{t} \ddot{A}_{90}$ & $-0,11$ & 0,00 & 0,00 & 0,00 & $-0,01$ & 0,00 & 0,00 & 0,00 & $-0,13$ \\
$E I_{t} \ddot{a}_{11}$ & 0,14 & 0,21 & 0,00 & 0,00 & 0,01 & 0,13 & 0,00 & 0,00 & 0,49 \\
$E I_{t} \ddot{a}_{12}$ & 0,08 & 0,00 & 0,00 & 0,00 & 0,02 & 0,18 & 0,00 & 0,00 & 0,29 \\
$E I_{t} \ddot{a}_{13}$ & 0,03 & 0,00 & 0,00 & 0,00 & 0,03 & 0,10 & 0,00 & 0,00 & 0,16 \\
$E I_{t} \ddot{a}_{14}$ & 0,16 & 0,25 & 0,00 & 0,00 & 0,01 & 0,00 & 0,00 & 0,00 & 0,43 \\
$E I_{t} \ddot{a}_{15}$ & 0,10 & 0,00 & 0,00 & 0,00 & 0,03 & 0,00 & 0,00 & 0,00 & 0,13 \\
$E I_{t} \ddot{a}_{16}$ & 0,04 & 0,00 & 0,00 & 0,00 & 0,04 & 0,00 & 0,00 & 0,00 & 0,08 \\
$E I_{t} \ddot{a}_{17}$ & 0,11 & 0,17 & 0,00 & 0,00 & 0,01 & 0,00 & 0,00 & 0,00 & 0,28 \\
$E I_{t} \ddot{a}_{18}$ & 0,07 & 0,00 & 0,00 & 0,00 & 0,02 & 0,00 & 0,00 & 0,00 & 0,08 \\
$E I_{t} \ddot{a}_{19}$ & 0,03 & 0,00 & 0,00 & 0,00 & 0,03 & 0,00 & 0,00 & 0,00 & 0,05 \\
$E I_{t} \ddot{a}_{22}$ & 0,05 & 0,00 & 0,21 & 0,00 & 0,05 & 0,33 & 0,00 & 0,00 & 0,64 \\
$E I_{t} \ddot{a}_{23}$ & 0,02 & 0,00 & 0,00 & 0,00 & 0,08 & 0,18 & 0,00 & 0,00 & 0,29 \\
$E I_{t} \ddot{a}_{24}$ & 0,10 & 0,00 & 0,00 & 0,00 & 0,03 & 0,00 & 0,00 & 0,00 & 0,13 \\
$E I_{t} \ddot{a}_{25}$ & 0,06 & 0,00 & 0,25 & 0,00 & 0,06 & 0,00 & 0,00 & 0,00 & 0,38 \\
$E I_{t} \ddot{a}_{26}$ & 0,03 & 0,00 & 0,00 & 0,00 & 0,10 & 0,00 & 0,00 & 0,00 & 0,13 \\
$E I_{t} \ddot{a}_{27}$ & 0,07 & 0,00 & 0,00 & 0,00 & 0,02 & 0,00 & 0,00 & 0,00 & 0,08
\end{tabular}


Tabela 24. Deslocamento ampliados da grelha de 3 transversinas calculados no programa desenvolvido numa planilha eletrônica.

\begin{tabular}{|c|c|c|c|c|c|c|c|c|c|}
\hline & long 1 & long 2 & long 3 & long 4 & long 5 & T 1 & T 2 & T 3 & $\Sigma$ \\
\hline$E I_{t} \ddot{a}_{28}$ & 0,04 & 0,00 & 0,17 & 0,00 & 0,04 & 0,00 & 0,00 & 0,00 & 0,25 \\
\hline$E I_{t} \ddot{a}_{29}$ & 0,02 & 0,00 & 0,00 & 0,00 & 0,07 & 0,00 & 0,00 & 0,00 & 0,08 \\
\hline$E I_{t} \ddot{a}_{33}$ & 0,01 & 0,00 & 0,00 & 0,21 & 0,14 & 0,13 & 0,00 & 0,00 & 0,49 \\
\hline$E I_{t} \ddot{a}_{34}$ & 0,04 & 0,00 & 0,00 & 0,00 & 0,04 & 0,00 & 0,00 & 0,00 & 0,08 \\
\hline$E I_{t} \ddot{a}_{35}$ & 0,03 & 0,00 & 0,00 & 0,00 & 0,10 & 0,00 & 0,00 & 0,00 & 0,13 \\
\hline$E I_{t} \ddot{a}_{36}$ & 0,01 & 0,00 & 0,00 & 0,25 & 0,16 & 0,00 & 0,00 & 0,00 & 0,43 \\
\hline$E I_{t} \ddot{a}_{37}$ & 0,03 & 0,00 & 0,00 & 0,00 & 0,03 & 0,00 & 0,00 & 0,00 & 0,07 \\
\hline$E I_{t} \ddot{a ̈}_{38}$ & 0,02 & 0,00 & 0,00 & 0,00 & 0,08 & 0,00 & 0,00 & 0,00 & 0,11 \\
\hline $\mathrm{EI}_{t} \ddot{a}_{39}$ & 0,01 & 0,00 & 0,00 & 0,21 & 0,14 & 0,00 & 0,00 & 0,00 & 0,35 \\
\hline$E I_{t} \ddot{a}_{44}$ & 0,23 & 0,36 & 0,00 & 0,00 & 0,01 & 0,00 & 0,13 & 0,00 & 0,73 \\
\hline$E I_{t} \ddot{a}_{45}$ & 0,14 & 0,00 & 0,00 & 0,00 & 0,04 & 0,00 & 0,18 & 0,00 & 0,36 \\
\hline$E I_{t} \ddot{a}_{46}$ & 0,06 & 0,00 & 0,00 & 0,00 & 0,06 & 0,00 & 0,10 & 0,00 & 0,21 \\
\hline$E I_{t} \ddot{a}_{47}$ & 0,16 & 0,25 & 0,00 & 0,00 & 0,01 & 0,00 & 0,00 & 0,00 & 0,43 \\
\hline$E I_{t} \ddot{a}_{48}$ & 0,10 & 0,00 & 0,00 & 0,00 & 0,03 & 0,00 & 0,00 & 0,00 & 0,13 \\
\hline$E I_{t} \ddot{a}_{49}$ & 0,04 & 0,00 & 0,00 & 0,00 & 0,04 & 0,00 & 0,00 & 0,00 & 0,08 \\
\hline$E I_{t} \ddot{a}_{55}$ & 0,09 & 0,00 & 0,36 & 0,00 & 0,09 & 0,00 & 0,33 & 0,00 & 0,86 \\
\hline$E I_{t} \ddot{a}_{56}$ & 0,04 & 0,00 & 0,00 & 0,00 & 0,14 & 0,00 & 0,18 & 0,00 & 0,36 \\
\hline$E I_{t} \ddot{a}_{57}$ & 0,10 & 0,00 & 0,00 & 0,00 & 0,03 & 0,00 & 0,00 & 0,00 & 0,13 \\
\hline$E I_{t} \ddot{a}_{58}$ & 0,06 & 0,00 & 0,25 & 0,00 & 0,06 & 0,00 & 0,00 & 0,00 & 0,38 \\
\hline$E I_{t} \ddot{a ̈}_{59}$ & 0,03 & 0,00 & 0,00 & 0,00 & 0,10 & 0,00 & 0,00 & 0,00 & 0,13 \\
\hline$E I_{t} \ddot{a}_{6 \sigma}$ & 0,01 & 0,00 & 0,00 & 0,36 & 0,23 & 0,00 & 0,13 & 0,00 & 0,73 \\
\hline$E I_{t} \ddot{a}_{67}$ & 0,04 & 0,00 & 0,00 & 0,00 & 0,04 & 0,00 & 0,00 & 0,00 & 0,08 \\
\hline$E I_{t} \ddot{a}_{68}$ & 0,03 & 0,00 & 0,00 & 0,00 & 0,10 & 0,00 & 0,00 & 0,00 & 0,13 \\
\hline$E I_{t} \ddot{a}_{69}$ & 0,01 & 0,00 & 0,00 & 0,25 & 0,16 & 0,00 & 0,00 & 0,00 & 0,43 \\
\hline$E I_{t} \ddot{a}_{77}$ & 0,14 & 0,21 & 0,00 & 0,00 & 0,01 & 0,00 & 0,00 & 0,13 & 0,49 \\
\hline$E I_{t} \ddot{a}_{78}$ & 0,08 & 0,00 & 0,00 & 0,00 & 0,02 & 0,00 & 0,00 & 0,18 & 0,29 \\
\hline$E I_{t} \ddot{a}_{79}$ & 0,03 & 0,00 & 0,00 & 0,00 & 0,03 & 0,00 & 0,00 & 0,10 & 0,16 \\
\hline$E I_{t} \ddot{a}_{88}$ & 0,05 & 0,00 & 0,21 & 0,00 & 0,05 & 0,00 & 0,00 & 0,33 & 0,64 \\
\hline$E I_{t} \ddot{a}_{89}$ & 0,02 & 0,00 & 0,00 & 0,00 & 0,08 & 0,00 & 0,00 & 0,18 & 0,29 \\
\hline$E I_{t} \ddot{a}_{99}$ & 0,01 & 0,00 & 0,00 & 0,21 & 0,14 & 0,00 & 0,00 & 0,13 & 0,49 \\
\hline
\end{tabular}


Com os deslocamentos calculados, obtém-se os valores de $x 1, x 2, x 3, x_{4}, x_{5}, x_{6}, x_{7}, x_{8}$ e $x 9$.

Substituindo-se os dados da última coluna desta Tabela nas equações (48), aplicadas para 9 incógnitas e resolvendo-se o sistema obtido pelo programa desenvolvido, obtiveram-se os valores de $\times 1$ a $x 9$ que eram as incógnitas procuradas (Tabela 25). Na Tabela 26 estão os momentos resultantes calculados em 3 posições das longarinas e na Tabela 27 estão os esforços cortantes calculados em 4 posições das transversinas.

Tabela 26. Momentos resultantes calculados nas 3 posições do carregamento do trem-tipo nas longarinas.

\begin{tabular}{|c|c|c|c|c|c|c|c|c|c|c|c|c|c|c|c|}
\hline \multicolumn{16}{|c|}{ Longarinas } \\
\hline & L1 & L1 & L1 & L2 & L2 & L2 & L3 & L3 & L3 & L4 & L4 & L4 & L5 & L5 & L5 \\
\hline * & 1,56 & 3,00 & 4,44 & 1,56 & 3,00 & 4,44 & 1,56 & 3,00 & 4,44 & 1,56 & 3,00 & 4,44 & 1,56 & 3,00 & 4,44 \\
\hline MO & 0,70 & 1,35 & 0,70 & 0,00 & 0,00 & 0,00 & 0,00 & 0,00 & 0,00 & 0,00 & 0,00 & 0,00 & 0,08 & 0,15 & 0,08 \\
\hline $\mathrm{x} 1 \mathrm{M} 1$ & 0,06 & 0,11 & 0,16 & $-0,07$ & $-0,14$ & $-0,21$ & 0,00 & 0,00 & 0,00 & 0,00 & 0,00 & 0,00 & 0,01 & 0,03 & 0,04 \\
\hline $\mathrm{x} 2 \mathrm{M} 2$ & $-0,07$ & $-0,13$ & $-0,20$ & 0,00 & 0,00 & 0,00 & 0,14 & 0,27 & 0,39 & 0,00 & 0,00 & 0,00 & $-0,07$ & $-0,13$ & $-0,20$ \\
\hline x3M3 & 0,03 & 0,06 & 0,10 & 0,00 & 0,00 & 0,00 & 0,00 & 0,00 & 0,00 & $-0,17$ & $-0,32$ & $-0,47$ & 0,13 & 0,26 & 0,38 \\
\hline$x 4 M 4$ & $-0,96$ & $-1,85$ & $-0,96$ & 1,20 & 2,31 & 1,20 & 0,00 & 0,00 & 0,00 & 0,00 & 0,00 & 0,00 & $-0,24$ & $-0,46$ & $-0,24$ \\
\hline x5M5 & 0,23 & 0,43 & 0,23 & 0,00 & 0,00 & 0,00 & $-0,45$ & $-0,87$ & $-0,45$ & 0,00 & 0,00 & 0,00 & 0,23 & 0,43 & 0,23 \\
\hline $\mathrm{x} 6 \mathrm{M} 6$ & 0,00 & 0,00 & 0,00 & 0,00 & 0,00 & 0,00 & 0,00 & 0,00 & 0,00 & 0,00 & 0,00 & 0,00 & 0,00 & 0,00 & 0,00 \\
\hline$\times 7 M 7$ & 1,42 & 0,96 & 0,50 & $-1,77$ & $-1,20$ & $-0,62$ & 0,00 & 0,00 & 0,00 & 0,00 & 0,00 & 0,00 & 0,35 & 0,24 & 0,12 \\
\hline x 8M8 & $-0,44$ & $-0,30$ & $-0,16$ & 0,00 & 0,00 & 0,00 & 0,89 & 0,60 & 0,31 & 0,00 & 0,00 & 0,00 & $-0,44$ & $-0,30$ & $-0,16$ \\
\hline x9M9 & $-0,11$ & $-0,07$ & $-0,04$ & 0,00 & 0,00 & 0,00 & 0,00 & 0,00 & 0,00 & 0,54 & 0,37 & 0,19 & $-0,43$ & $-0,29$ & $-0,15$ \\
\hline $\mathrm{Mr}$ & 0,85 & 0,56 & 0,33 & $-0,64$ & 0,98 & 0,38 & 0,57 & 0,00 & 0,25 & 0,38 & 0,05 & $-0,28$ & $-0,38$ & $-0,08$ & 0,10 \\
\hline
\end{tabular}

* distância do apoio, em metros. 
Tabela 27. Esforços cortantes em 4 posições das transversinas.

\begin{tabular}{|c|c|c|c|c|c|c|c|c|c|c|c|c|}
\hline \multicolumn{13}{|c|}{ Longarinas } \\
\hline & $\mathrm{T} 1$ & $\mathrm{~T} 1$ & $\mathrm{~T} 1$ & $\mathrm{~T} 1$ & $\mathrm{~T} 2$ & $\mathrm{~T} 2$ & $\mathrm{~T} 2$ & $\mathrm{~T} 2$ & T3 & T3 & T3 & T3 \\
\hline & 0,25 & 0,50 & 1,25 & 2,00 & 0,25 & 0,50 & 1,25 & 2,00 & 0,25 & 0,50 & 1,25 & 2,00 \\
\hline $\mathrm{MO}$ & 0,00 & 0,00 & 0,00 & 0,00 & 0,23 & 0,20 & 0,13 & 0,05 & 0,00 & 0,00 & 0,00 & 0,00 \\
\hline $\mathrm{x} 1 \mathrm{M} 1$ & 0,04 & 0,07 & 0,04 & 0,02 & 0,00 & 0,00 & 0,00 & 0,00 & 0,00 & 0,00 & 0,00 & 0,00 \\
\hline $\mathrm{x} 2 \mathrm{M} 2$ & $-0,04$ & $-0,09$ & $-0,21$ & $-0,09$ & 0,00 & 0,00 & 0,00 & 0,00 & 0,00 & 0,00 & 0,00 & 0,00 \\
\hline$\times 3 M 3$ & 0,02 & 0,04 & 0,10 & 0,16 & 0,00 & 0,00 & 0,00 & 0,00 & 0,00 & 0,00 & 0,00 & 0,00 \\
\hline $\mathrm{x} 4 \mathrm{M} 4$ & 0,00 & 0,00 & 0,00 & 0,00 & $-0,31$ & $-0,62$ & $-0,39$ & $-0,15$ & 0,00 & 0,00 & 0,00 & 0,00 \\
\hline x5M5 & 0,00 & 0,00 & 0,00 & 0,00 & 0,07 & 0,14 & 0,36 & 0,14 & 0,00 & 0,00 & 0,00 & 0,00 \\
\hline $\mathrm{x} 6 \mathrm{M} 6$ & 0,00 & 0,00 & 0,00 & 0,00 & 0,00 & 0,00 & 0,00 & 0,00 & 0,00 & 0,00 & 0,00 & 0,00 \\
\hline$\times 7 M 7$ & 0,00 & 0,00 & 0,00 & 0,00 & 0,00 & 0,00 & 0,00 & 0,00 & 0,31 & 0,61 & 0,38 & 0,15 \\
\hline x 8M8 & 0,00 & 0,00 & 0,00 & 0,00 & 0,00 & 0,00 & 0,00 & 0,00 & $-0,10$ & $-0,19$ & $-0,48$ & $-0,19$ \\
\hline x9M9 & 0,00 & 0,00 & 0,00 & 0,00 & 0,00 & 0,00 & 0,00 & 0,00 & $-0,02$ & $-0,05$ & $-0,12$ & $-0,19$ \\
\hline $\mathrm{Mr}$ & 0,01 & 0,03 & $-0,07$ & 0,10 & $-0,01$ & $-0,27$ & 0,10 & 0,04 & 0,19 & 0,37 & $-0,21$ & $-0,23$ \\
\hline
\end{tabular}

* distância do apoio, em metros.

A Figura 57 mostra os diagramas de momentos e cortantes resultantes na grelha de três transversinas idealizadas e carga unitária na transversina central a 25 cm da longarina 1. A Figura 58 mostra os diagramas de momentos cortantes da mesma estrutura e para o mesmo carregamento, calculados pelo programa SAP 90. Os resultados obtidos são praticamente os mesmos da Figura 57, calculados pelo programa simplificado desenvolvido no presente trabalho. 
Tabela 25. Valores de $\mathrm{x} 1$ a $x 9$ calculados no programa desenvolvido pelo método de Gauss

\begin{tabular}{|c|c|c|c|c|c|c|c|c|c|c|c|c|c|c|c|c|c|c|c|c|c|}
\hline $\mathrm{X1}$ & $\mathrm{x} 2$ & $\mathrm{x} 3$ & $\mathrm{x} 4$ & $\mathrm{x} 5$ & $\mathrm{X} 6$ & X7 & $\mathrm{X} 8$ & X9 & $\overline{\mathrm{A}}$ & & & & & & & & & & & & \\
\hline 0,488 & 0,291 & 0,164 & 0,425 & 0,127 & 0,081 & 0,280 & 0,083 & 0,053 & $-0,187$ & $\mathrm{X1}$ & 0,187 & $-0,025$ & $-0,064$ & 0,430 & 0,000 & 0,073 & $-0,656$ & 0,067 & $-0,099$ & $-0,087$ & $-0,178$ \\
\hline 0,291 & 0,643 & 0,291 & 0,127 & 0,380 & 0,127 & 0,083 & 0,250 & 0,083 & $-0,127$ & $\mathrm{x} 1$ & 0,127 & $-0,039$ & $-0,192$ & 0,128 & 0,000 & 0,220 & $-0,196$ & 0,120 & $-0,219$ & $-0,052$ & $-0,178$ \\
\hline 0,164 & 0,291 & 0,488 & 0,081 & 0,127 & 0,425 & 0,068 & 0,106 & 0,355 & $-0,066$ & $\mathrm{x} 1$ & 0,066 & $-0,166$ & $-0,081$ & 0,104 & $-0,001$ & 0,073 & $-0,125$ & 0,201 & $-0,099$ & $-0,029$ & $-0,178$ \\
\hline 0,425 & 0,127 & 0,081 & 0,733 & 0,363 & 0,210 & 0,425 & 0,127 & 0,081 & $-0,337$ & $\mathrm{x} 1$ & 0,337 & $-0,038$ & $-0,098$ & 0,653 & $-0,001$ & 0,210 & $-1,130$ & 0,033 & $-0,043$ & $-0,076$ & $-0,178$ \\
\hline 0,127 & 0,380 & 0,127 & 0,363 & 0,861 & 0,363 & 0,127 & 0,380 & 0,127 & $-0,275$ & $\mathrm{x} 1$ & 0,275 & $-0,059$ & $-0,292$ & 0,194 & $-0,001$ & 0,499 & $-0,561$ & 0,052 & $-0,129$ & $-0,023$ & $-0,178$ \\
\hline 0,081 & 0,127 & 0,425 & 0,210 & 0,363 & 0,733 & 0,081 & 0,127 & 0,425 & $-0,142$ & $\mathrm{X} 1$ & 0,142 & $-0,200$ & $-0,098$ & 0,124 & $-0,002$ & 0,210 & $-0,324$ & 0,175 & $-0,043$ & $-0,014$ & $-0,178$ \\
\hline 0,280 & 0,083 & 0,068 & 0,425 & 0,127 & 0,081 & 0,488 & 0,291 & 0,164 & $-0,085$ & $\mathrm{x} 1$ & 0,085 & $-0,077$ & $-0,223$ & 0,749 & 0,000 & 0,073 & $-0,656$ & 0,028 & $-0,028$ & $-0,050$ & $-0,178$ \\
\hline 0,083 & 0,250 & 0,106 & 0,127 & 0,380 & 0,127 & 0,291 & 0,643 & 0,291 & $-0,187$ & $\mathrm{x} 1$ & 0,187 & $-0,136$ & $-0,494$ & 0,446 & 0,000 & 0,220 & $-0,196$ & 0,044 & $-0,085$ & $-0,015$ & $-0,178$ \\
\hline \multirow[t]{37}{*}{0,053} & 0,083 & 0,355 & 0,081 & 0,127 & 0,425 & 0,164 & 0,291 & 0,488 & $-0,127$ & $\mathrm{x} 1$ & 0,127 & $-0,229$ & $-0,223$ & 0,251 & $-0,001$ & 0,073 & $-0,125$ & 0,146 & $-0,028$ & $-0,010$ & $-0,178$ \\
\hline & 0,229 & 0,094 & $-0,062$ & 0,149 & 0,038 & $-0,041$ & 0,098 & 0,025 & $-0,007$ & $\mathrm{x} 2$ & 0,007 & $-0,012$ & $-0,075$ & $-0,062$ & 0,000 & 0,086 & 0,095 & 0,039 & 0,078 & 0,340 & \\
\hline & 0,094 & 0,211 & $-0,030$ & 0,041 & 0,194 & $-0,013$ & 0,038 & 0,164 & $-0,001$ & $\mathrm{x} 2$ & 0,001 & $-0,077$ & $-0,029$ & $-0,020$ & $-0,001$ & 0,024 & 0,046 & 0,087 & 0,032 & 0,340 & \\
\hline & $-0,062$ & $-0,030$ & 0,176 & 0,123 & 0,068 & 0,088 & 0,026 & 0,017 & $-0,085$ & $\mathrm{x} 2$ & 0,085 & $-0,008$ & $-0,020$ & 0,136 & 0,000 & 0,071 & $-0,272$ & $-0,012$ & $-0,021$ & 0,340 & \\
\hline & 0,149 & 0,041 & 0,123 & 0,404 & 0,167 & 0,026 & 0,175 & 0,055 & $-0,110$ & $x 2$ & 0,110 & $-0,026$ & $-0,134$ & 0,040 & 0,000 & 0,234 & $-0,190$ & 0,017 & 0,051 & 0,340 & \\
\hline & 0,038 & 0,194 & 0,068 & 0,167 & 0,351 & 0,017 & 0,055 & 0,203 & $-0,054$ & $\mathrm{x} 2$ & 0,054 & $-0,095$ & $-0,042$ & 0,026 & $-0,001$ & 0,097 & $-0,105$ & 0,080 & 0,013 & 0,340 & \\
\hline & $-0,041$ & $-0,013$ & 0,088 & 0,026 & 0,017 & 0,160 & 0,118 & 0,065 & 0,011 & $\mathrm{x} 2$ & $-0,011$ & $-0,030$ & $-0,091$ & 0,245 & 0,000 & 0,015 & $-0,136$ & $-0,005$ & $-0,014$ & 0,340 & \\
\hline & 0,098 & 0,038 & 0,026 & 0,175 & 0,055 & 0,118 & 0,307 & 0,137 & $-0,076$ & $\mathrm{x} 2$ & 0,076 & $-0,064$ & $-0,236$ & 0,182 & 0,000 & 0,101 & $-0,041$ & 0,016 & 0,033 & 0,340 & \\
\hline & 0,025 & 0,164 & 0,017 & 0,055 & 0,203 & 0,065 & 0,137 & 0,235 & $-0,052$ & $\mathrm{x} 2$ & 0,052 & $-0,110$ & $-0,106$ & 0,100 & $-0,001$ & 0,032 & $-0,026$ & 0,068 & 0,009 & 0,340 & \\
\hline & & 0,040 & $-0,001$ & $-0,005$ & 0,041 & 0,001 & $-0,001$ & 0,035 & 0,000 & x3 & 0,000 & $-0,017$ & 0,000 & 0,001 & 0,000 & $-0,003$ & 0,002 & $-0,016$ & $-0,412$ & & \\
\hline & & $-0,001$ & 0,037 & 0,037 & 0,018 & 0,018 & 0,012 & 0,005 & $-0,020$ & x3 & 0,020 & $-0,003$ & $-0,009$ & 0,027 & 0,000 & 0,022 & $-0,056$ & 0,000 & $-0,412$ & & \\
\hline & & $-0,005$ & 0,037 & 0,071 & 0,033 & 0,012 & 0,026 & 0,009 & $-0,024$ & x3 & 0,024 & $-0,004$ & $-0,020$ & 0,019 & 0,000 & 0,041 & $-0,058$ & 0,002 & $-0,412$ & & \\
\hline & & 0,041 & 0,018 & 0,033 & 0,079 & 0,005 & 0,009 & 0,046 & $-0,012$ & x3 & 0,012 & $-0,021$ & $-0,007$ & 0,008 & 0,000 & 0,019 & $-0,028$ & $-0,017$ & $-0,412$ & & \\
\hline & & 0,001 & 0,018 & 0,012 & 0,005 & 0,035 & 0,031 & 0,016 & 0,002 & x3 & $-0,002$ & $-0,007$ & $-0,024$ & 0,054 & 0,000 & 0,007 & $-0,027$ & 0,000 & $-0,412$ & & \\
\hline & & $-0,001$ & 0,012 & 0,026 & 0,009 & 0,031 & 0,061 & 0,029 & $-0,017$ & x3 & 0,017 & $-0,014$ & $-0,047$ & 0,048 & 0,000 & 0,015 & $-0,019$ & 0,000 & $-0,412$ & & \\
\hline & & 0,035 & 0,005 & 0,009 & 0,046 & 0,016 & 0,029 & 0,053 & $-0,012$ & x3 & 0,012 & $-0,025$ & $-0,022$ & 0,024 & 0,000 & 0,005 & $-0,008$ & $-0,015$ & $-0,412$ & & \\
\hline & & & 0,001 & 0,001 & 0,001 & 0,001 & 0,000 & 0,000 & $-0,001$ & $\mathrm{x} 4$ & 0,001 & 0,000 & 0,000 & 0,001 & 0,000 & 0,001 & 0,002 & 1,543 & & & \\
\hline & & & 0,001 & 0,003 & 0,001 & 0,000 & 0,001 & 0,001 & $-0,001$ & $\mathrm{x} 4$ & 0,001 & 0,000 & $-0,001$ & 0,001 & 0,000 & 0,002 & 0,002 & 1,543 & & & \\
\hline & & & 0,001 & 0,001 & 0,001 & 0,000 & 0,000 & 0,000 & 0,000 & $\mathrm{x} 4$ & 0,000 & 0,000 & 0,000 & 0,000 & 0,000 & 0,001 & 0,001 & 1,543 & & & \\
\hline & & & 0,001 & 0,000 & 0,000 & 0,001 & 0,001 & 0,001 & 0,000 & $\mathrm{x} 4$ & 0,000 & 0,000 & $-0,001$ & 0,002 & 0,000 & 0,000 & 0,001 & 1,543 & & & \\
\hline & & & 0,000 & 0,001 & 0,000 & 0,001 & 0,002 & 0,001 & $-0,001$ & $\mathrm{x} 4$ & 0,001 & $-0,001$ & $-0,002$ & 0,002 & 0,000 & 0,001 & 0,001 & 1,543 & & & \\
\hline & & & 0,000 & 0,001 & 0,000 & 0,001 & 0,001 & 0,001 & 0,000 & $\mathrm{x} 4$ & 0,000 & 0,000 & $-0,001$ & 0,001 & 0,000 & 0,000 & 0,000 & 1,543 & & & \\
\hline & & & & 0,000 & 0,000 & 0,000 & 0,000 & 0,000 & 0,000 & x5 & 0,000 & 0,000 & 0,000 & 0,000 & 0,000 & 0,000 & $-0,579$ & & & & \\
\hline & & & & 0,000 & 0,000 & 0,000 & 0,000 & 0,000 & 0,000 & x5 & 0,000 & 0,000 & 0,000 & 0,000 & 0,000 & 0,000 & $-0,579$ & & & & \\
\hline & & & & 0,000 & 0,000 & 0,000 & 0,000 & 0,000 & 0,000 & $\mathrm{x} 5$ & 0,000 & 0,000 & 0,000 & 0,000 & 0,000 & 0,000 & $-0,579$ & & & & \\
\hline & & & & 0,000 & 0,000 & 0,000 & 0,000 & 0,000 & 0,000 & x5 & 0,000 & 0,000 & 0,000 & 0,000 & 0,000 & 0,000 & $-0,579$ & & & & \\
\hline & & & & 0,000 & 0,000 & 0,000 & 0,000 & 0,000 & 0,000 & x5 & 0,000 & 0,000 & 0,000 & 0,000 & 0,000 & 0,000 & $-0,579$ & & & & \\
\hline & & & & & 0,000 & 0,000 & 0,000 & 0,000 & 0,000 & $\mathrm{x} 6$ & 0,000 & 0,000 & 0,000 & 0,000 & 0,000 & 0,003 & & & & & \\
\hline & & & & & 0,000 & 0,000 & 0,000 & 0,000 & 0,000 & $\mathrm{x} 6$ & 0,000 & 0,000 & 0,000 & 0,000 & 0,000 & 0,003 & & & & & \\
\hline & & & & & 0,000 & 0,000 & 0,000 & 0,000 & 0,000 & $\mathrm{x} 6$ & 0,000 & 0,000 & 0,000 & 0,000 & 0,000 & 0,003 & & & & & \\
\hline & & & & & 0,000 & 0,000 & 0,000 & 0,000 & 0,000 & $\mathrm{x} 6$ & 0,000 & 0,000 & 0,000 & 0,000 & 0,000 & 0,003 & & & & & \\
\hline & & & & & & 0,000 & 0,000 & 0,000 & 0,000 & X7 & 0,000 & 0,000 & 0,000 & 0,000 & $-1,535$ & & & & & & \\
\hline & & & & & & 0,000 & 0,000 & 0,000 & 0,000 & $\mathrm{x} 7$ & 0,000 & 0,000 & 0,000 & 0,000 & $-1,535$ & & & & & & \\
\hline & & & & & & 0,000 & 0,000 & 0,000 & 0,000 & $\mathrm{x} 7$ & 0,000 & 0,000 & 0,000 & 0,000 & $-1,535$ & & & & & & \\
\hline & & & & & & & 0,000 & 0,000 & 0,000 & $\mathrm{x} 8$ & 0,000 & 0,000 & 0,000 & 0,769 & & & & & & & \\
\hline & & & & & & & 0,000 & 0,000 & 0,000 & $\mathrm{x} 8$ & 0,000 & 0,000 & 0,000 & 0,769 & & & & & & & \\
\hline & & & & & & & & 0,000 & 0,000 & $\times 9$ & 0,469 & & & & & & & & & & \\
\hline
\end{tabular}



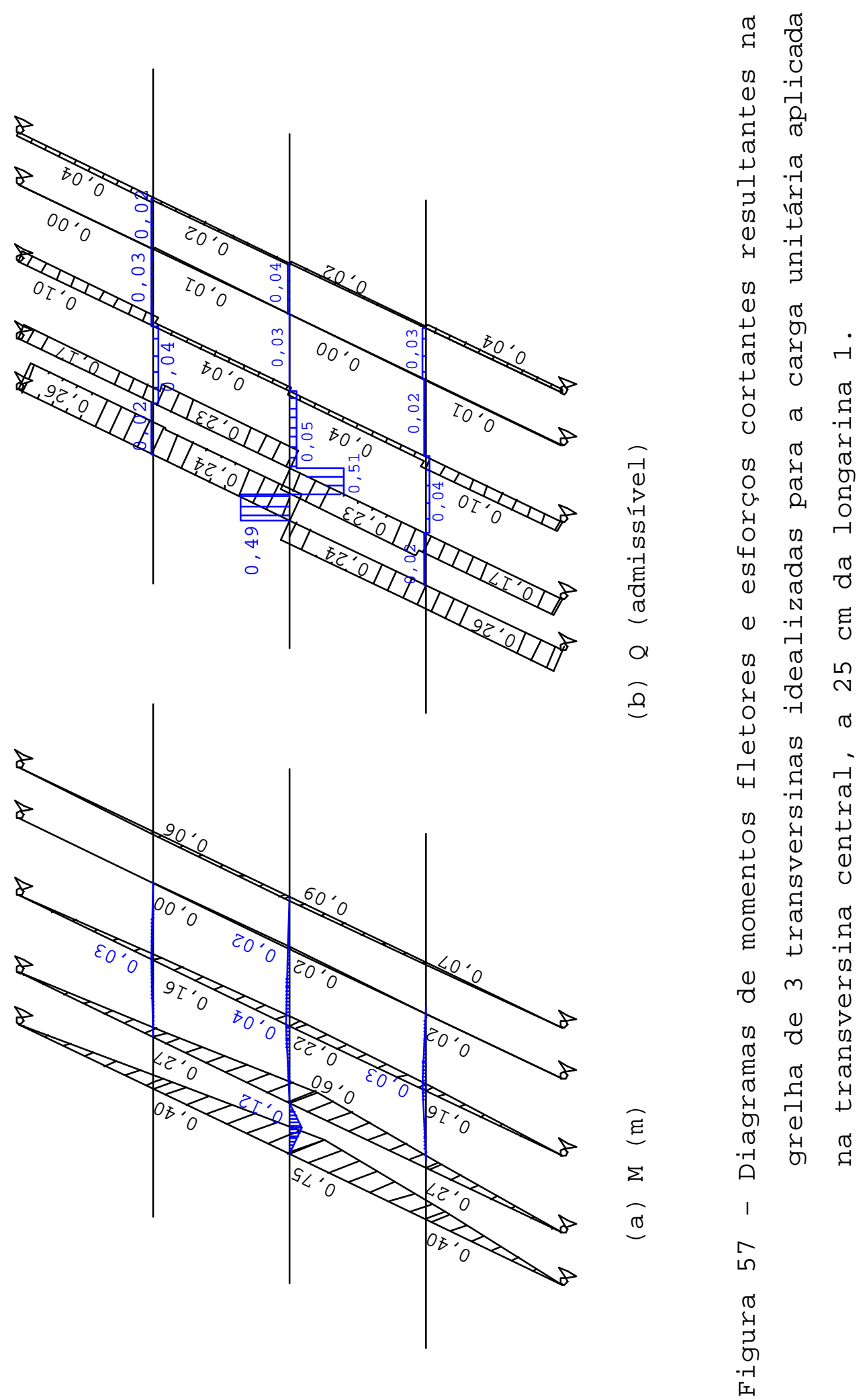


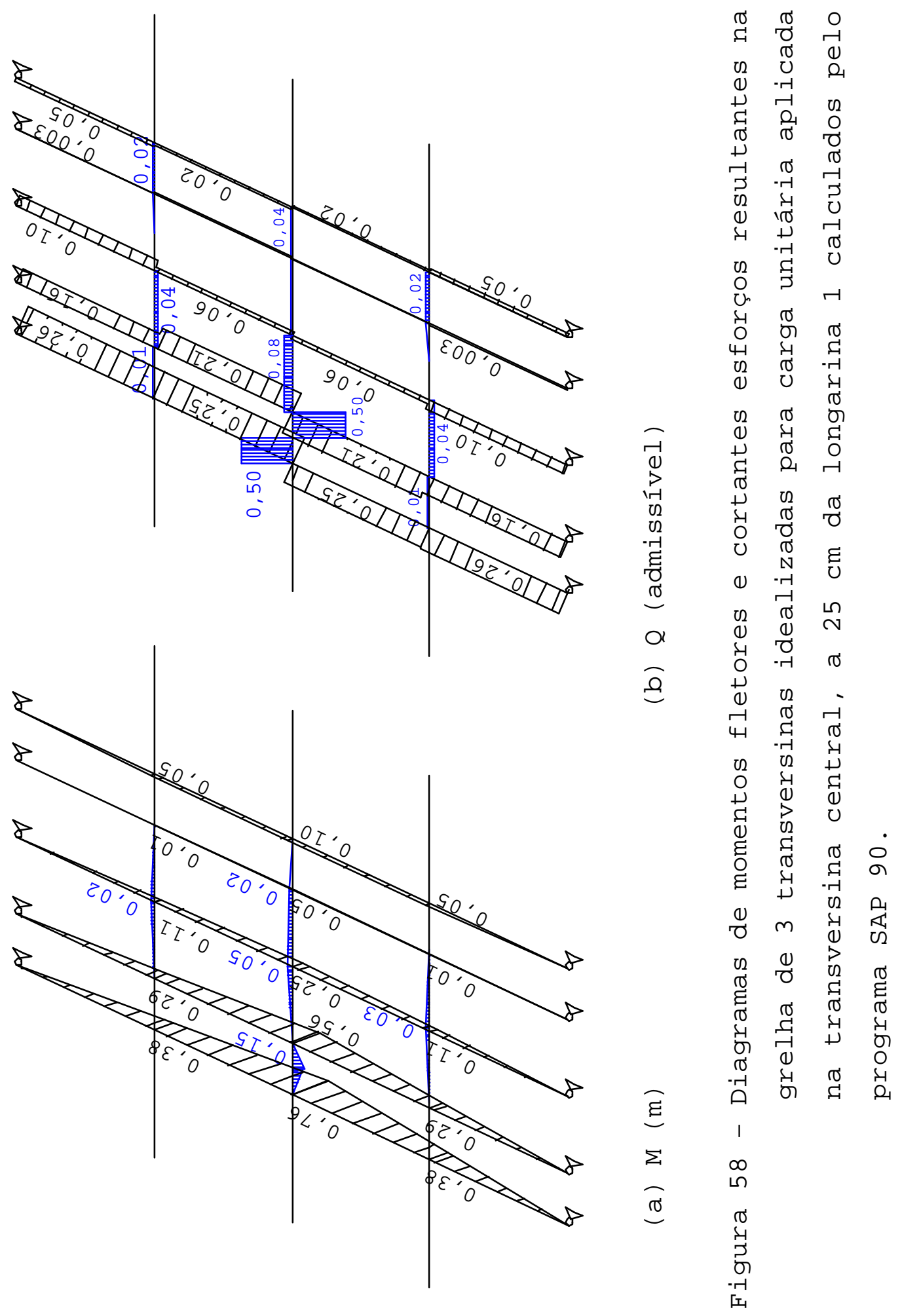




\title{
4.5.3 Grelha completa com 33 transversinas
}

\author{
Para o cálculo da grelha com 33 transversinas \\ utilizou-se o programa SAP 90. Foram calculados os momentos \\ fletores e esforços cortantes de todas as longarinas e de \\ todas as transversinas para cada um dos 7 carregamentos. \\ Cada carregamento consistia da carga unitária posicionada \\ nas posições críticas do trem - tipo, para facilitar a \\ obtenção das linhas de influência. \\ Na Figura 59 mostra o diagrama de momento para a \\ carga unitária aplicada na tranversina T17 a $25 \mathrm{~cm}$ da \\ longarina L1 e na Figura 60 mostra o diagrama de cortante \\ para a carga unitária aplicada na transversina T32 a $25 \mathrm{~cm}$ \\ da longarina L1. \\ Nas Figuras 61 a 65 encontram-se as linhas de \\ influencia necessárias para o cálculo da viga de seção bi- \\ circular, à saber: \\ Na Tabela 26 encontram-se os valores dos esforços \\ solicitantes críticos devido ao trem-tipo obtidos através \\ do programa SAP 90 .
}




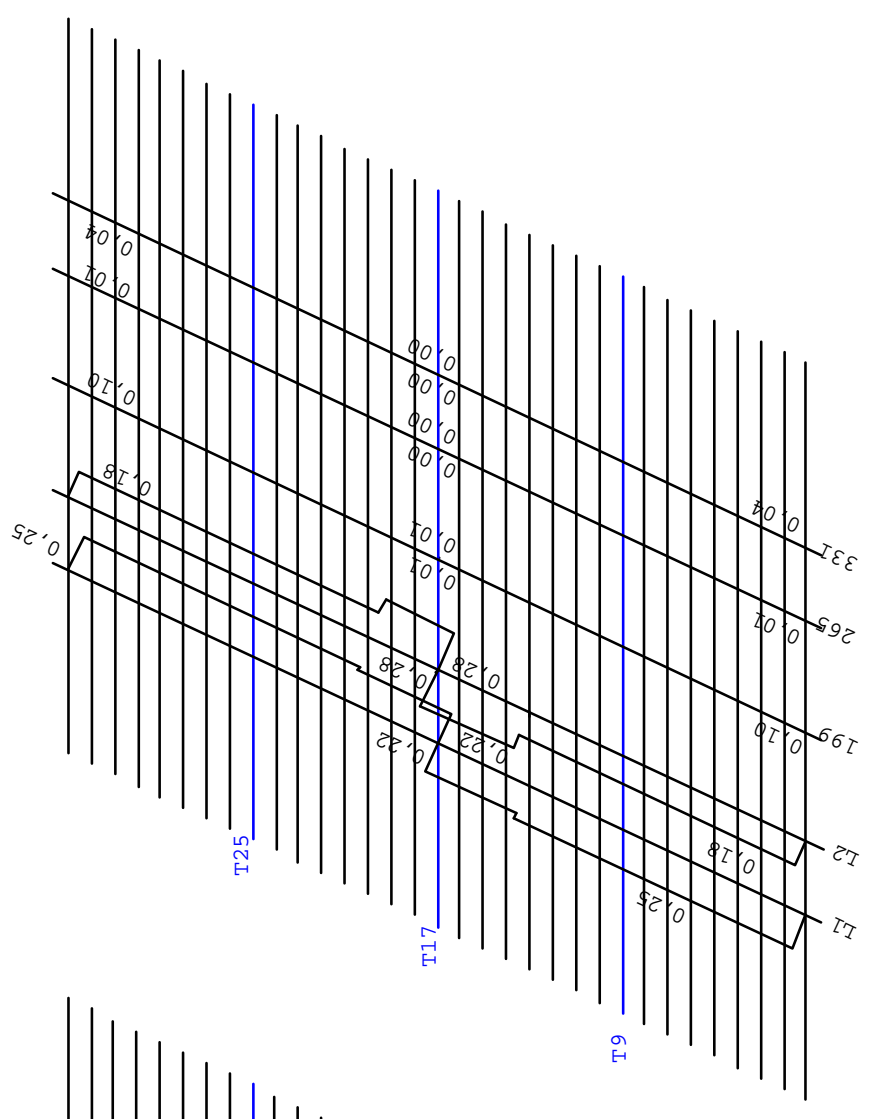

0
+1
0
-1
0
0
0
0
0

$\stackrel{\sigma}{-1}$

c.

ชू

๘

a

$\stackrel{0}{+}$

$+_{-4}^{\pi} \hat{\xi}$

U ।

$\begin{array}{ll}0 & \sum \\ 0 & 1 \\ 0 & 1\end{array}$

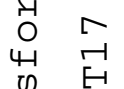

(1)

(1)

$\begin{array}{cc}02 & 0 \\ 0 & 0 \\ 0 & 0 \\ 4 & 0 \\ 0 & 0 \\ + & -7 \\ 0 & -1 \\ 0 & -1 \\ -1 & 0 \\ 4-1 & 0\end{array}$

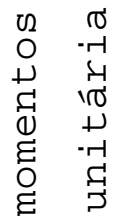

ช)

$\begin{array}{ll}0 & 0 \\ 0 & 0\end{array}$

ह

पु

$\begin{array}{cc}0 & 1 \\ \sigma & 4 \\ -1 & 0 \\ 0 & 0\end{array}$

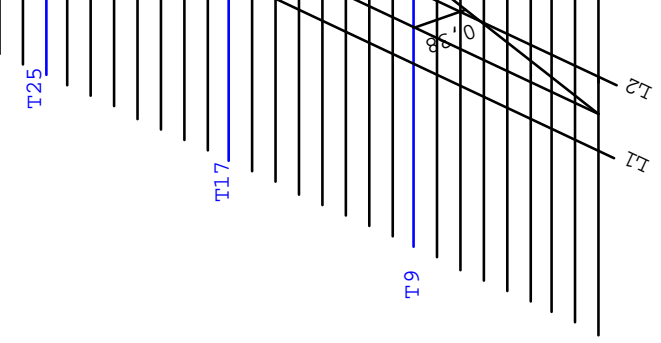

I

ก)

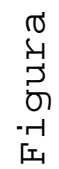




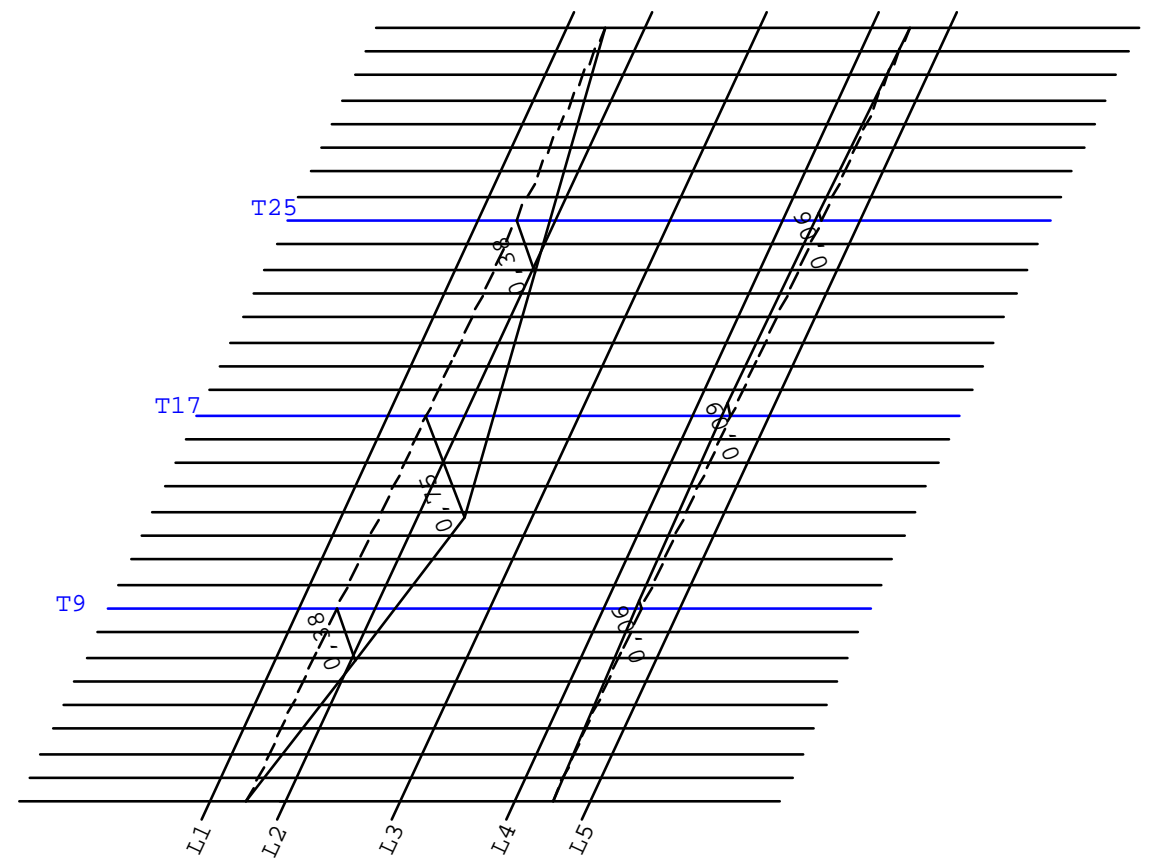

Figura 60 - LI de momento no meio do vão da longarina (L1) mais solicitada $(M-m)$.

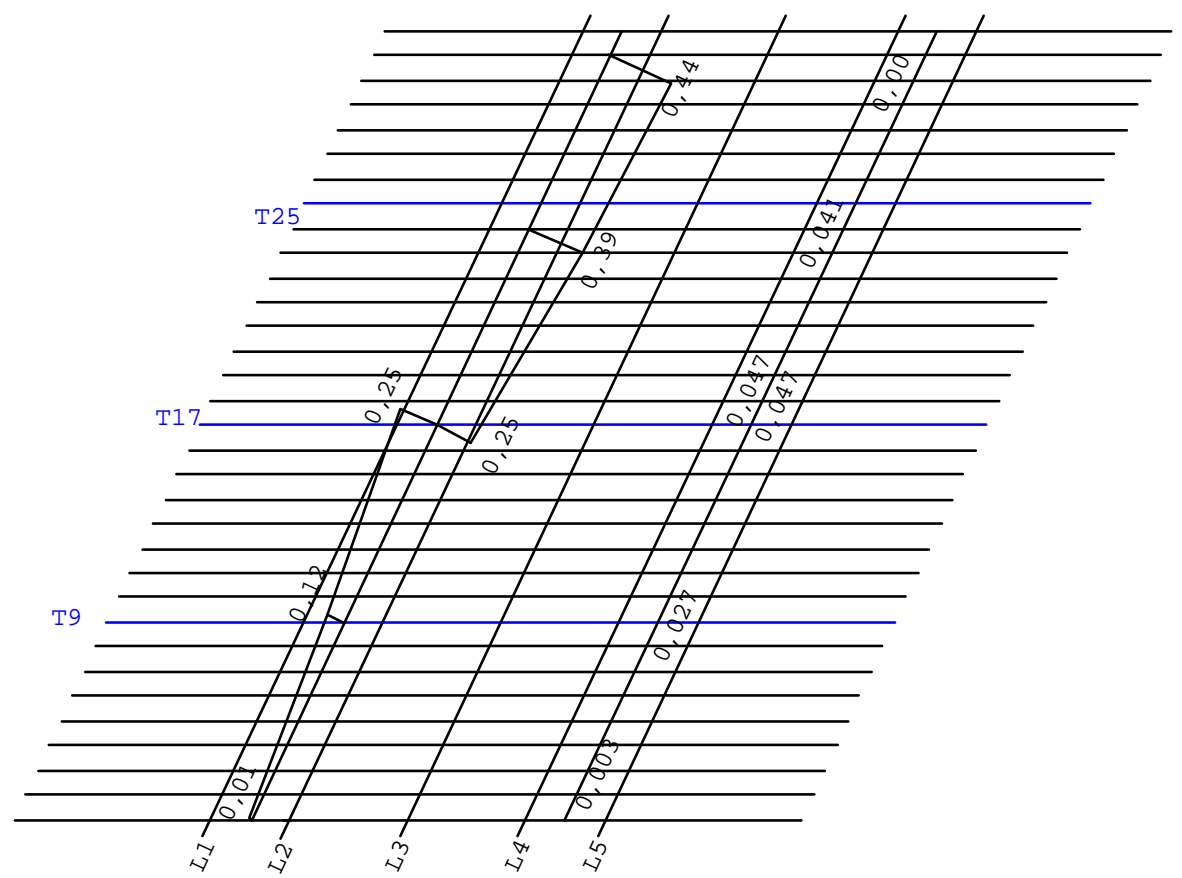

Figura 60 - LI de cortante na seção do apoio longarina (L1) (Q - admissível). 


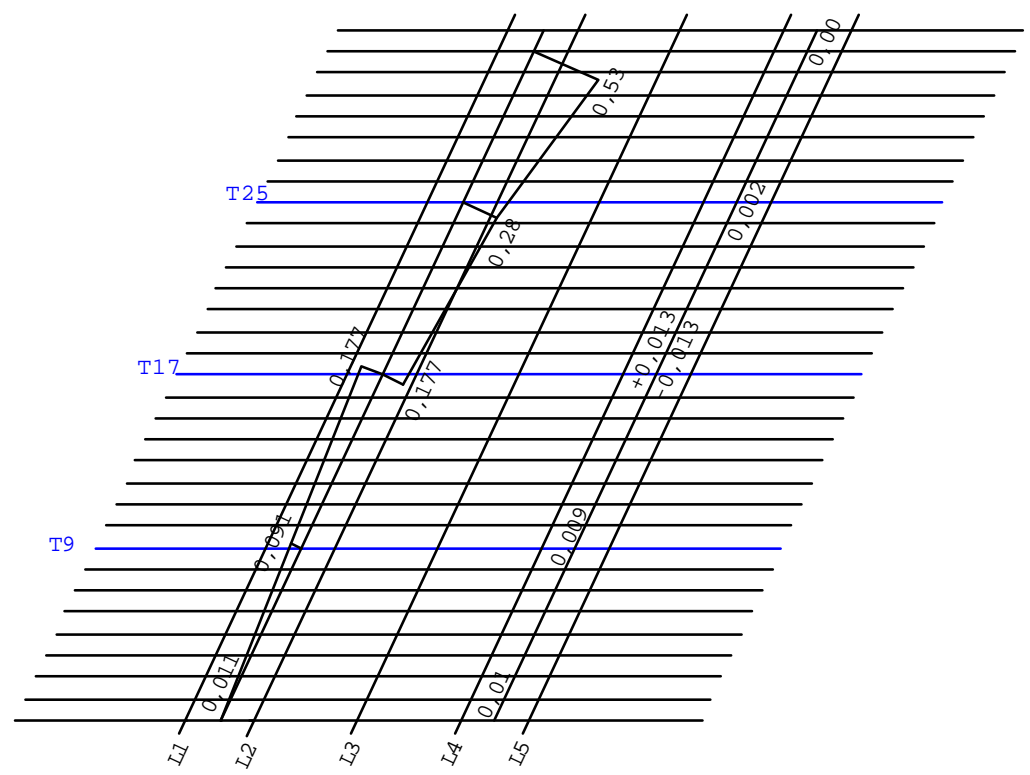

Figura 62 - LI de cortante na seção do apoio da longarina L2 (Q-admissível).

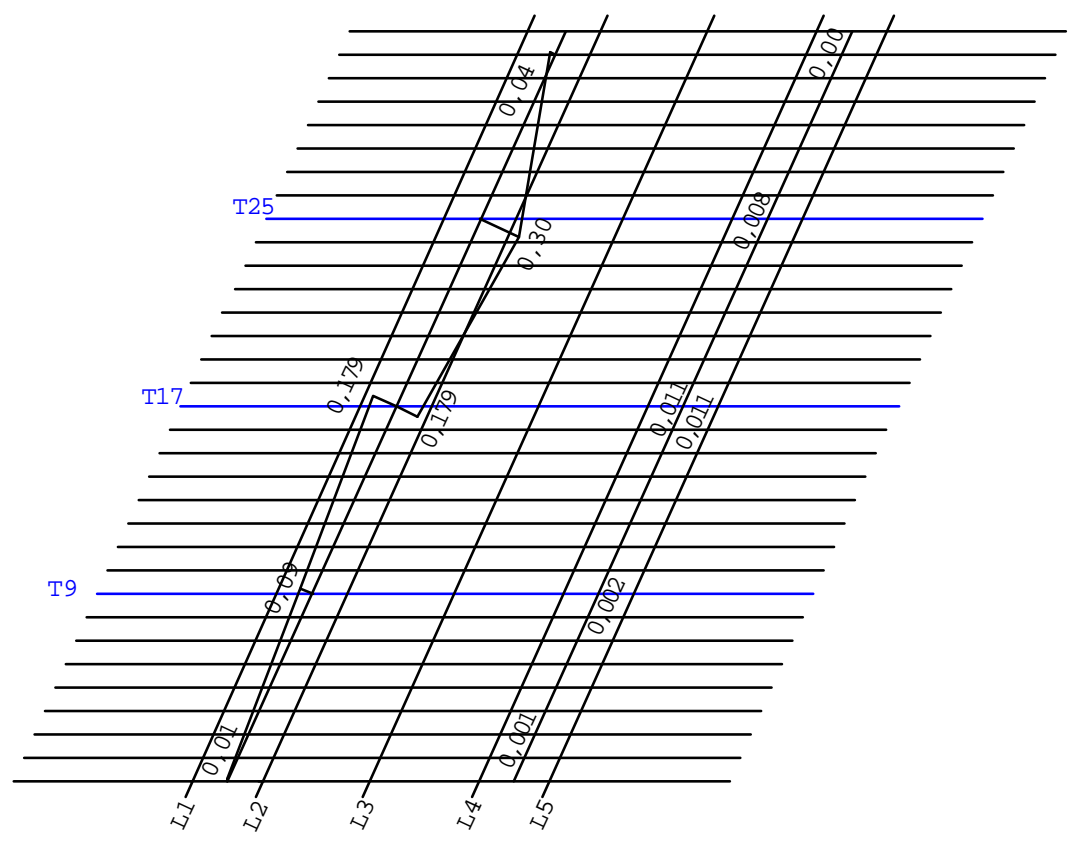

Figura 63 - LI de cortante a 1,0 m do apoio da longarina L2 (Q-admissível). 


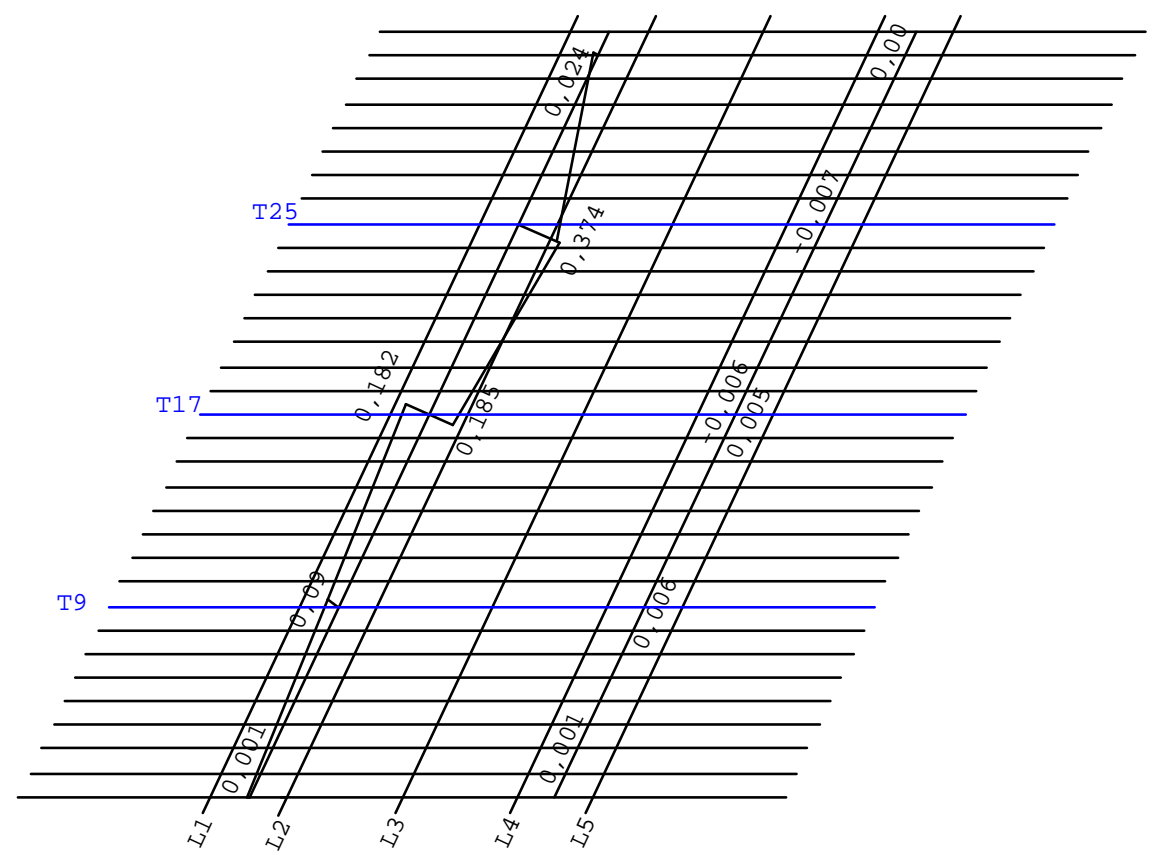

Figura 64 - LI de cortante a 1,5 m apoio da longarina L2 (Q-admissível).

Tabela 25. Esforços solicitantes críticos na longarina da grelha completa, devidos apenas ao trem-tipo.

\begin{tabular}{|c|c|c|c|c|}
\hline & esforços & solicitantes & críticos & \\
\hline & Momento & cortante & cortante & cortante \\
\hline & $(\mathrm{daNcm})$ & $(\mathrm{daN})$ & $(\mathrm{daN})$ & $(\mathrm{daN})$ \\
\hline & no meio do vão & na seção apoio & a $1 \mathrm{~m}$ do apoio ${ }^{3}$ & a $1,5 \mathrm{~m}$ do apoio \\
\hline L1 & $648.185^{1}$ & $4.960^{2}$ & - & - \\
\hline $\mathrm{L} 2$ & & $5.025^{3}$ & $2260^{4}$ & $2755^{5}$ \\
\hline
\end{tabular}

\footnotetext{
$1-(0,7458+2 \times 0,3885-0,086-2 \times 0,0602) .100 .5000=648.185$

$2-(0,44+0,39+0,25-0,047-0,041-0) .5000=4.960$

$3-(0,53+0,283+0,17+0,013+0,002) .5000=5.025$

$4-(-0,04+0,30+0,179-0+0,002-0,011) .5000=2.260$

$5-(-0,02+0,374+0,185+0,007+0,006) .5000=2.755$
} 


\subsubsection{Dimensionamento da viga bi-circular}

Com o valor do momento fletor crítico (Tabela

25), $E$ e Iteórico apresentados nas Tabelas 17 e 19 respectivamente calculou-se através da eq. (35) o valor do raio de curvatura para a viga monolítica.

$$
\begin{aligned}
& r=\frac{I_{\text {teórico }} \cdot E}{M}=\frac{514.289 \times 120.293}{648.185}=96.154 \mathrm{~cm} \\
& \text { Com o valor do raio de curvatura da viga bi- }
\end{aligned}
$$
apoiada de seção monolítica conhecido calculou-se o valor da deformação teórica, de acordo com a eq.(34).

$\varepsilon_{\text {monolitico }}=\frac{32}{96 \cdot 154}=0,00033=0,033 \%$

Dos diagramas de força $x$ deslocamento obtidos nos ensaios das ligações madeira-anel metálico (Figura 41) obteve-se o valor médio do deslocamento da ligação para o cortante crítico da grelha e através da eq. (36) obteve-se a correspondente deformação (Tabela 29).

Tabela 29. Valor médio do deslocamento para ligação madeira - anel metálico.

\begin{tabular}{cccc}
\hline CP & Regressão linear & Q (daN) & Deformação (cm) \\
\hline I & $\ddot{a}=\frac{f+9.647}{65.642}$ & 5.025 & 0,22 \\
II & $\ddot{a}=\frac{f+20.252}{77.501}$ & 5.025 & 0,33 \\
III & $\ddot{a}=\frac{f+10.057}{72.284}$ & 5.025 & 0,21 \\
& $\delta_{\text {ligação }}$ & & 0,25 \\
\hline
\end{tabular}


$\varepsilon_{\text {ligação }}=\frac{\delta_{\text {ligação }}}{\ell}=\frac{0,25}{600}=0,00042$

Substituindo-se os valores das equações (51) e (52) na eq. (33) obtém-se o valor da deformação da viga composta, como mostra a eq. (53).

$\varepsilon_{\text {total }}=0,00033+0,00042=0,00075$

Com esse valor calculou-se o valor do raio de curvatura da viga bi-circular, através da eq. (37) .

$r_{\text {total }}=\frac{y}{\varepsilon_{\text {Total }}}=\frac{32}{0,00075}$

$r_{\text {total }}=42.667 \mathrm{~cm}$

Substituindo-se esse valor na eq. (38) obteve-se - momento de inércia real necessário para que a viga composta suporte o momento aplicado.

$I_{\text {real }}=\frac{M \times r}{E}=\frac{648.275 \times 42.667}{120.293}=229.938 \mathrm{~cm}^{4}$

Isso significa que a viga trabalhará com apenas $44,70 \%$ do momento de inércia teórico da viga bi-circular ideal.

Tomando-se a resistência de cálculo do anel como sendo de aproximadamente $1 / 4,3$ de sua capacidade máxima (Tabela 18) obteve-se o valor de 7.953 daN, bem inferior à carga admissível na ligação madeira - anel metálico $150 \mathrm{~mm}$, correspondente ao deslocamento relativo admissível de 1,5 mm, que seria de 10.783 daN (Tabela 30). Adotando-se então 
a resistência da ligação como sendo de $R_{a n e l, d}=8.000$ daN, obteve-se através da eq. (32) o espaçamento entre os dois primeiros anéis.

$$
S_{12}=\frac{8.000}{\frac{5.025 \times 12.861}{229.938}}=28,46 \mathrm{~cm}
$$

Tabela 30. Resistência da ligação madeira-anel metálico de $150 \mathrm{~mm}$.

\begin{tabular}{|c|c|c|c|}
\hline & Valores da & esistência & \\
\hline $\mathrm{R}_{a n e l, \max }$ - médio & $\mathrm{R}_{1,5}$ & $R_{\text {anel,d eq. (1) }}$ & Ranel,d - adotado \\
\hline 34.200 & 10.783 & 5.917 & 8.000 \\
\hline
\end{tabular}

Para o cálculo do espaçamento entre $\circ 2^{\circ}$ e $\circ 3^{\circ}$ anel tomou-se o cortante já reduzido no trecho (Tabela 28). Os espaçamentos entre os demais anéis foram mantidos constantes de valor igual a s23 (Figura 65).

$$
\mathrm{s}_{23}=\frac{8.000}{\frac{2.755 \times 12.861}{229.938}}=51,90 \mathrm{~cm}
$$

Finalmente calculou-se através da eq.(46) a flecha no meio do vão da longarina mais solicitada (L1).

$$
f_{\mathrm{bi}-\mathrm{circular}}=\mathrm{v}(300)=\frac{(300)^{2}}{2 \times 42.667}-\frac{600 \times 300}{2 \times 42.667}=-1,05 \mathrm{~cm}
$$


750

75,5

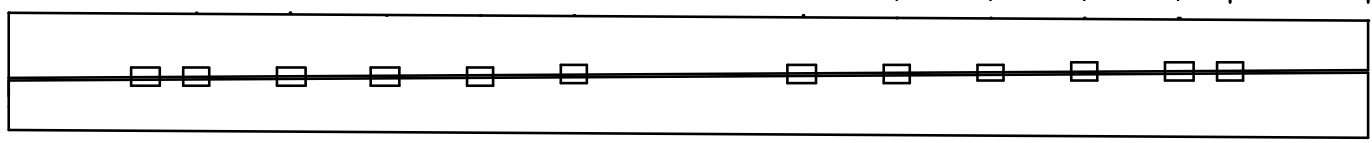

Figura 65 - Espaçamento dos anéis na viga de seção bicircular para ensaio à flexão.

\subsubsection{Comprovação Experimental}

Os pesos das toras usadas como carregamento na viga bi-circular encontram-se na Tabela 31, ficando distribuído como mostra a Figura 66 .

Tabela 40. Peso das toras utilizadas como carga.

\begin{tabular}{|c|c|c|c|c|}
\hline & & s Toras & & \\
\hline $\bar{A}$ & $\bar{B}$ & $\bar{C}$ & $\bar{D}$ & $E$ \\
\hline 1.520 & 1.360 & 1.490 & 920 & 980 \\
\hline
\end{tabular}

Na Tabela 41 estão apresentados os valores dos deslocamentos medidos obtidos nos dois ensaios à flexão no meio do vão das vigas bi-circulares. Substituindo-se esses valores na eq. (54), de uma forma cumulativa obteve-se a Figura 67, que mostra a evolução do momento de inércia experimental com o aumento da carga aplicada.

$y=\frac{P \cdot b}{E \cdot 16 \cdot \ell}\left[x^{3}-\left(\ell^{2}-b^{2}\right) \cdot x\right]$ para $0<x<a$

onde:

$\mathrm{P}=$ carga aplicada sobre a viga; 
$\mathrm{b}=$ maior distancia da carga ao apoio;

$\ell=$ vão da viga;

$\mathrm{E}=$ módulo de elasticidade da madeira;

$\mathrm{x}$ = variável que indica a posição onde se deseja medir a flecha.
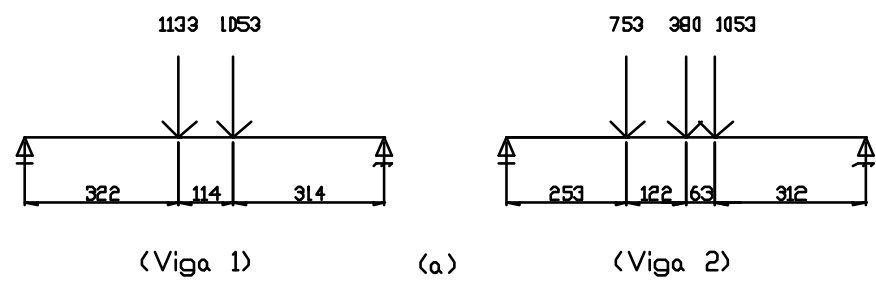

(a)
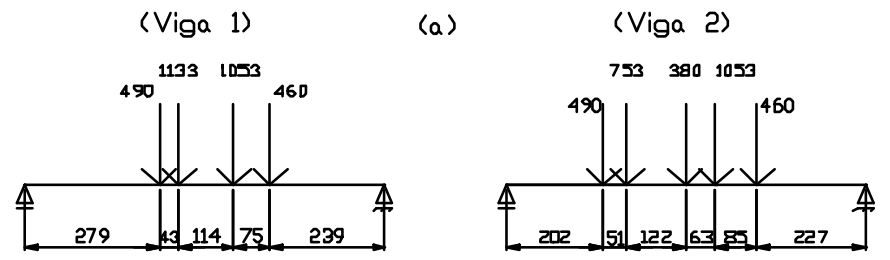

(b)

Figura 66 - Posicionamento das cargas nas vigas quando foram ensaiadas sem estarem ligadas por anéis metálicos (a) e quando já estavam ligadas por anéis (b) .

Tabela 41. Valores das flechas observados no ensaio.

\begin{tabular}{ccccc}
\hline \multicolumn{5}{c}{ flecha $(\mathrm{cm})$} \\
\hline Carga & \multicolumn{3}{c}{ Viga 1} & Viga 2 \\
\hline daN & sem anel & com anel & sem anel & com anel \\
760 & 0,30 & 0,18 & 0,42 & 0,23 \\
1440 & 0,58 & 0,42 & 1,11 & 0,50 \\
2186 & 1,00 & 0,75 & 1,62 & 0,87 \\
2646 & & 0,92 & & 1,08 \\
3136 & & 1,09 & 1,28 \\
\hline
\end{tabular}




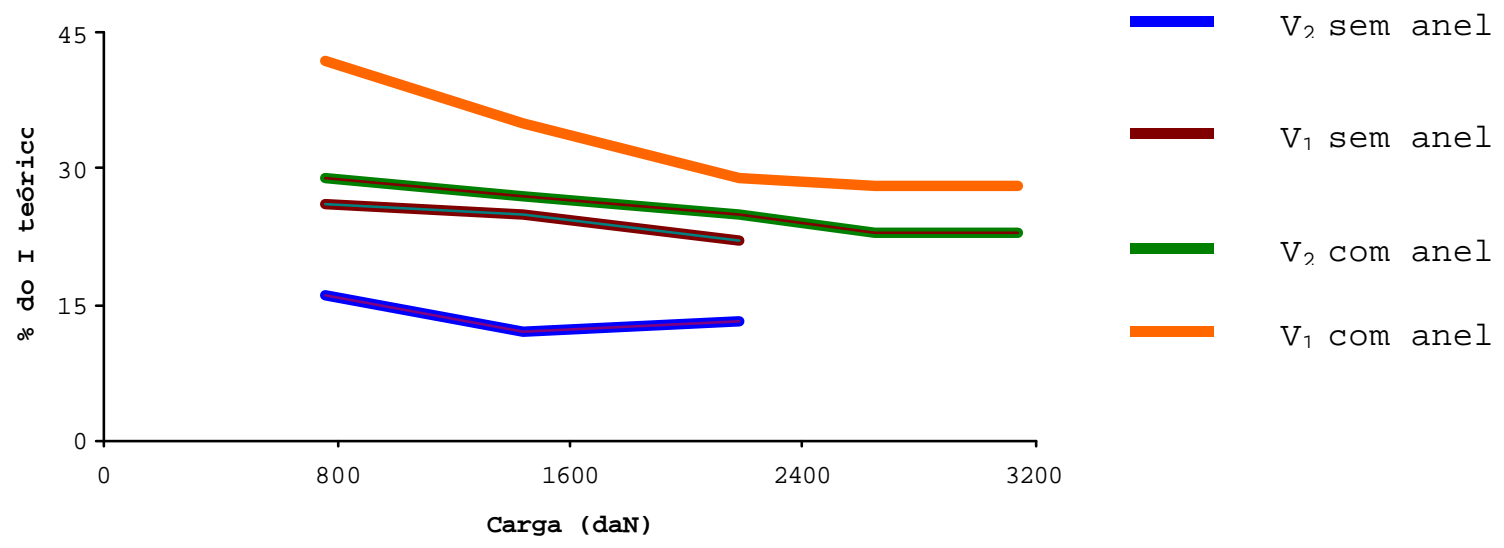

Figura 67 - Evolução do momento de inércia experimental obtido comparado com teórico.

Observa-se nesta figura que a ligação por anel aumentou em cerca de $100 \% 0$ momento de inércia da viga composta de duas seções não interligadas entre si. O decréscimo verificado na viga 2 com anel aparenta ser devido a um recalque de apoio e portanto deverá ser melhor investigado. 


\section{CONCLUSÕES}

Com base nos dados colhidos e apresentados no conclui-se:

$\checkmark$ O lote de Eucalyptus citriodora de 19 anos de idade em estudo enquadra-se, segundo a NBR 7190/97, na classe de resistência C 40 e pode ser utilizado como material estrutural.

$\checkmark$ o corpo de prova do ensaio de ligação de peças roliças de madeira ligadas por anel metálico de $150 \mathrm{~mm}$ foi idealizado para estar o mais próximo da realidade. $\mathrm{Na}$ experimentação mostrou-se auto equilibrante uma vez que foi projetado para que a resultante passasse pelo centro de gravidade da ligação.

$\checkmark$ A serra copo desenvolvida apresentou excelente estabilidade no manuseio podendo ser utilizada no campo.

$\checkmark$ Não houve diferenças nos esforços solicitantes calculados nas grelhas de 1 e 3 transversinas idealizadas tanto pelo programa simplificado desenvolvido neste trabalho quanto pelo programa SAP 90. 
$\checkmark$ Os esforços críticos calculados nas grelhas de 1 ou 3 transversinas idealizadas foram idênticas aos calculados para a grelha completa.

$\checkmark$ A viga composta de duas peças circulares solidarizadas por anéis metálicos apresenta desempenho muito dependente do processo de fabricação e da homogeneidade das peças ligadas. Entretanto apresenta, seguramente, um momento de inércia real de no mínimo, duas vezes o momento de inércia do conjunto não solidarizado. 


\section{REFERÊNCIAS BIBLIOGRÁFICAS}

ALMEIDA, P.A.O. Estruturas de grande porte de madeira composta. São Paulo,1990. 277p. Tese (Doutorado) - Escola Politécnica - Universidade de São Paulo.

ALMEIDA, S.M.B. Pontes estaiadas de madeira. São Paulo, 1989. 248p. Tese (Doutorado) - Escola Politécnica, Universidade de São Paulo.

ASSOCIAÇÃO BRASILEIRA DE NORMAS TÉCNICAS. Cargas móveis em pontes rodoviárias e passarelas de pedestre: NBR 7188 . Rio de Janeiro,1984. 6p.

ASSOCIAÇÃO BRASILEIRA DE NORMAS TÉCNICAS. Cálculo e execução de estruturas de madeira: NBR 7190. Rio de Janeiro, 1997. 107p.

BUSNARDO,C.A.; FOELKEL,C.E.B.; ZVINAKEVICIUS,C., KAJIYA, . ; ALVES,E.E. Estudo comparativo da qualidade da madeira de algumas espécies de eucaliptos tropicais. In: CONGRESSO ANUAL DA ABCP,11., São Paulo, 1978. Anais. São Paulo: $\mathrm{ABCP}, 1978$. p.191-197. 
CALIL,C.J.; OKIMOTO,F.S. Pontes protendidas de madeira: conceito e aplicações. In: ENCONTRO BRASILEIRO EM MADEIRAS E EM ESTRUTURAS DE MADEIRA, 4., Florianóplis, 1998. Anais.Florianópolis: EBRAMEM; UF SC, 1998. p. $301-312$.

CONGER,D.; RITTER,M.A ; WACKER, J.P. Field performance of timber bridges-8. lynches woods park stress-laminated deck bridge. Madison: USDA, Forest Service, 1996. 14p. (Research Paper FPL - RP, 550).

DIAS,A.A. Contribuição para estudo da distribuição transversal de cargas em pontes de madeira. São Carlos, 1987. 152p. Dissertação (Mestrado) - Escola de Engenharia de São Carlos, Universidade de São Paulo.

ERICKSON,E.C.O.; ROMSTAD, K.M. Distribution of whell loads on timber bridges. Madison: USDA, Forest Service, 1965. 61p. (Research Paper FPL, 44)

GALVÃO, A.P.M. Estimativa da umidade de equilíbrio da madeira em diferentes cidades do Brasil. Piracicaba: IPEF, 1975. 12p.

GESUALDO, F.A.R. Deformação nas ligações nas estruturas de madeira. São Carlos. 1987. 170p. Tese (Doutorado)- Escola de Engenharia de São Carlos, Universidade de São Paulo.

GOODMAN, J.R.; RASSAM H.Y. Buckling behavior of layred wood columns. Wood Science, v.2, n.4, p.238-246, Apr. 1970. 
HELLMEISTER, J.C. Pontes de eucalipto citriodora. São

Carlos, 1978. 85p. Tese (Livre-Docência) - Escola de Engenharia de São Carlos, Universidade de São Paulo.

HELLMEISTER, J.C. Madeira dos eucaliptos e suas propriedades. Silvicultura, v.12, 3p., jul./ago. 1992.

HILSON, B.O. The ultimate strength of timber joints with split-ring connectors when loaded parallel to the grain. London: University of London, 1968. 20p.

HISLOP, L.E.; RITTER, M.A. Field performance of timber bridges-7: connell lake stress-laminated deck bridge. Madison: USDA, Forest Service, 1996. 16p. (Research Paper, FPL-RP, 550 ).

INSTITUTO DE PESQUISAS TECNOLÓGICAS DO ESTADO DE SÃO PAULO. Manual de preservação de madeiras. São Paulo, 1986, v.1, $342 \mathrm{p}$.

LOGSDON, N.B. Contribuição ao estudo das pontes de madeira. São Carlos, 1982. 366p. Dissertação (Mestrado)-Escola de Engenharia de São Carlos, Universidade de São Paulo.

MATTHIESEN, J.A. Ligações de peças estruturais de madeira por anéis metálicos. São Carlos, 1981. 138p. Dissertação (Mestrado) - Escola de Engenharia de São Carlos, Universidade de São Paulo. 
MATHIESSEN, J. A. Contribuição ao estudo das pontes de Eucalipto Citriodora. São Carlos, 1987. 220p. Tese (Doutorado) - Escola de Engenharia de São Carlos, Universidade de São Paulo.

MELO, J. E. Classificação Mecânica de peças estruturais de madeira. São Carlos,1984. 84p. Dissertação (Mestrado) Escola de Engenharia de São Carlos, Universidade de São Paulo.

NASCIMENTO, M.L. Sistemas estruturais e construtivos de pontes de madeira - ênfase em pontes laminadas protendidas. São Carlos, 1993. 149p. Dissertação (Mestrado) - Escola de Engenharia de São Carlos, Universidade de São Paulo.

NOGUEIRA, M.C.J. Proposta de método de ensaio e parâmetros para o dimensionamento de ligações entre peças de madeira por anéis metálicos fechados. São Carlos, 1996. 131p. Tese (Doutorado) - Escola de Engenharia de São Carlos, Universidade de São Paulo.

OKIMOTO, F.S. Pontes protendidas de Madeira: Parâmetros de Projeto. São Carlos, 1997. 180p. Dissertação (Mestrado) Escola de Engenharia de São Carlos, Universidade de São Paulo.

OLIVA,M.; TUOMI, R.; DIMAKIS,A. New ideas for timber bridges. Washington: D.C., 1985. 6p. (Transportation Research Record, 1053) 
OLIVEIRA, J.T.S. Caracterização da madeira de Eucalipto para Construção Civil. São Paulo, 1997. 429p. Tese (Doutorado) - Escola Politécnica - Universidade de São Paulo.

PAIVA, M.V.V. Tabuleiro de madeira formado por duas camadas de peças ortogonais entre si e a $45^{\circ} \mathrm{com}$ as bordas. São Carlos, 1995. 86p. Dissertação (Mestrado)-Escola de Engenharia de São Carlos, Universidade de São Paulo.

QUENNEVILLE, J.H.P.; DALEN, K.V.; CHARRON, A. Effect of end distance on the resistance of split-ring connectors in timber joints loaded in compression. Canadian Journal of Civil Engineering, v.20, n.5, p. 863-871, Oct. 1993.

RICHTER,H.G.; BURGER,L.M. Anatomia da madeira. Curitiba: Universidade Federal do Paraná, 1978. 76p.

SALES, A. Características de resistência mecânica de algumas espécies de eucalipto do Estado de São Paulo. São Carlos, 1991. 204p. Dissertação (Mestrado) - Escola de Engenharia de São Carlos, Universidade de São Paulo. 